\title{
Aerobic Oxidative Cascade Thiolation and Cyclization to Construct \\ Indole-fused Isoquinolin-6(5H)-ones Derivatives in EtOH
}

\author{
Huanhuan Cui, ${ }^{\dagger}$ Changhao $\mathrm{Niu}^{\dagger}$ and Chun $\mathrm{Zhang}^{*}, \dagger, \dot{+}$ \\ $\dagger$ Institute of Molecular Plus, Tianjin Key Laboratory of Molecular Optoelectronic \\ Science, Department of Chemistry, School of Science, Tianjin University, Weijin Rd. \\ 92, Tianjin 300072, China. \\ $\$$ Zhejiang Institute of Tianjin University, Ningbo, Zhejiang, 315201, China. \\ E-mail: chunzhang@tju.edu.cn.
}




\section{Supporting Information}

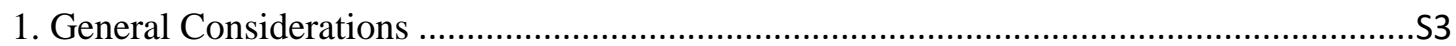

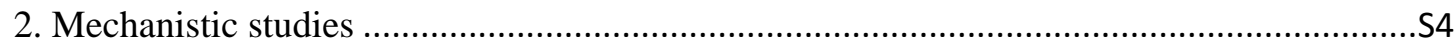

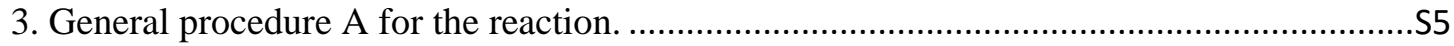

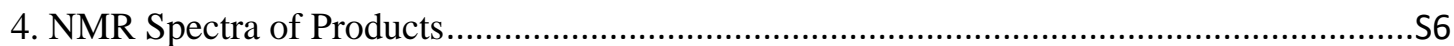




\section{General Considerations}

All manipulations were conducted with Schlenk tube. ${ }^{1} \mathrm{H}$ NMR spectra were recorded on JNM-ECZ400S/L1, JNM-ECZ600R/S1 and Bruker AVIII-400 spectrometers. Chemical shifts (in ppm) were referenced to tetramethylsilane ( $\delta=0 \mathrm{ppm})$ in $\mathrm{CDCl}_{3}$ as an internal standard. Data were reported as follows: chemical shift (ppm), multiplicity $(\mathrm{s}=$ singlet, $\mathrm{d}=$ doublet, $\mathrm{t}=$ triplet, $\mathrm{q}=$ quar-tet, $\mathrm{dd}=$ doublet of doublets, $\mathrm{m}=$ multiplet $)$, coupling constants $(\mathrm{Hz})$, integration and assignment. ${ }^{13} \mathrm{C}$ NMR spectra were ob-tained by using the same NMR spectrometers and were calibrat-ed with $\mathrm{CDCl}_{3}(\delta=77.00 \mathrm{ppm}) .{ }^{19} \mathrm{~F}$ NMR spectra were obtained by the same NMR and $\mathrm{CF}_{3} \mathrm{COOH}$ was employed as external standard for the ${ }^{19} \mathrm{~F}-\mathrm{NMR}$ measurement. High resolution mass spectrometry (HRMS) data were obtained on a QTOF mass ana-lyzer with electrospray ionization (ESI) through a Waters Ac-quity UPLC Class I/Xevo G2 Q-Tof. Substrates were purchased from Aldrich, TCI, Acros, Energy, Aladdin, or synthesized ac-cording to the procedures outlined below. Unless otherwise noted, materials obtained from commercial suppliers were used without further purification. Oil bath was used as the heat source. 


\section{Mechanistic studies}

2-methyl-1-(2-phenyl-1H-indol-1-yl)prop-2-en-1-one 1a $(0.2 \mathrm{mmol})$ was added into the solution of 4-methylbenzenethiol $2 \mathrm{a}(0.4 \mathrm{mmol})$ and TEMPO $(0.4 \mathrm{mmol})$ in $\mathrm{EtOH}$ $2 \mathrm{~mL}$. The reaction mixture was stirred at $80^{\circ} \mathrm{C}$ under air for $12 \mathrm{~h}$ (Stirring speed is around 850 revolutions). After completion of the reaction, the solution was concentrated in vacuum, only a trace amount of desired product $3 \mathrm{a}$ was detected. In addition, TEMPO-trapped complex (p-MePhS-TEMPO) was also detected by HRMS analysis.
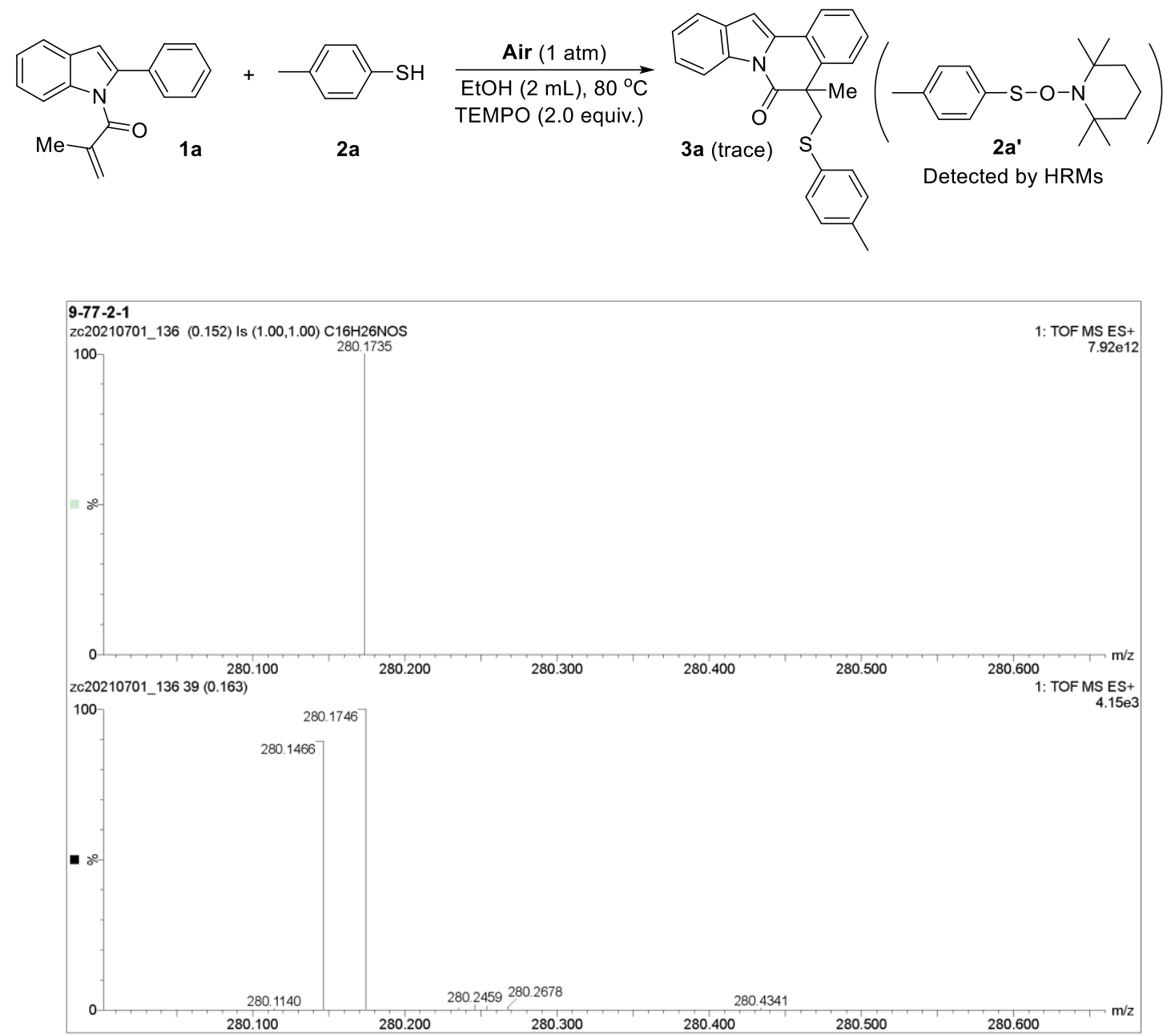

Figure S1. The HRMS spectrum of 2a' 


\section{General procedure A for the reaction.}

Alkene $1(0.2 \mathrm{mmol})$ was added into the solution of thiol $2(0.4 \mathrm{mmol})$ in EtOH $2 \mathrm{~mL}$. The reaction mixture was open to the air and stirred at $80^{\circ} \mathrm{C}$ for $24 \mathrm{~h}$ (Stirring speed is around 850 revolutions). After completion of the reaction, the solution was concentrated in vacuum. The residue was purified by flash column chromatography using a mixture of petroleum ether and ethyl acetate as eluent to give the desired product 3 or 4 .<smiles>[R][R]1cccc(-c2c([R])c3cc[R1]([R])cc3n2C(=O)C(=C)C)c1</smiles>
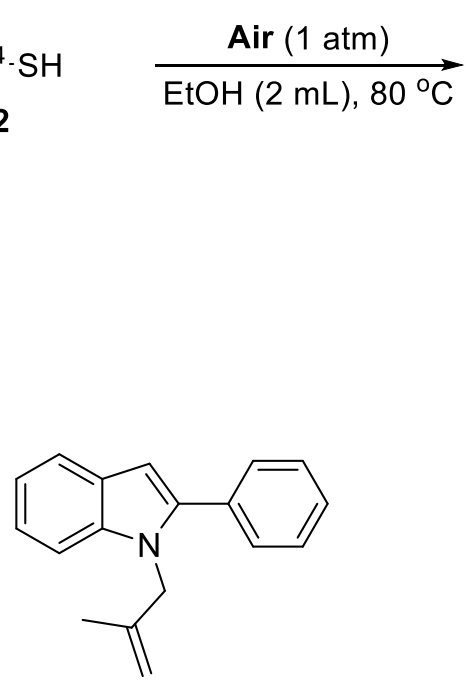

Figure S2. No reaction substrate<smiles>[R15]CC1(C)C(=O)n2c(c([R])c3c[R]#ccc32)-c2ccccc21</smiles> 


\section{NMR Spectra of Products}

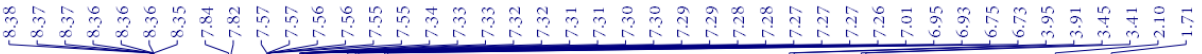
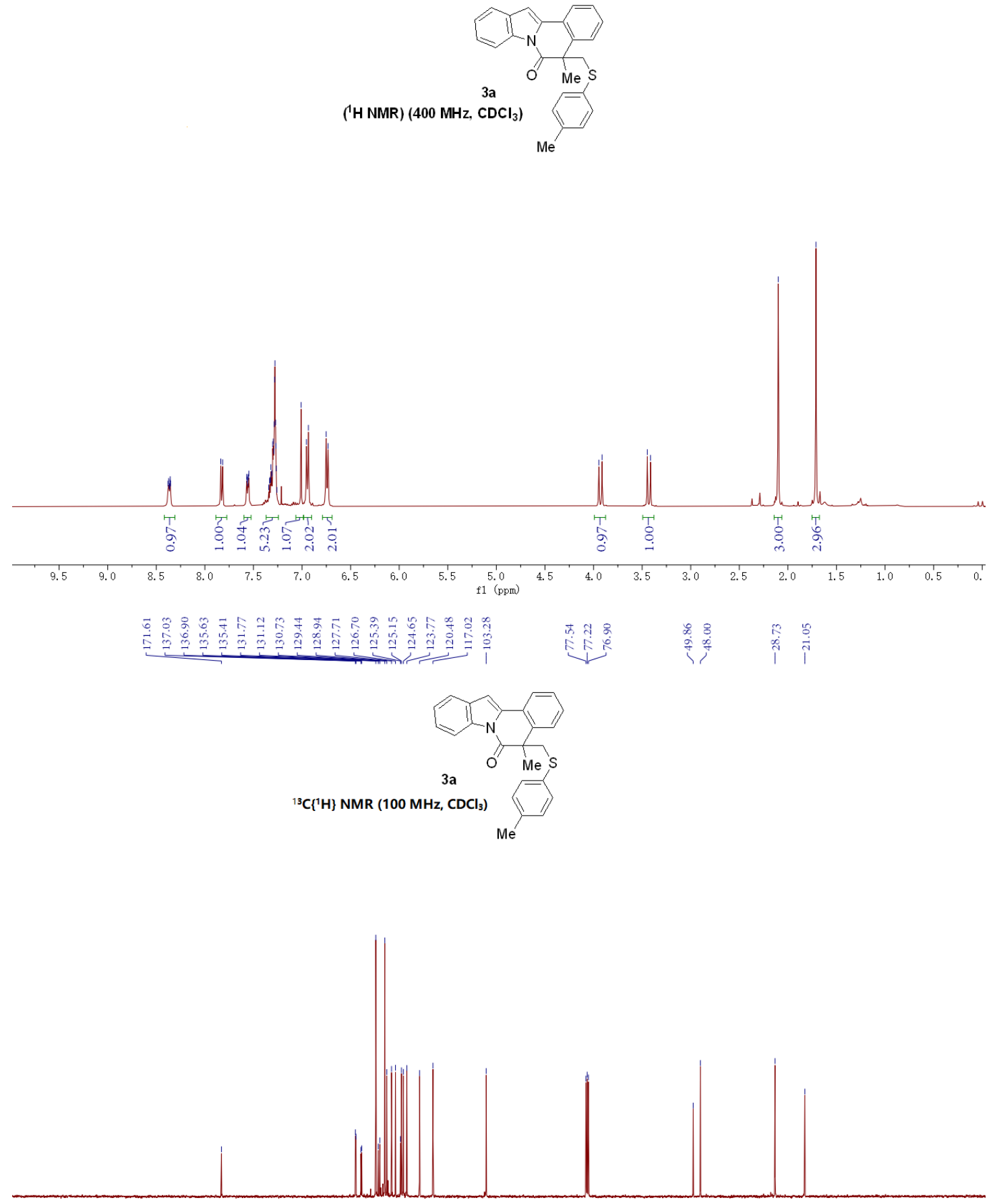

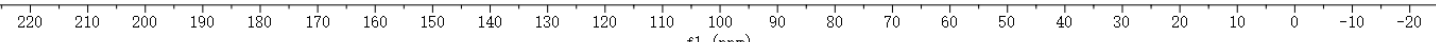




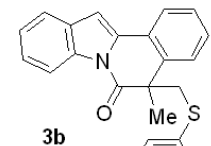

('H NMR) (400 MHz, $\mathrm{CDCl}_{3}$ )

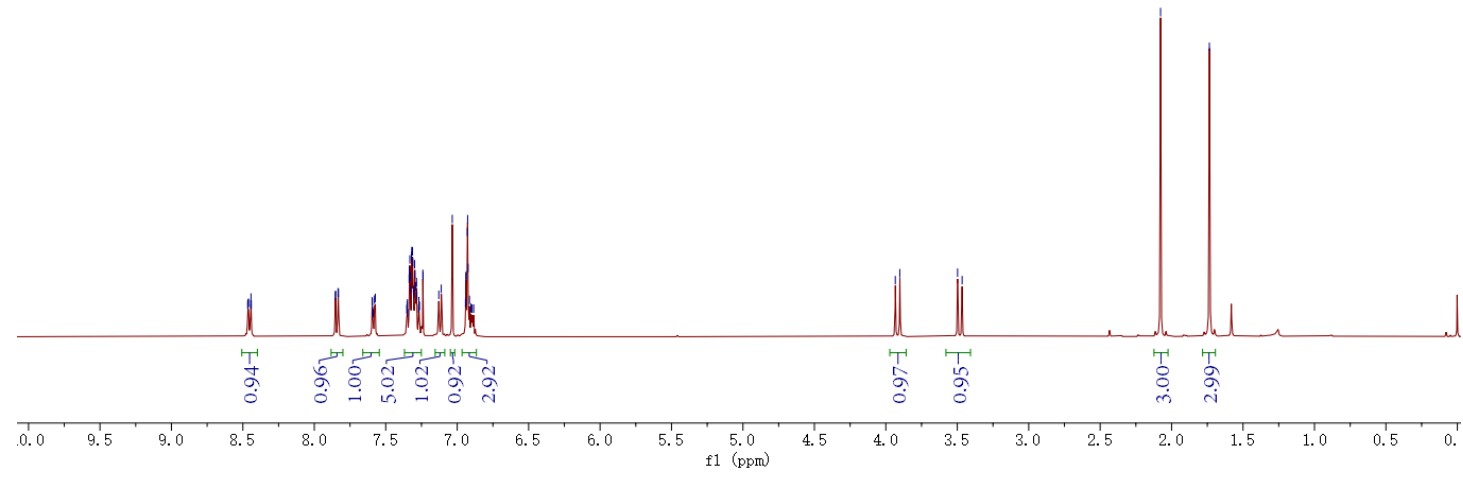

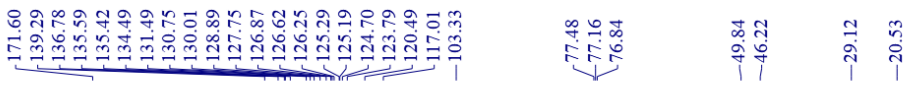

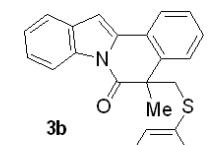

${ }^{13} \mathrm{C}\left\{{ }^{1} \mathrm{H}\right\}$ NMR $\left(100 \mathrm{MHz}_{1} \mathrm{CDCl}_{3}\right)$

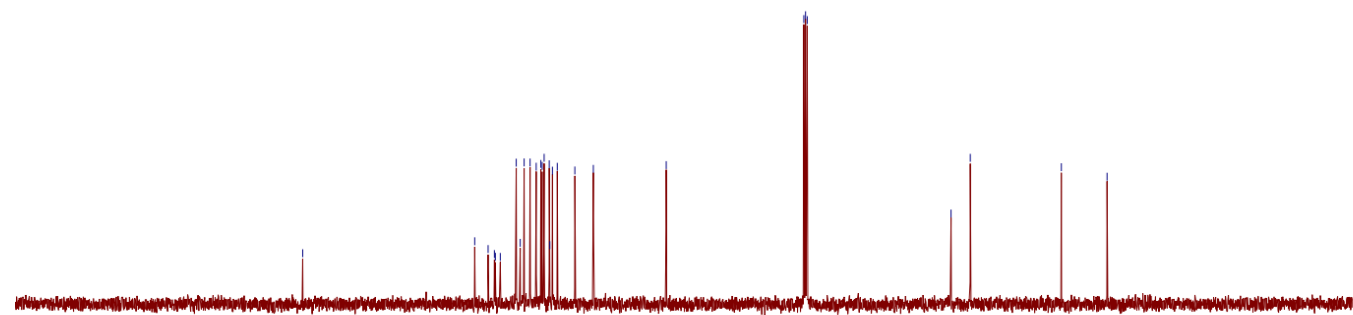

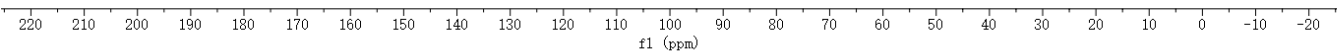




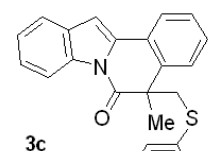

('H NMR) (400 MHz, $\left.\mathrm{CDCl}_{3}\right)$
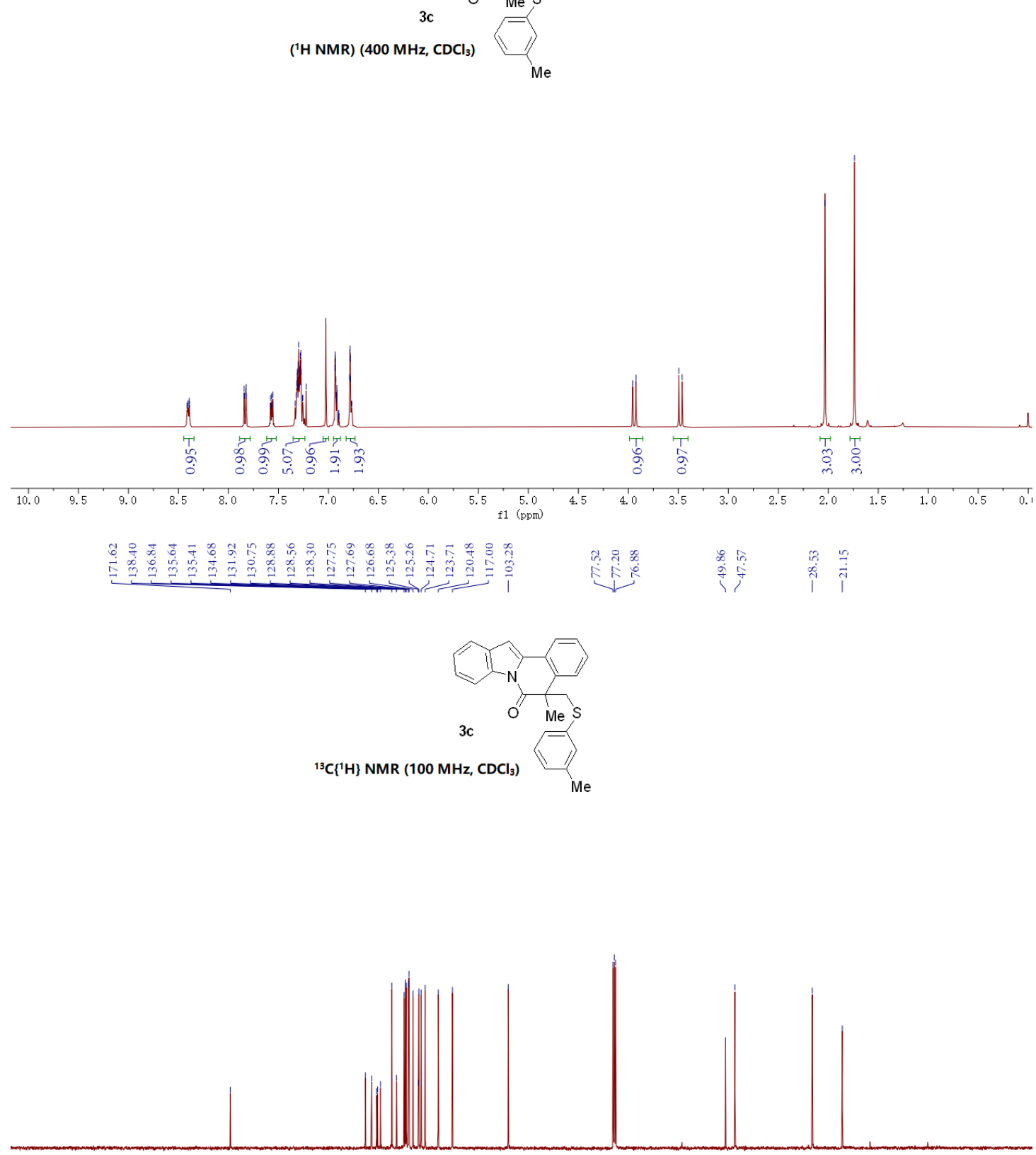

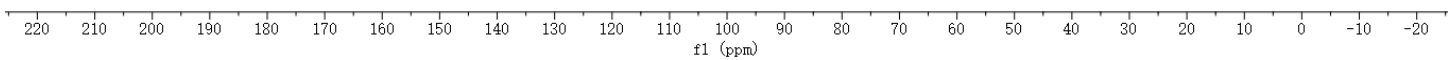




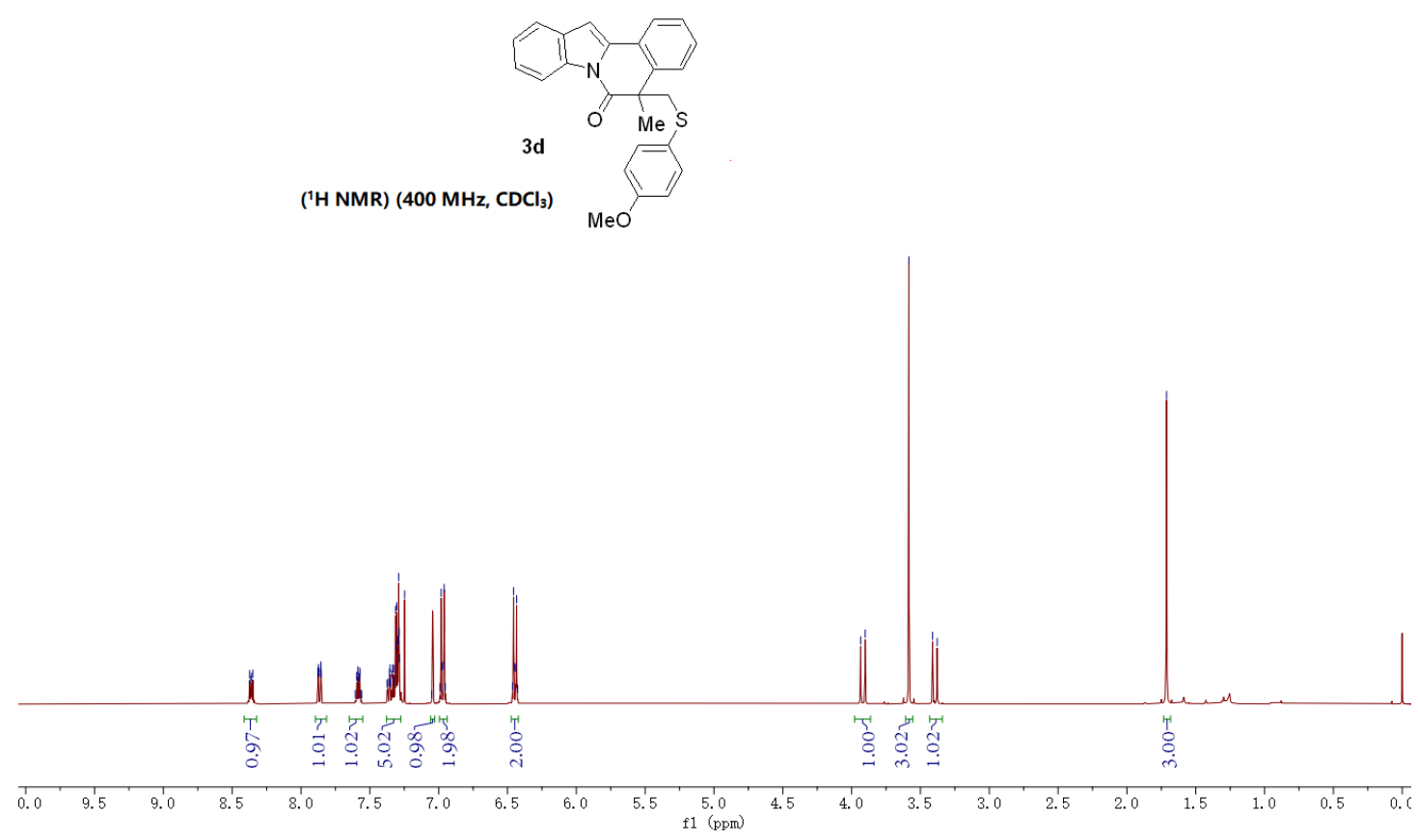

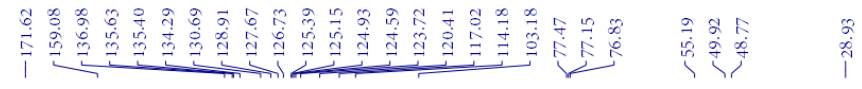
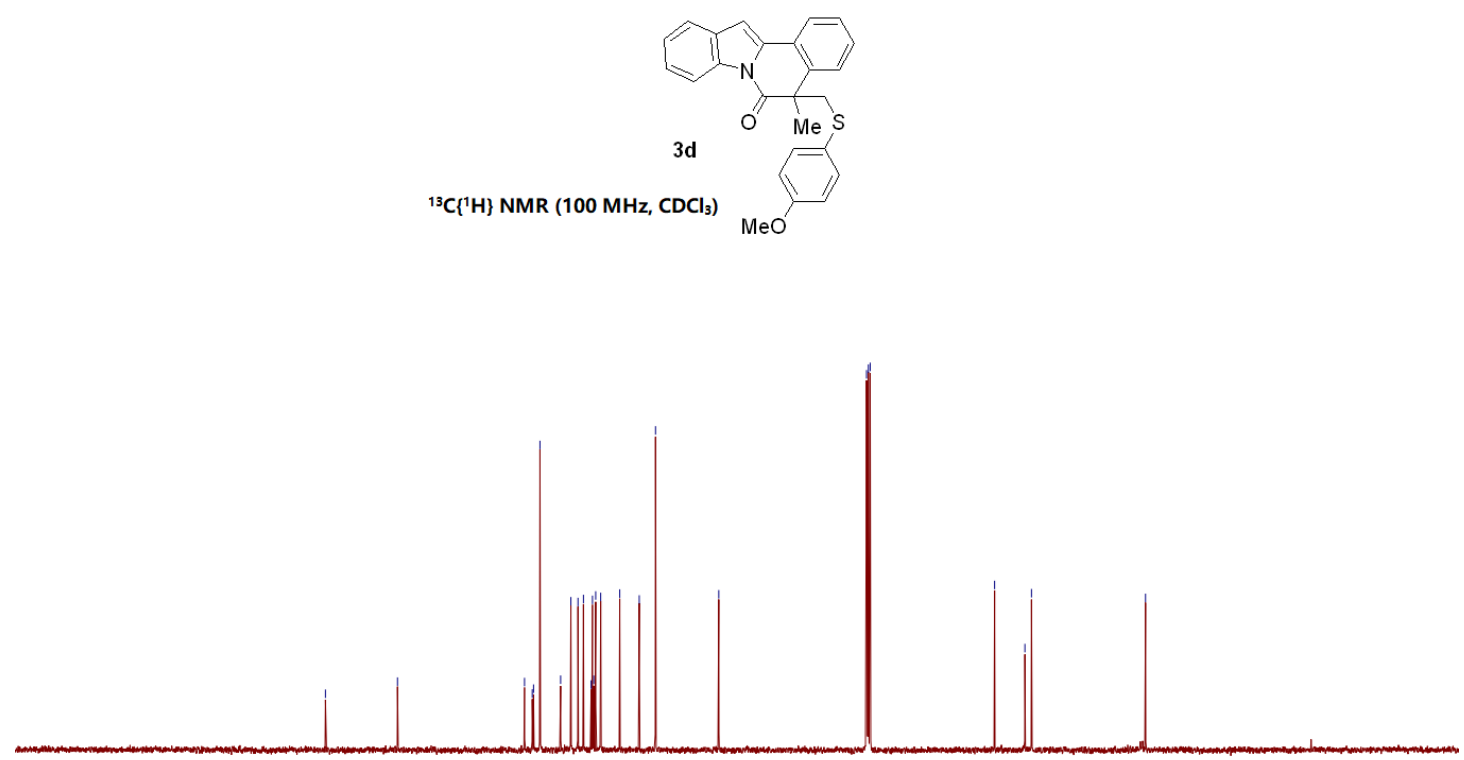

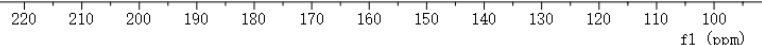




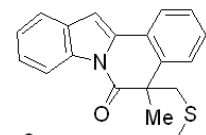

('H NMR) (400 MHz, $\left.\mathrm{CDCl}_{3}\right)$

Me S
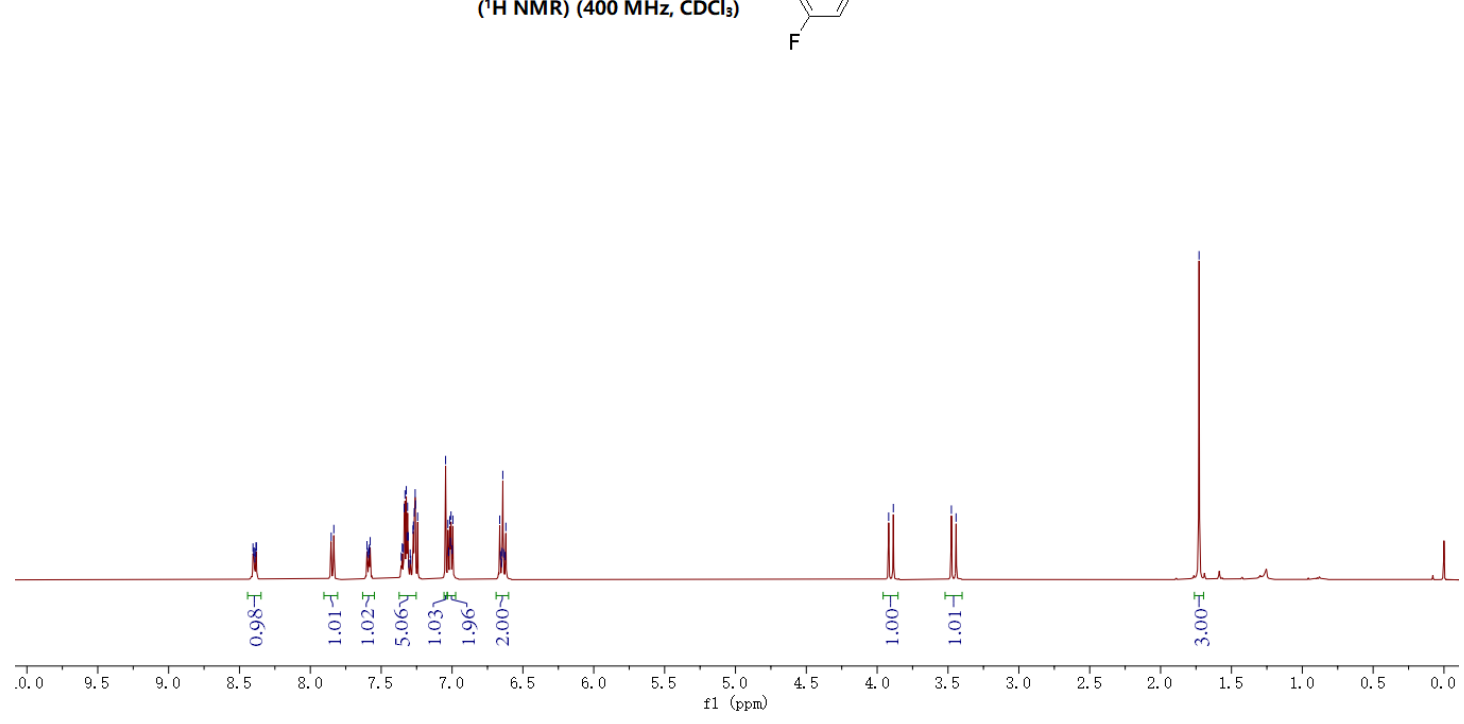

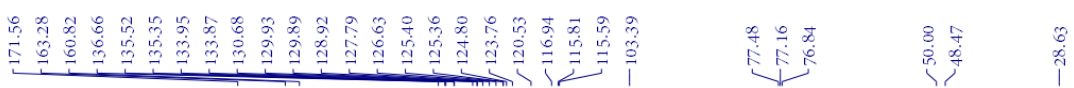
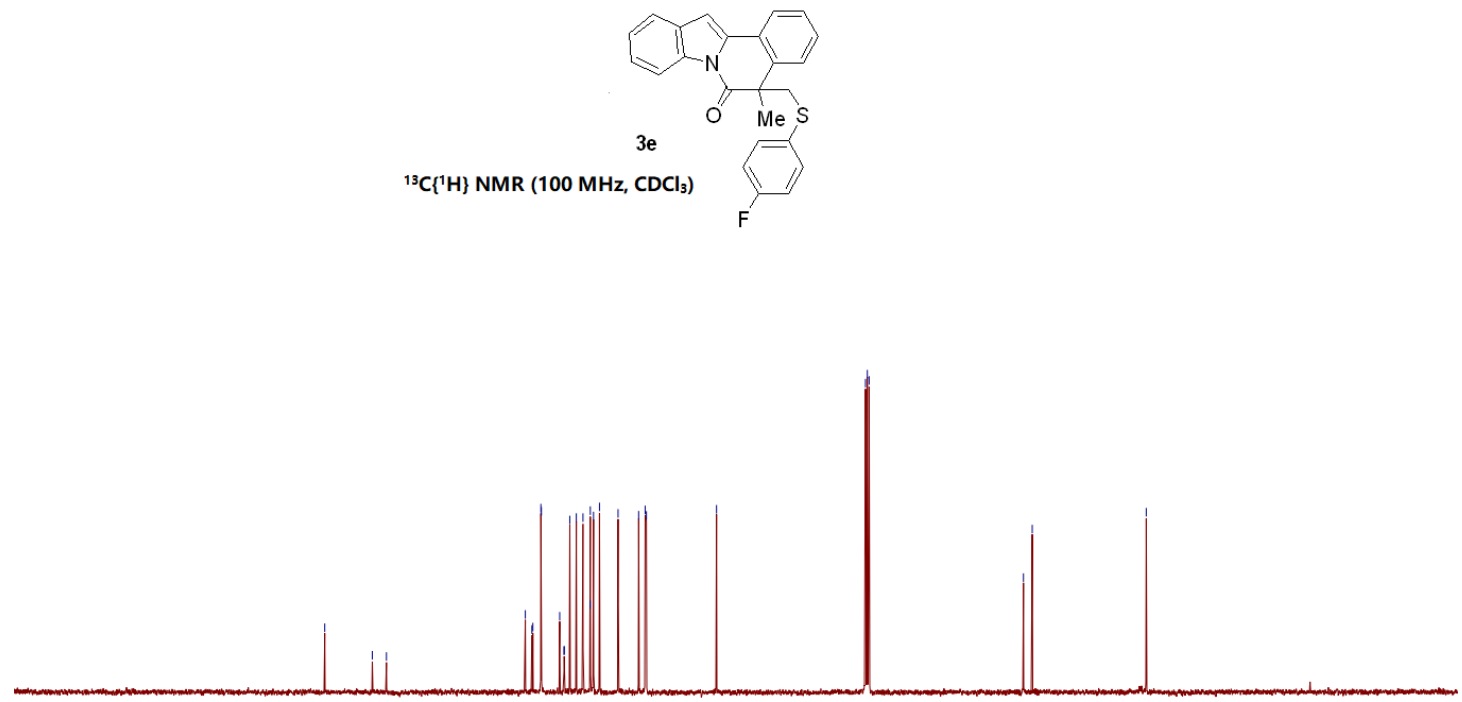

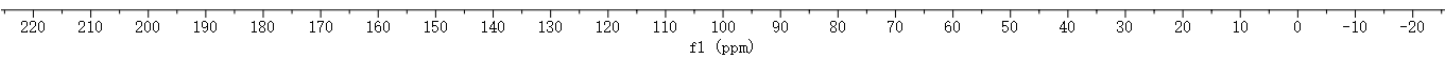




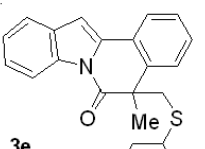

$\mathrm{CDCl}_{3}$ )
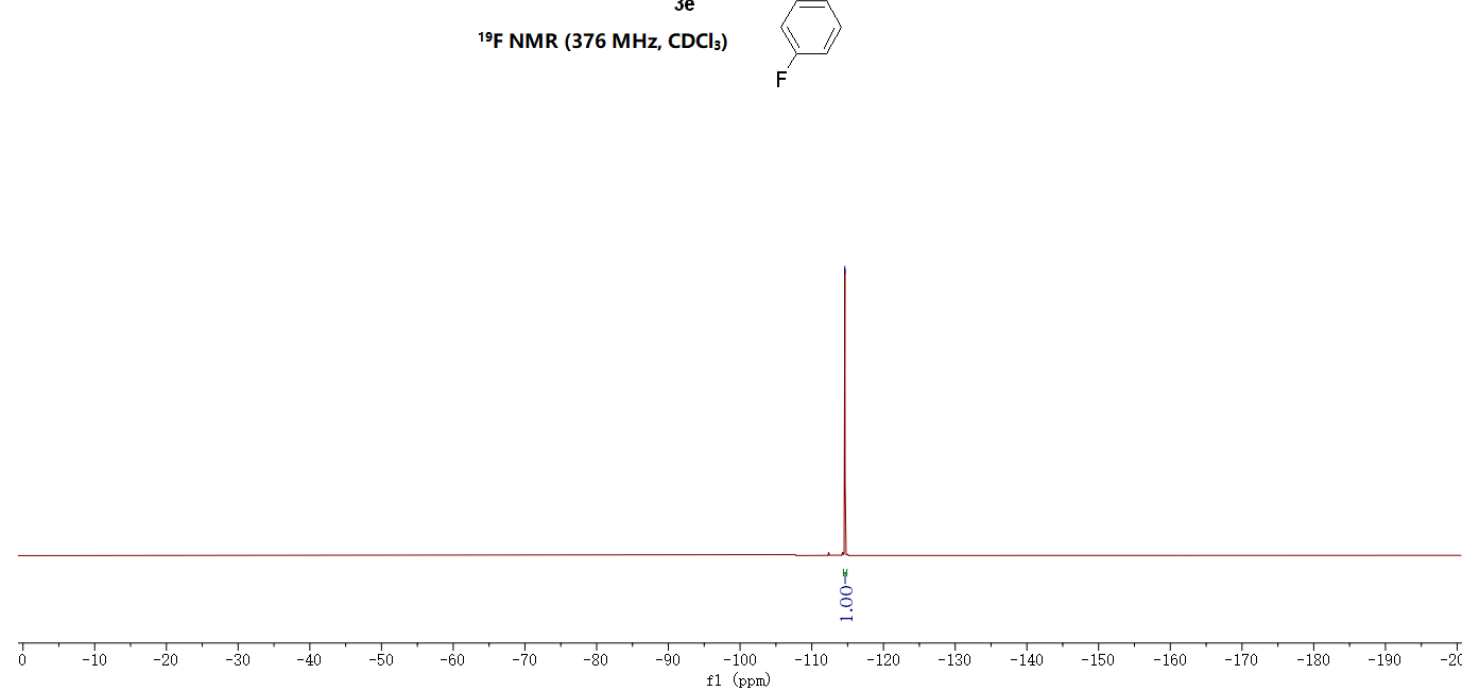

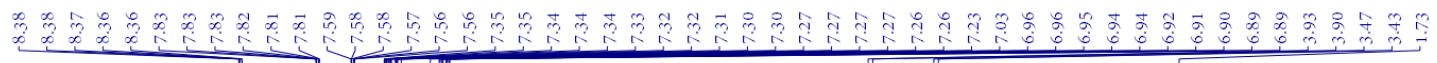
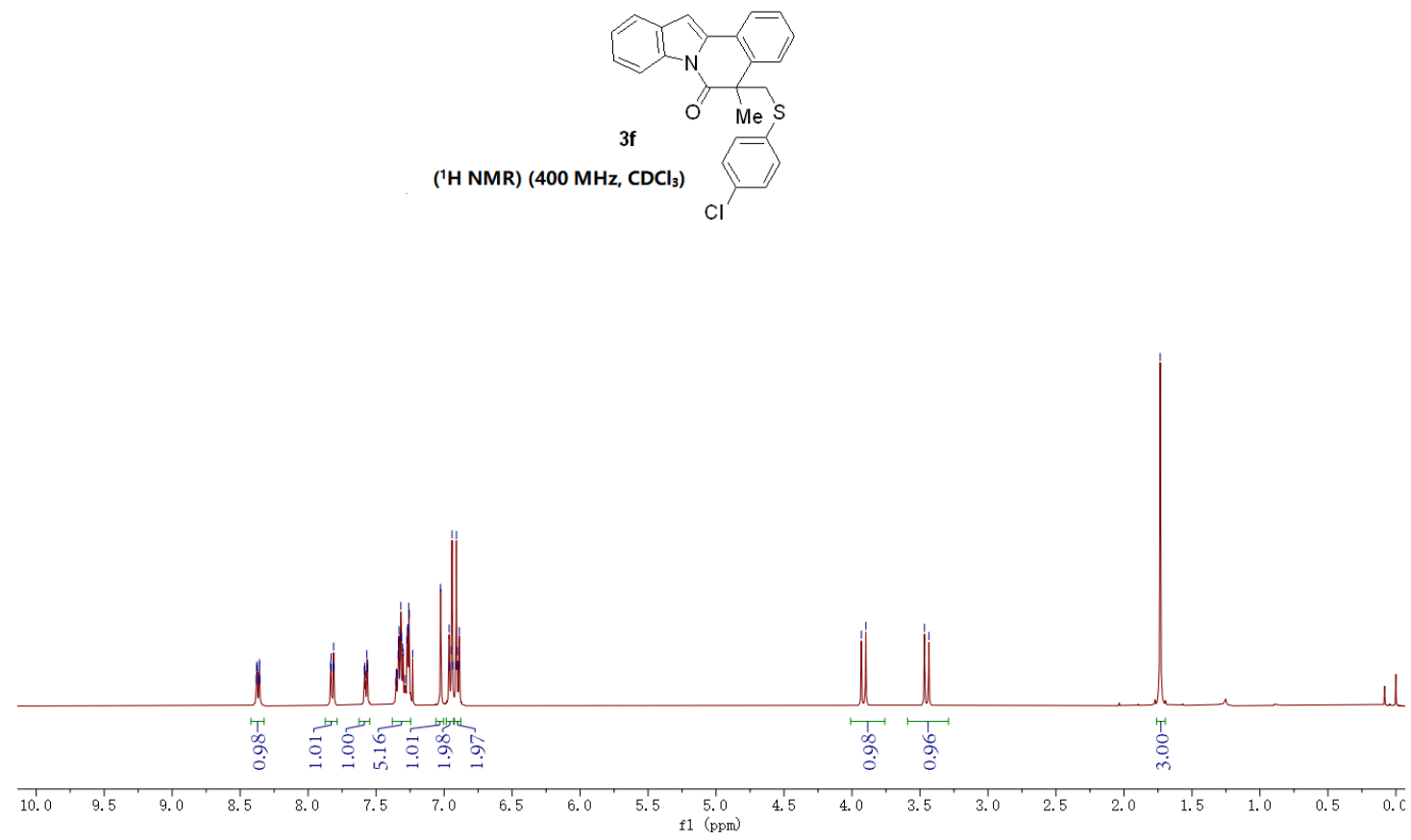


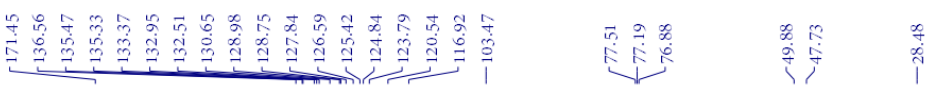
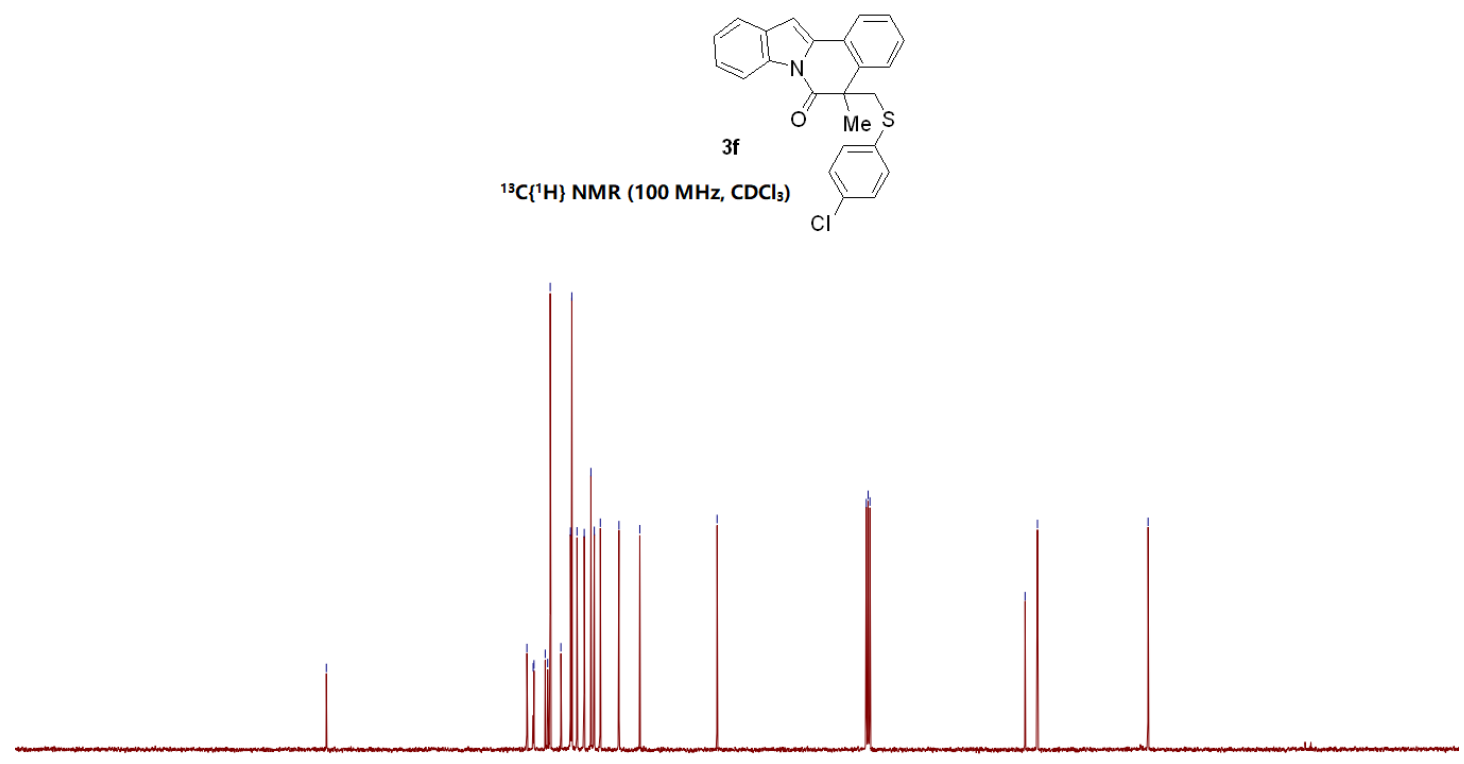

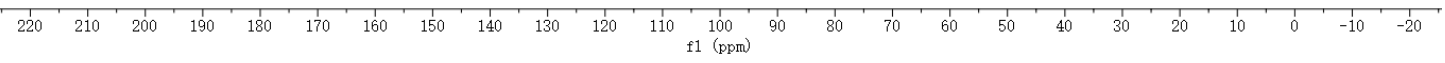

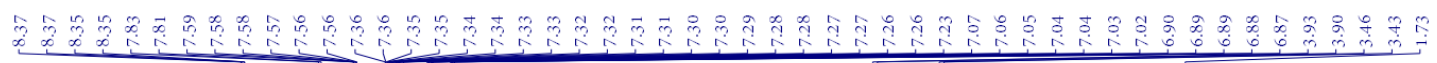
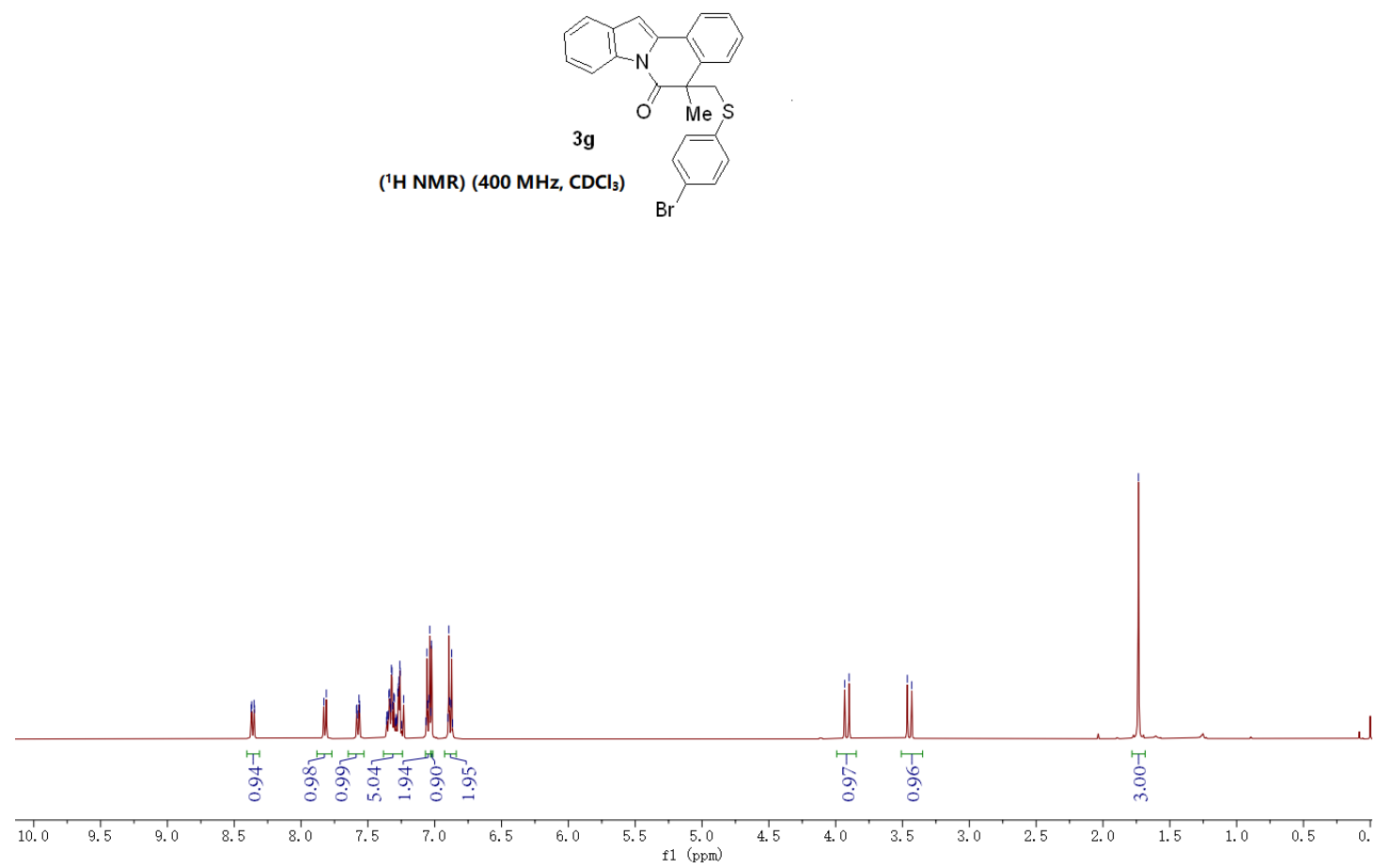


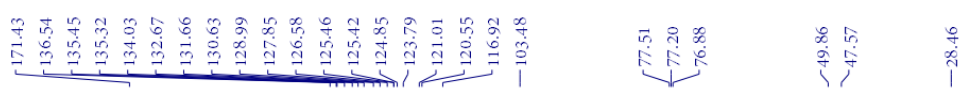
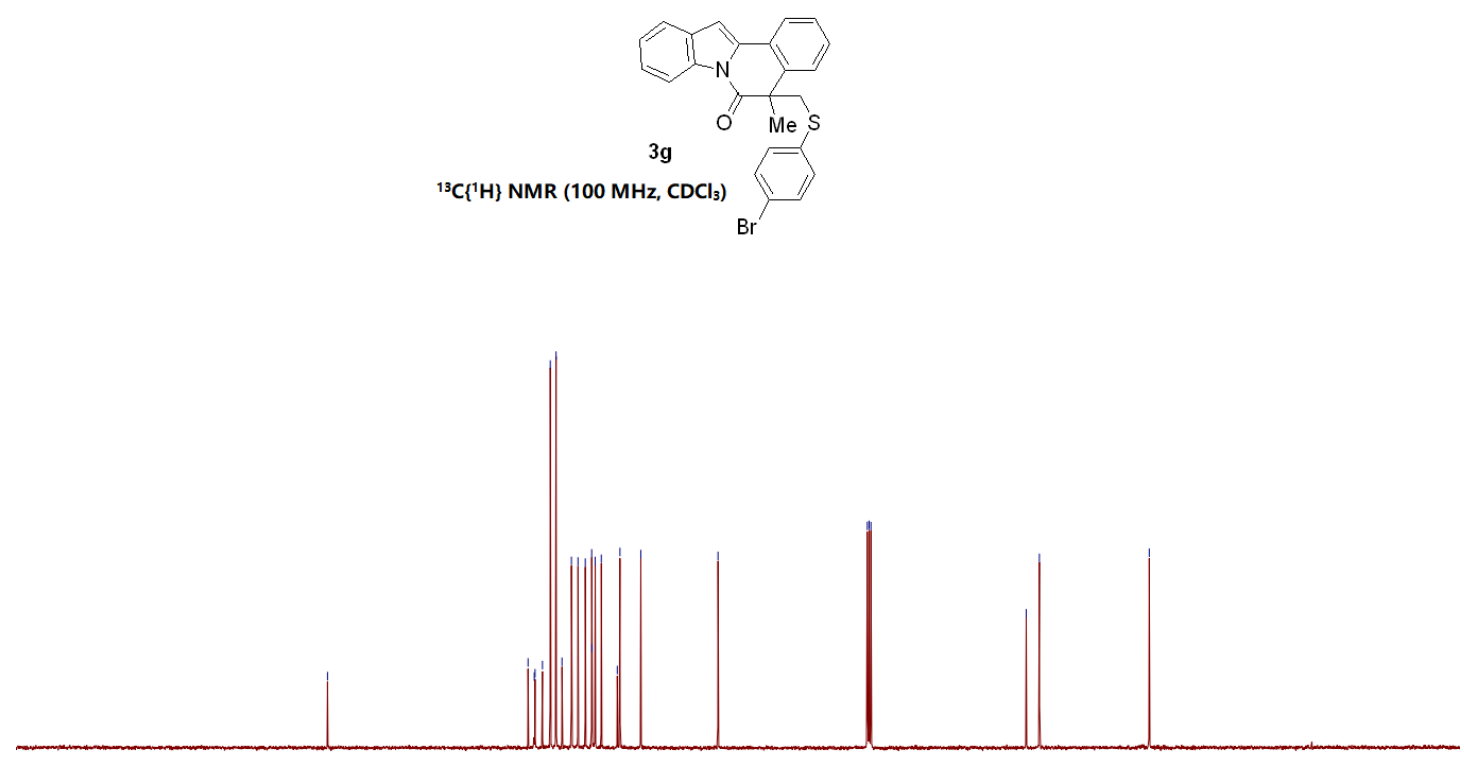

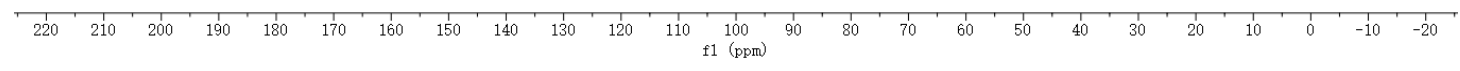

$\underbrace{3}$

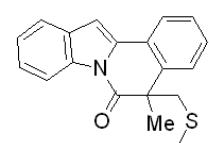

3h

('H NMR) (400 MHz, $\left.\mathrm{CDCl}_{3}\right)$

Me $\mathrm{S}$

$\mathrm{O}_{2} \mathrm{~N}$

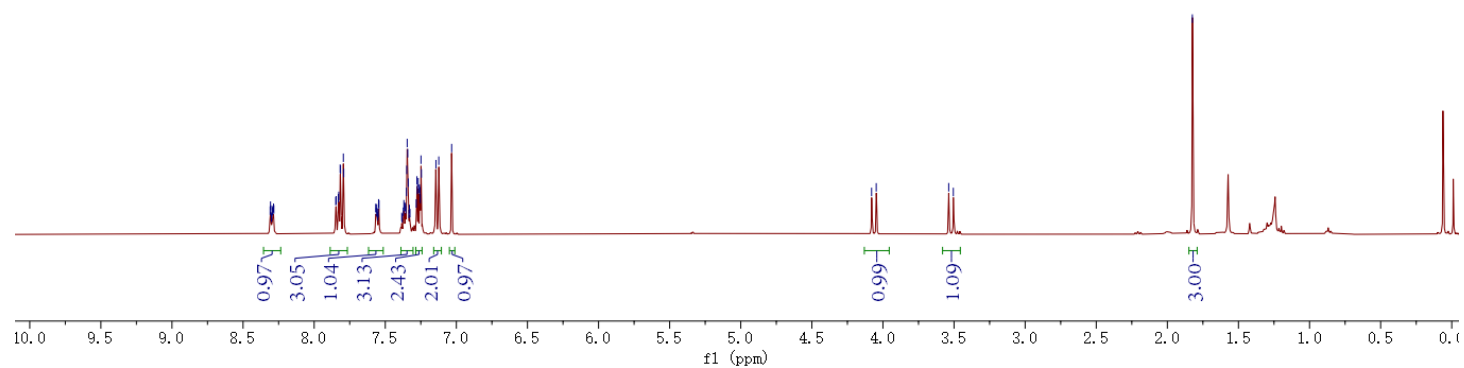



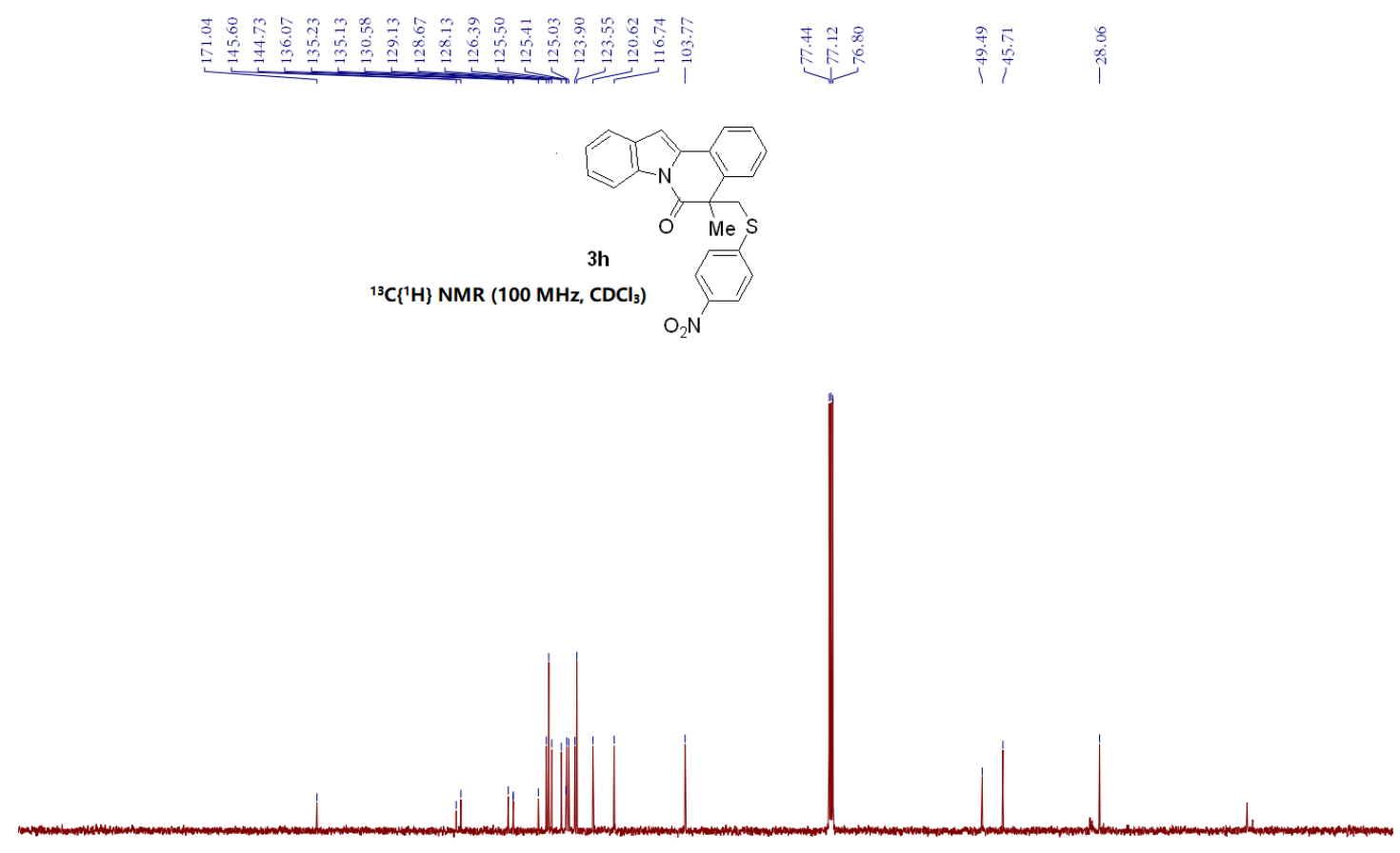

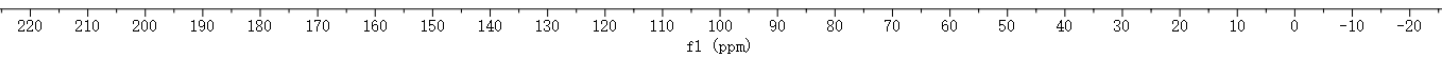

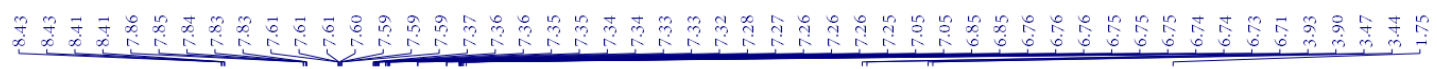
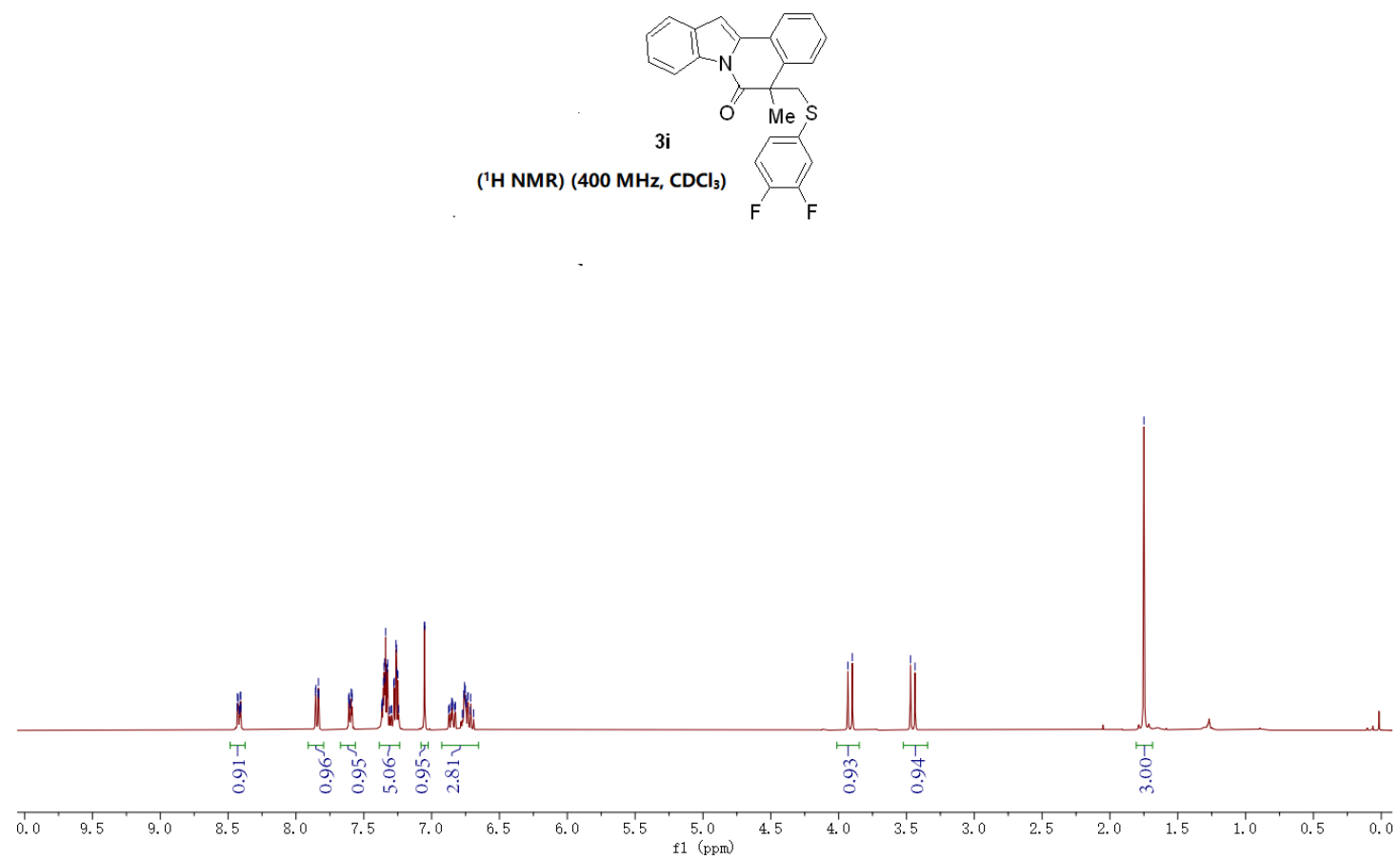

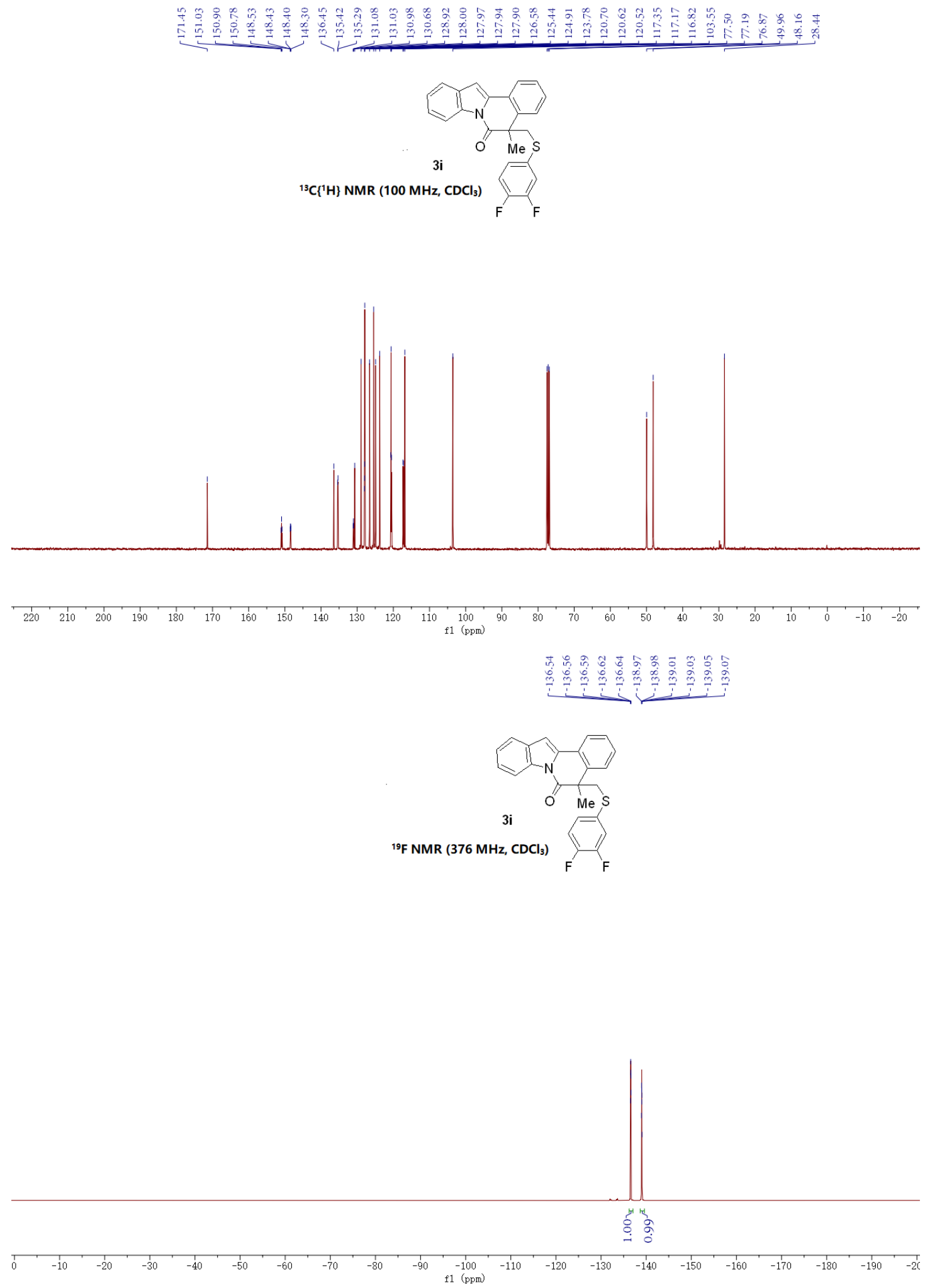

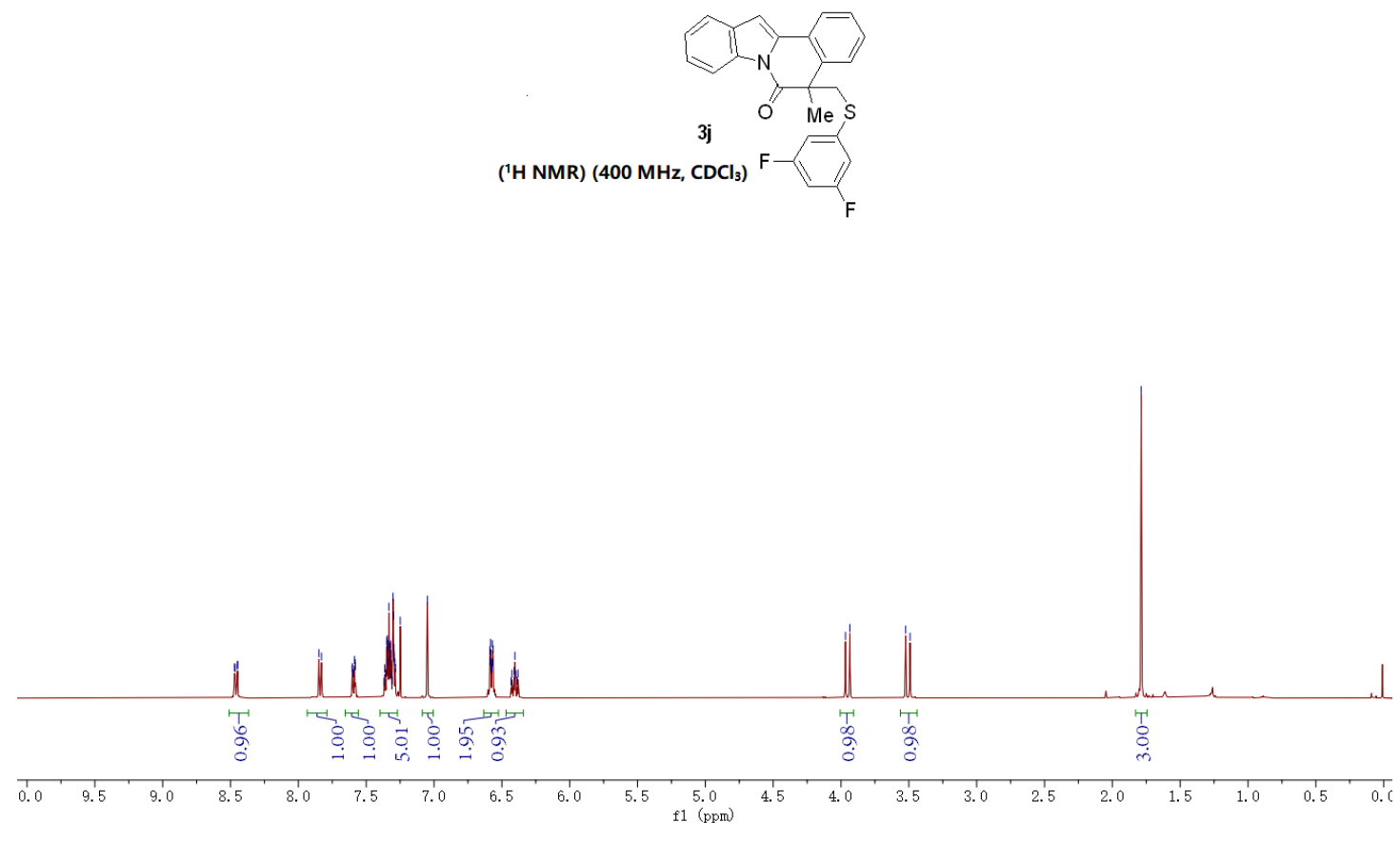

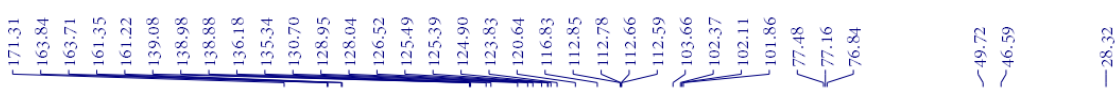
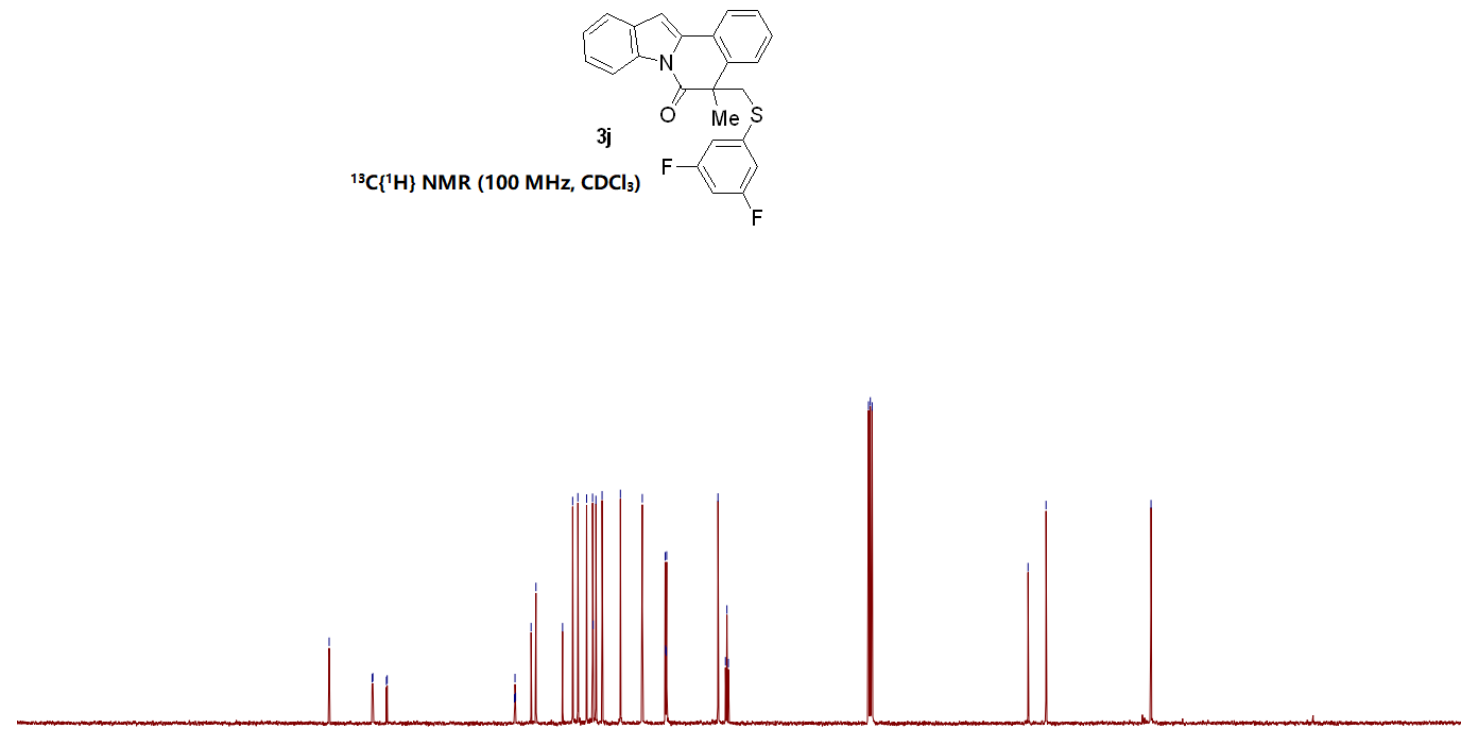

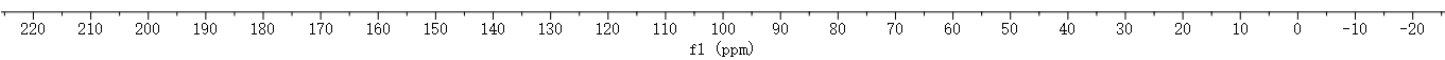




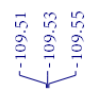
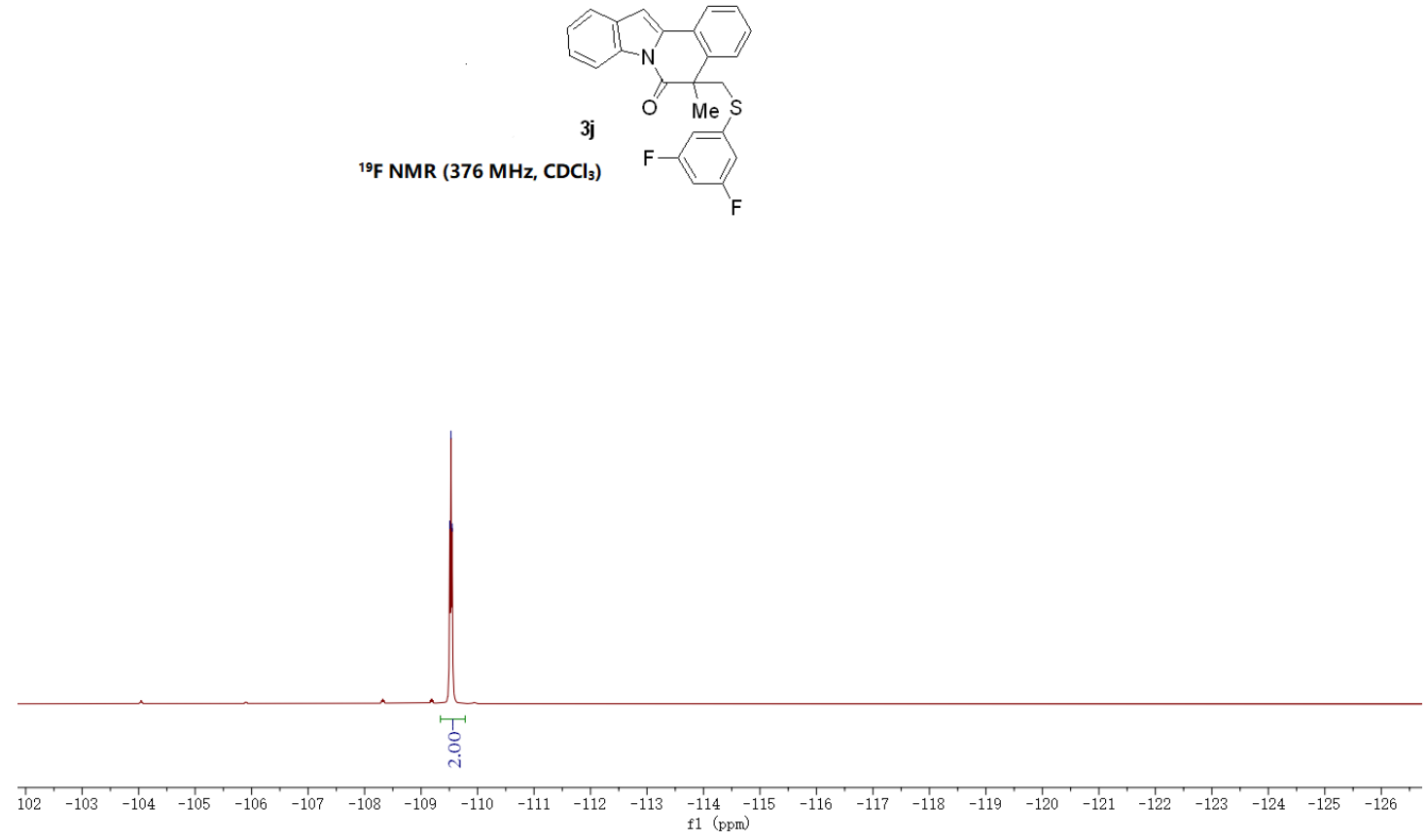

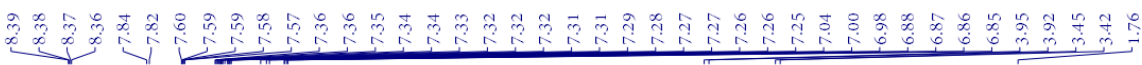
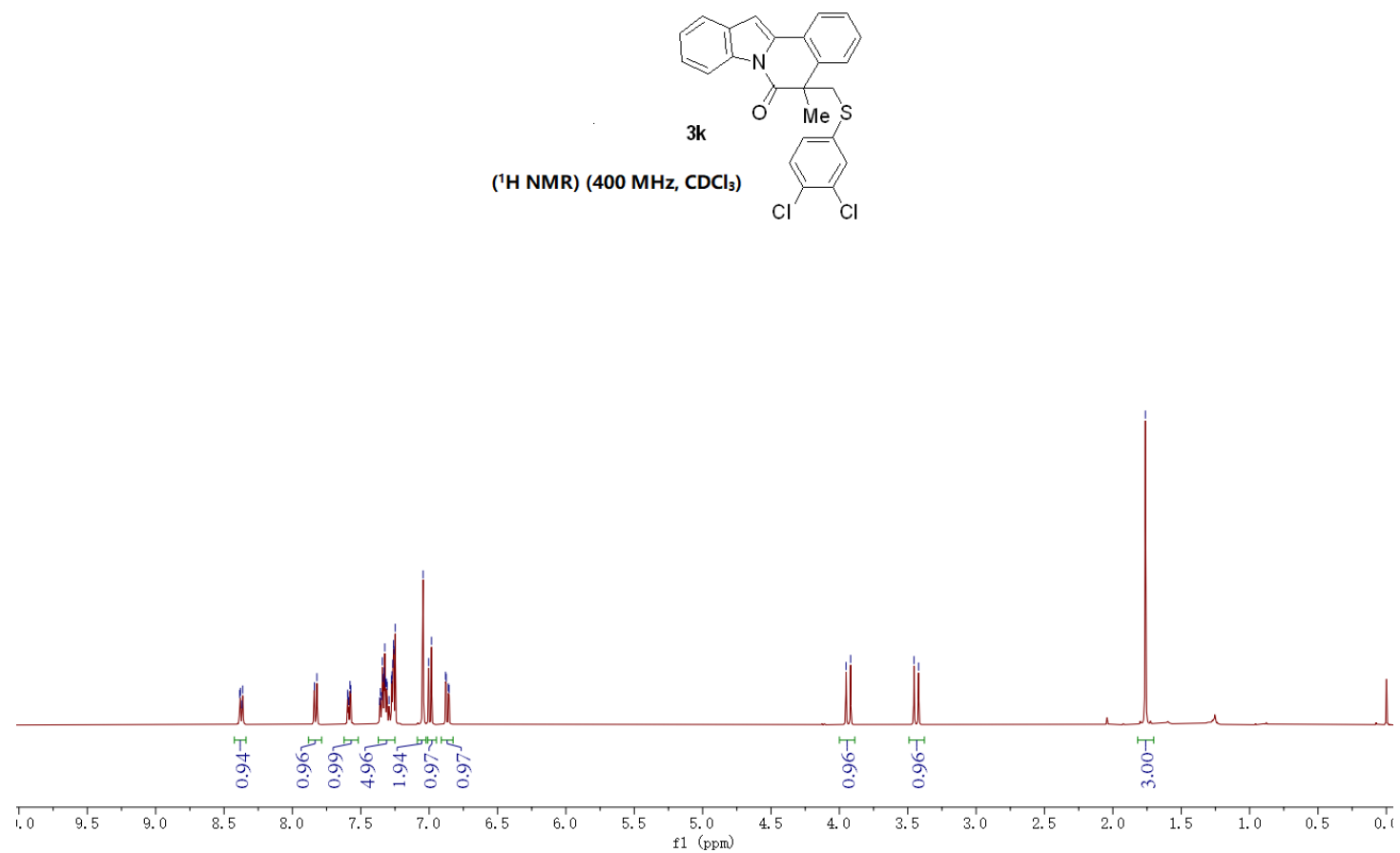


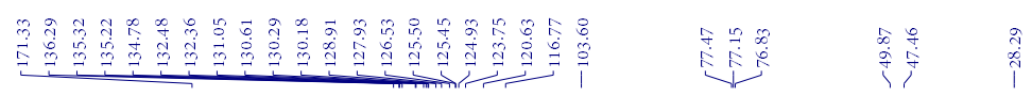
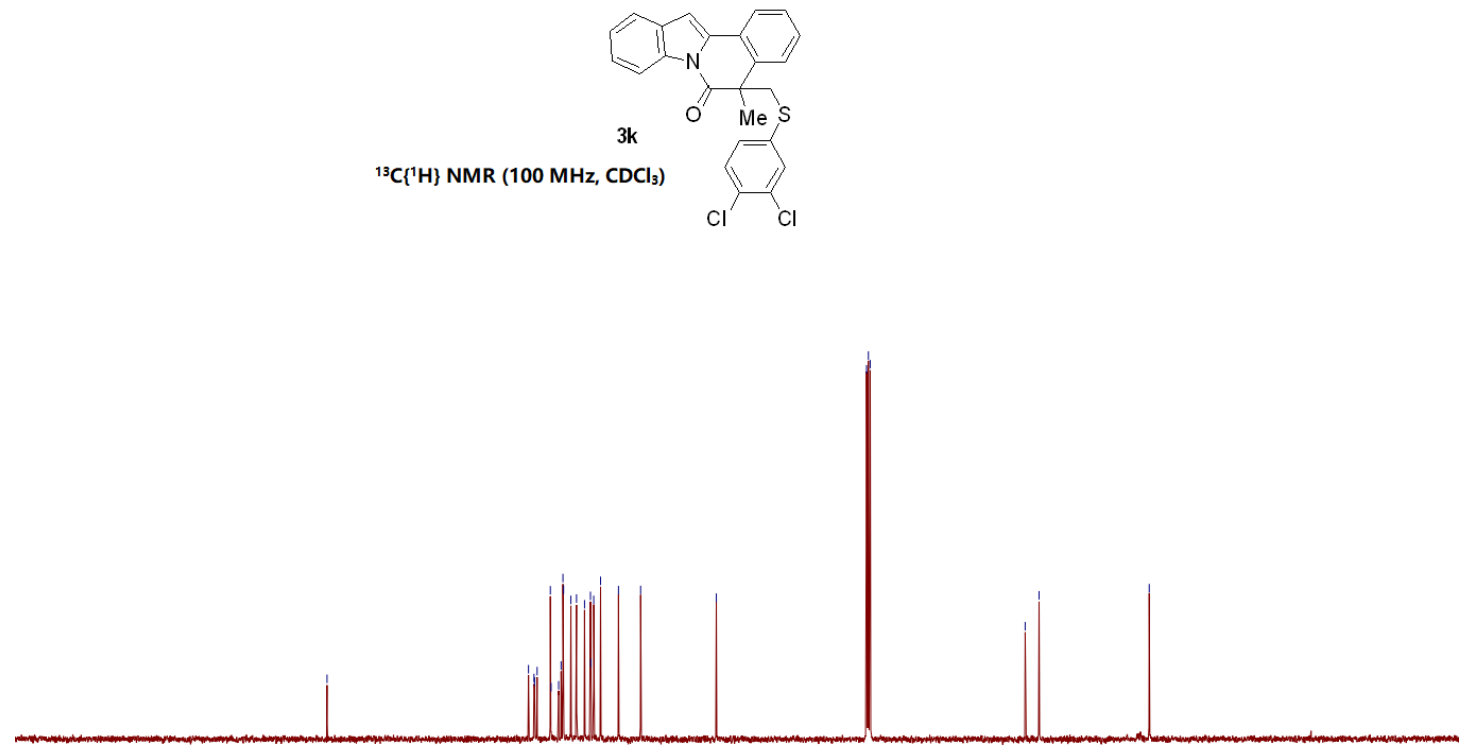

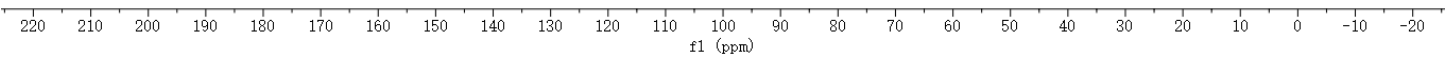

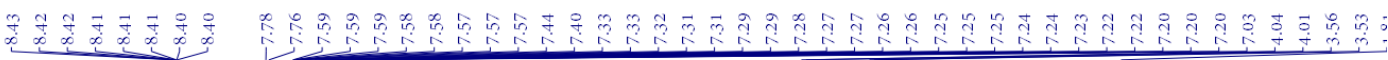
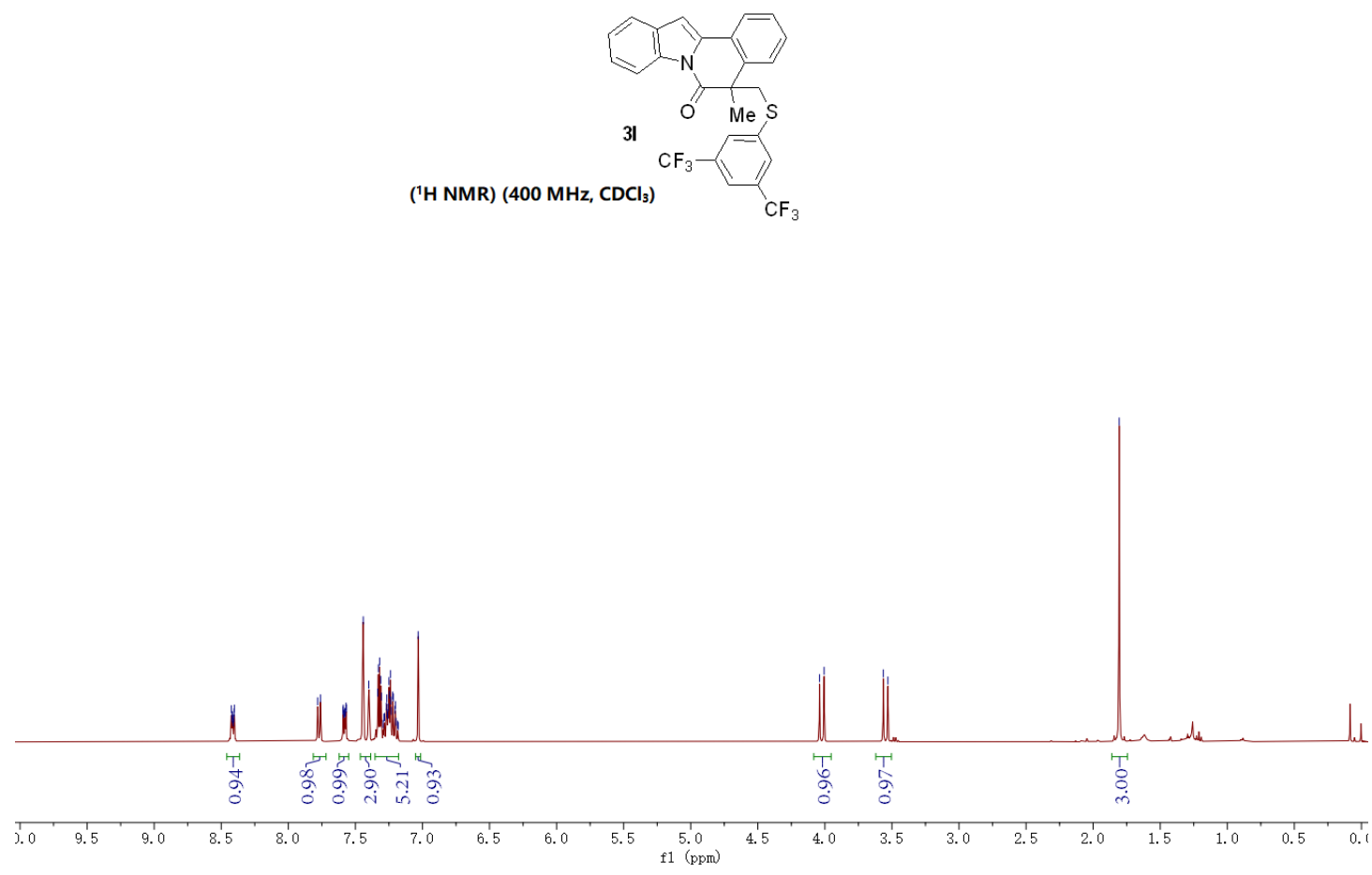

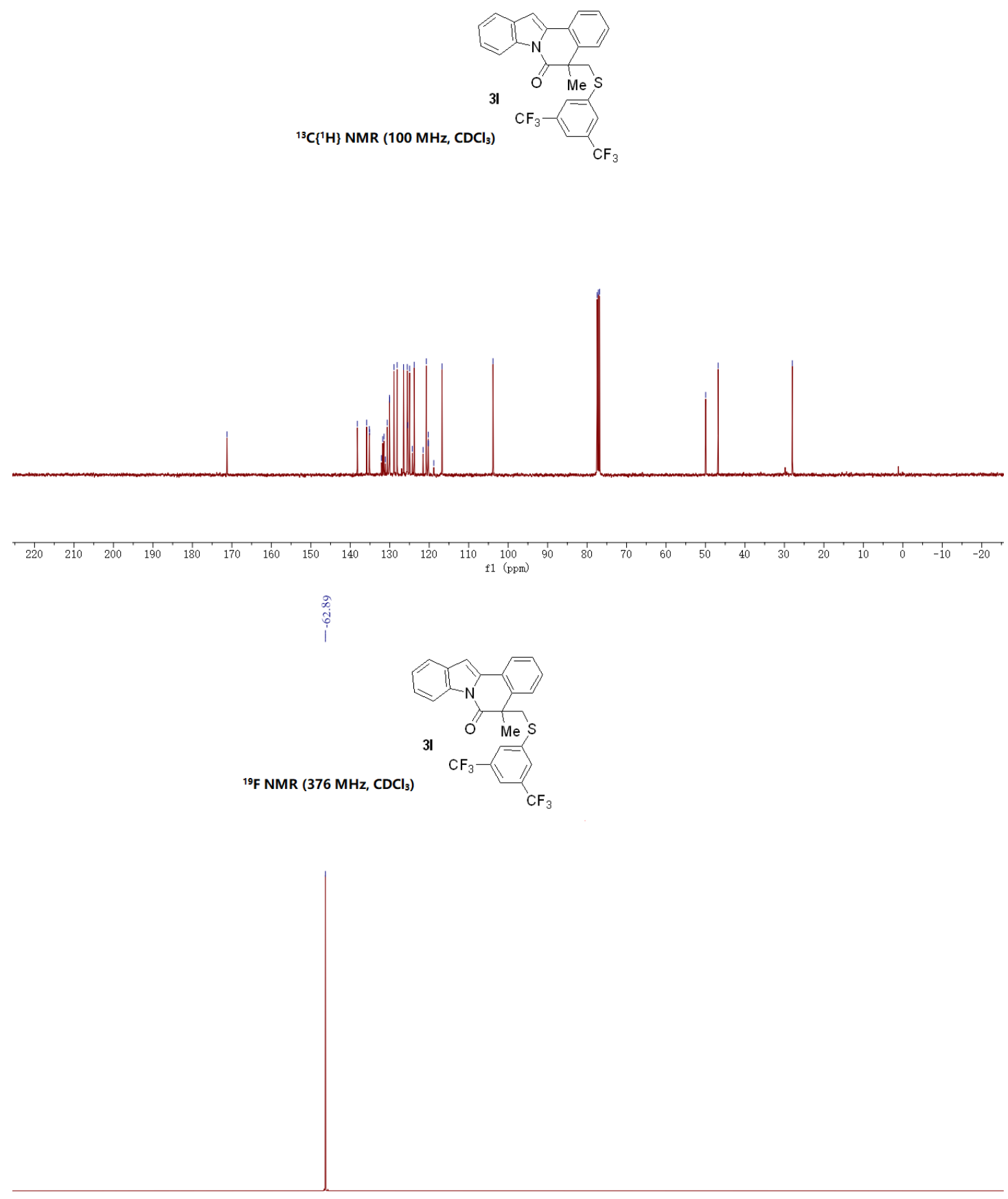

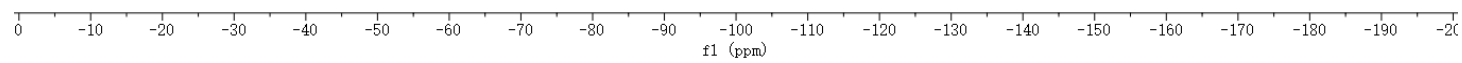




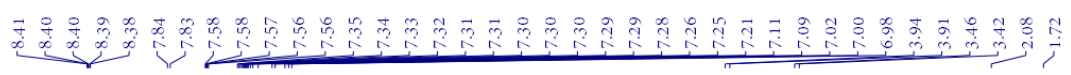
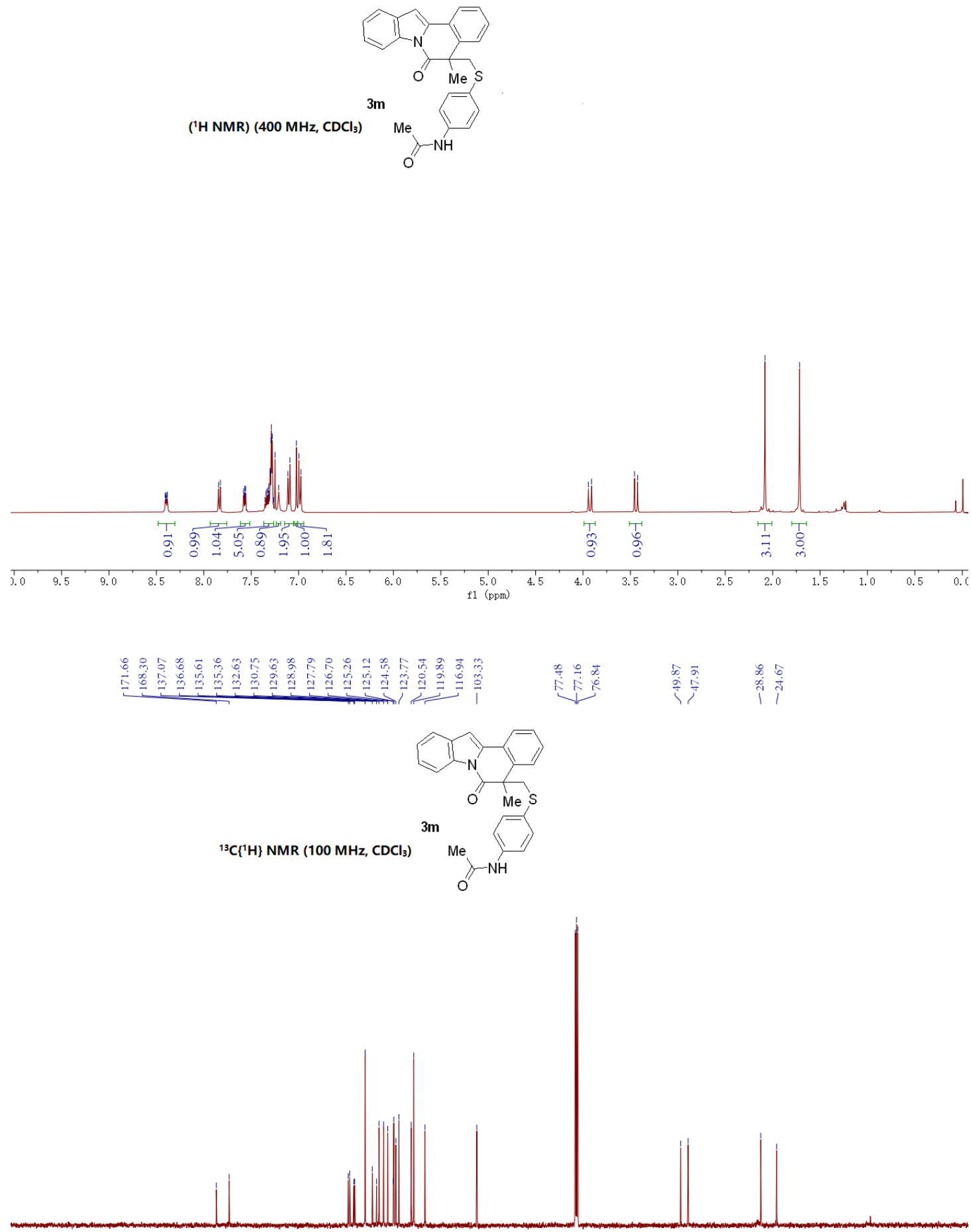

$\begin{array}{lllllllllllll}1 & 1 & 1 & 1 & 1 & 1 & 1 & 1 & 1 & 1 & 1 & 1 & 1 \\ 1 & 200 & 190 & 180 & 170 & 160 & 150 & 140 & 130 & 120 & 110 & 100\end{array}$ 


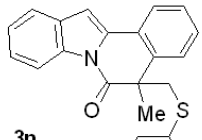

('H NMR) (400 MHz, $\left.\mathrm{CDCl}_{3}\right)$

$\mathrm{HO}$

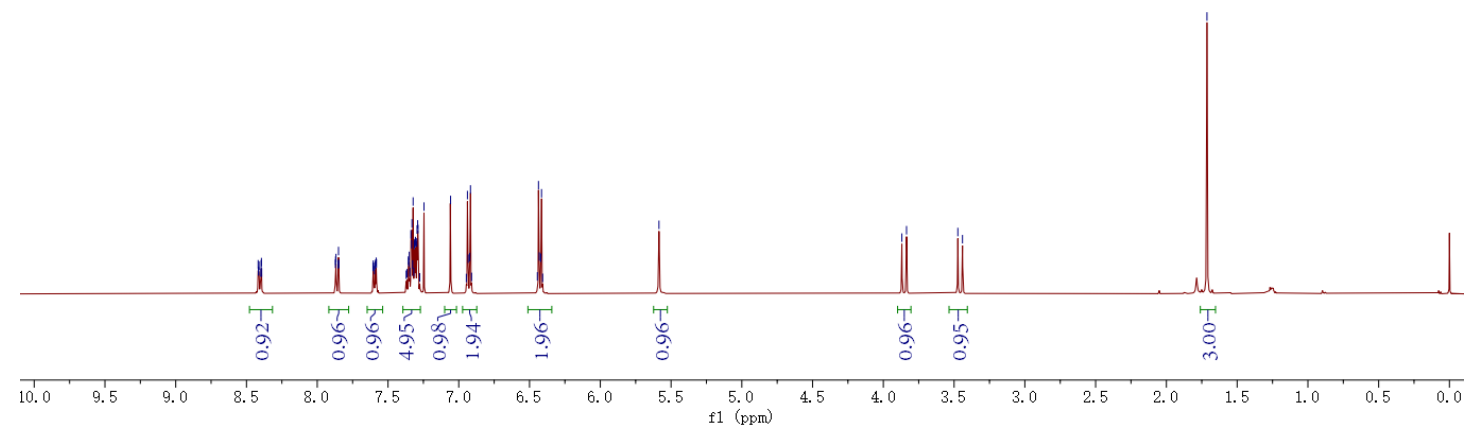

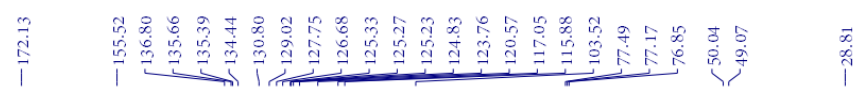

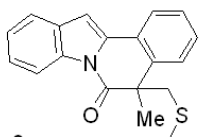

${ }^{13} \mathrm{C}\left\{{ }^{1} \mathrm{H}\right\}$ NMR $\left(100 \mathrm{MHz}, \mathrm{CDCl}_{3}\right)$

Me S

HO

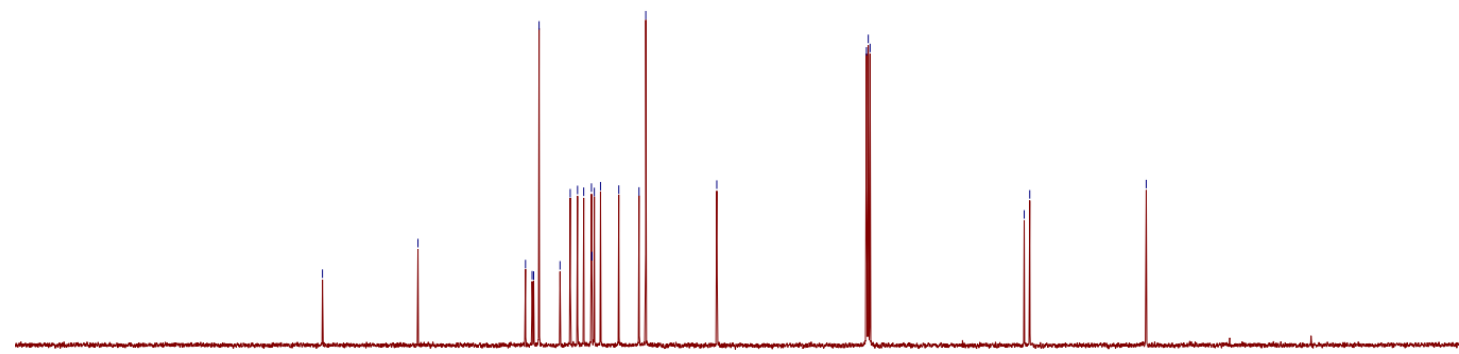

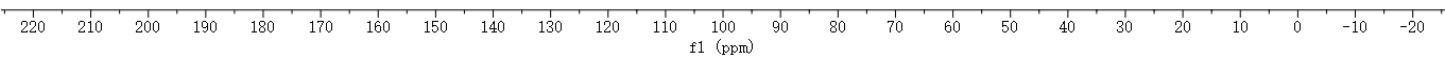




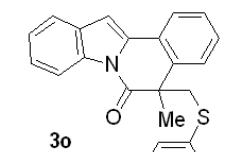

('H NMR) (400 MHz, $\left.\mathrm{CDCl}_{3}\right)$

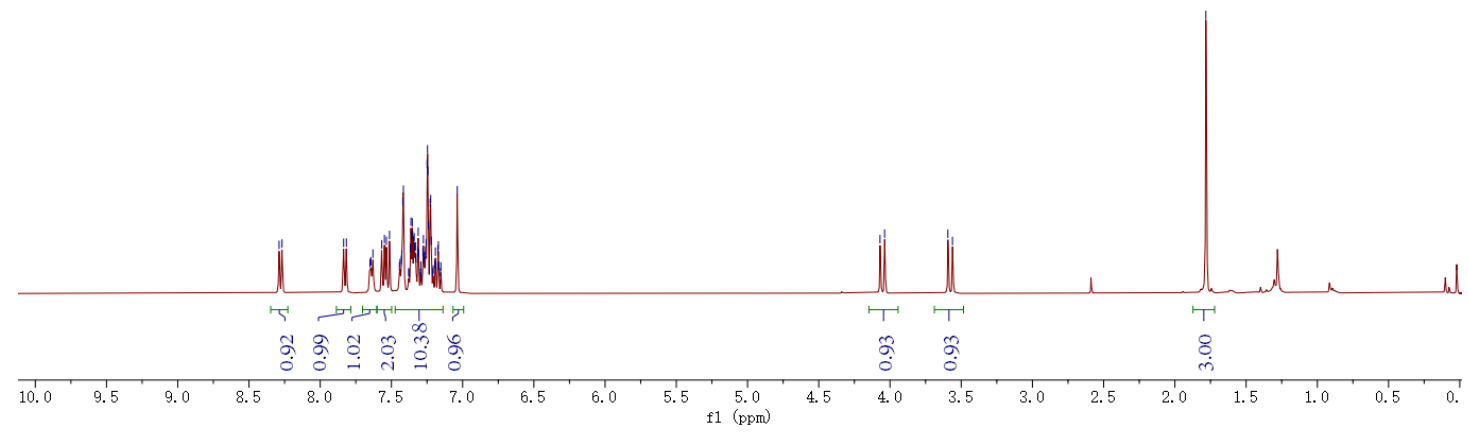

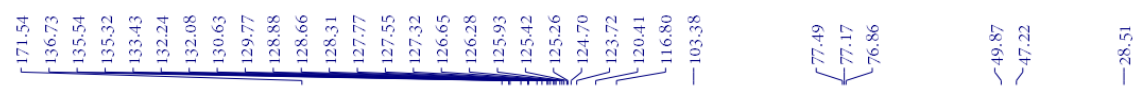

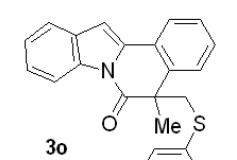

${ }^{13} \mathrm{C}\left\{{ }^{1} \mathrm{H}\right\}$ NMR $\left(100 \mathrm{MHz}, \mathrm{CDCl}_{3}\right)$

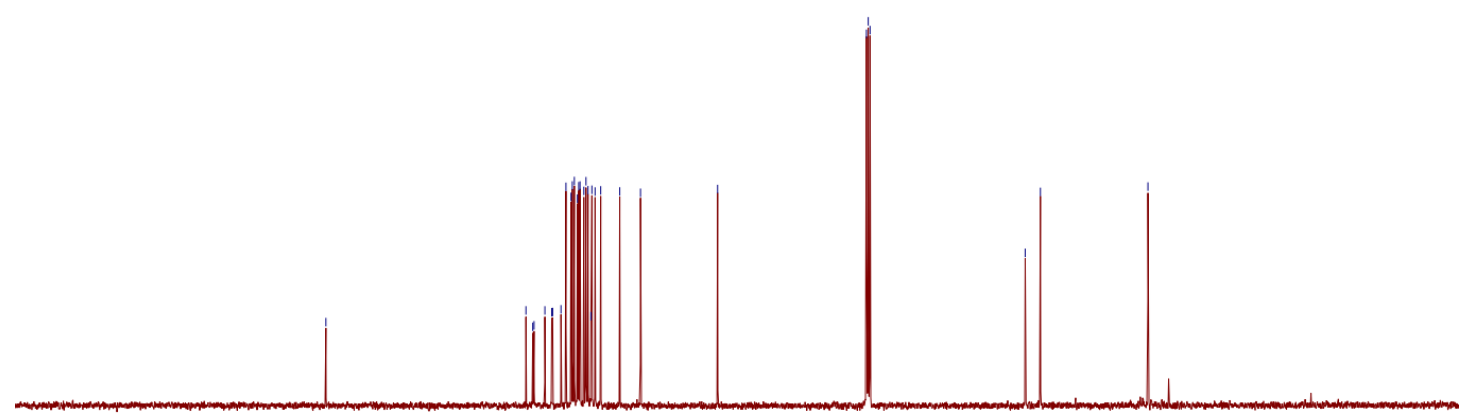

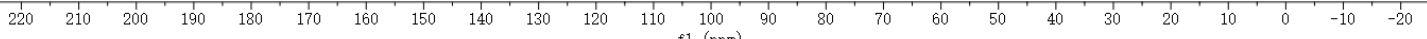




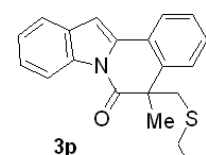

${ }^{1} \mathrm{H}$ NMR $\left(400 \mathrm{MHz}, \mathrm{CDCl}_{3}\right)$

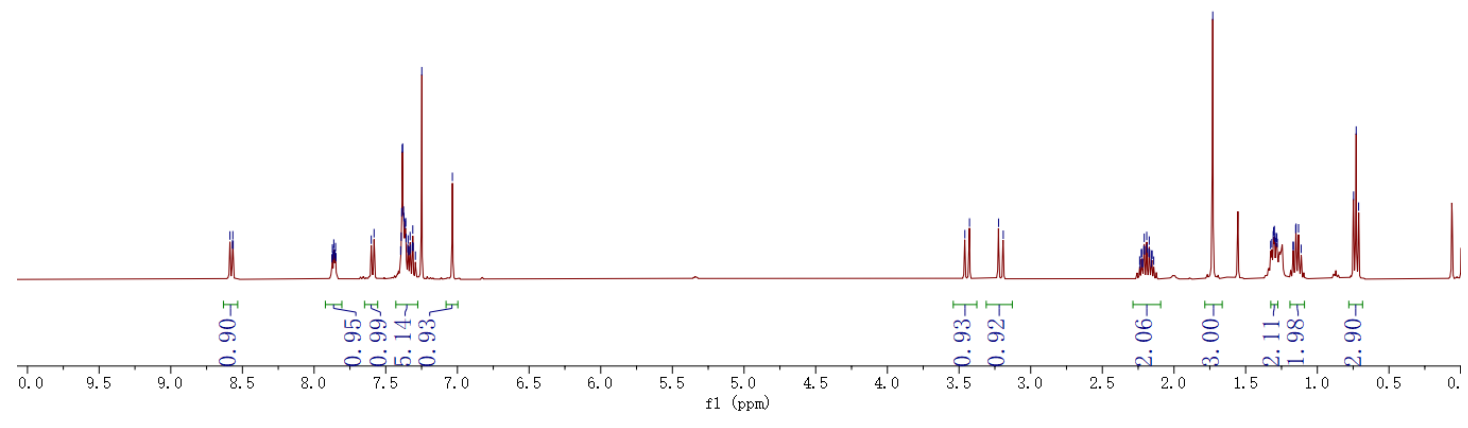

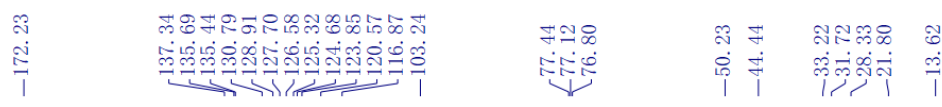

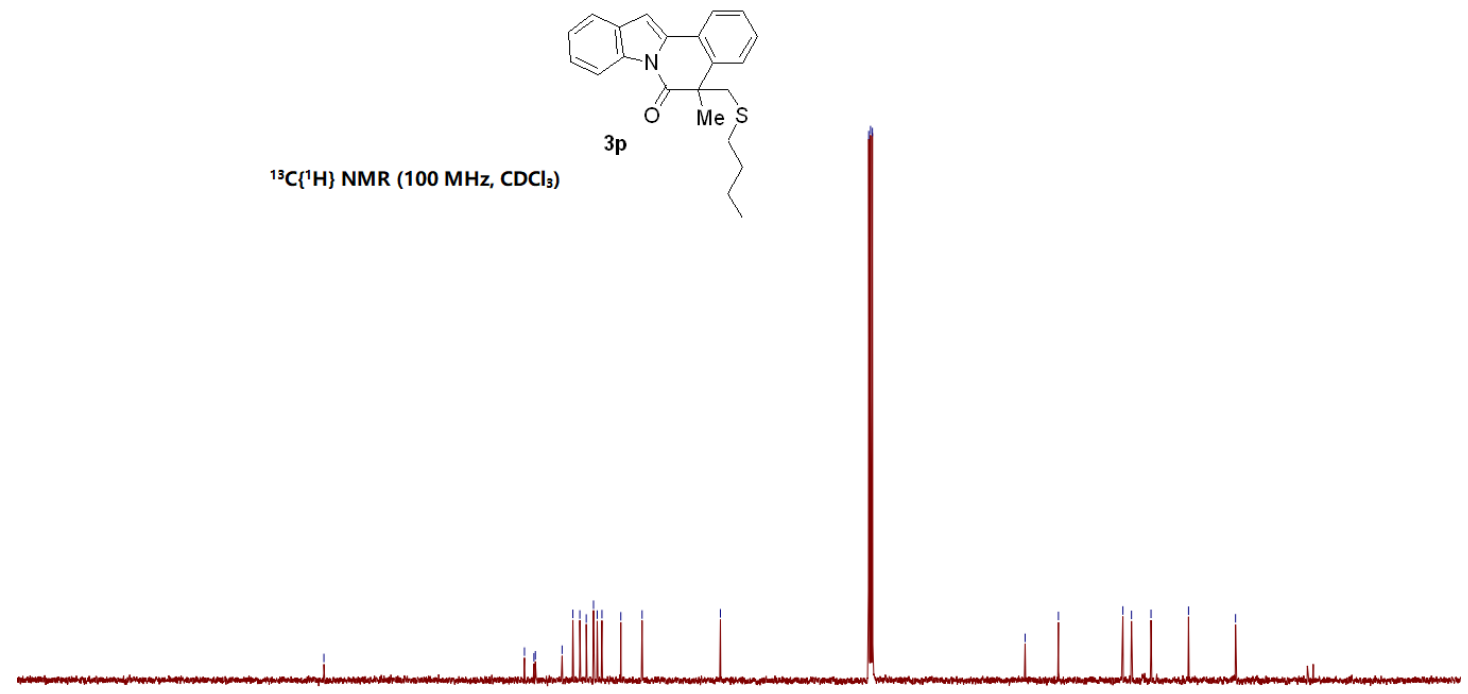

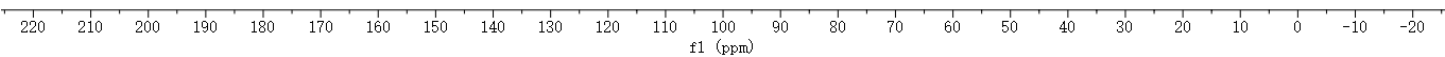




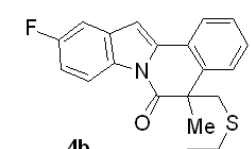

('H NMR) (400 MHz, $\left.\mathrm{CDCl}_{3}\right)$

Me S

$\mathrm{Me}$

$\mathrm{Me}$
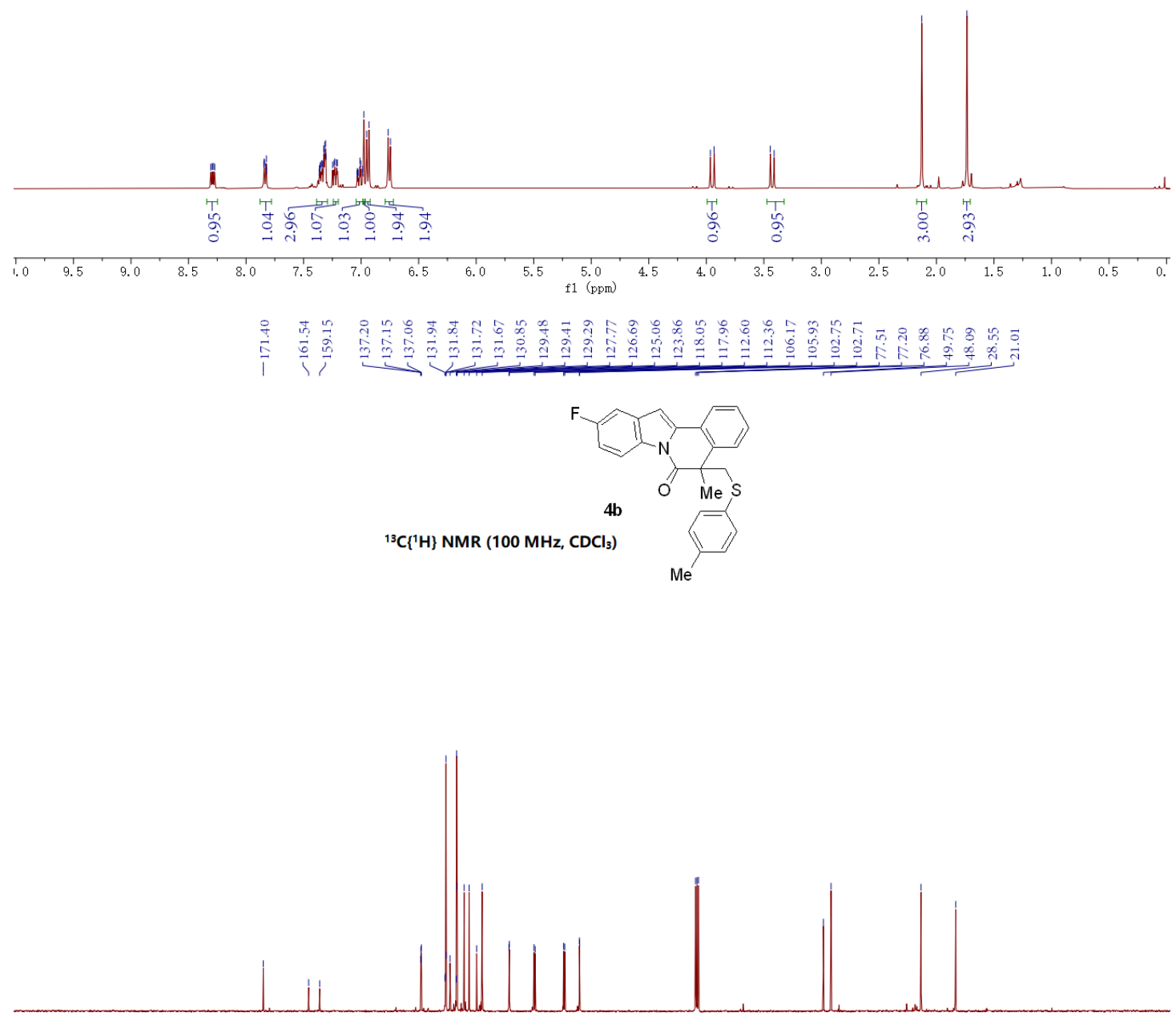

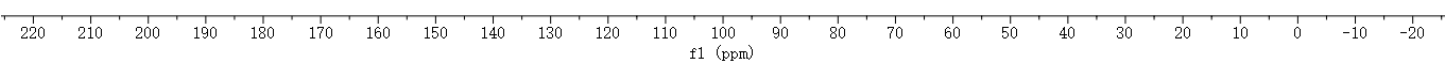



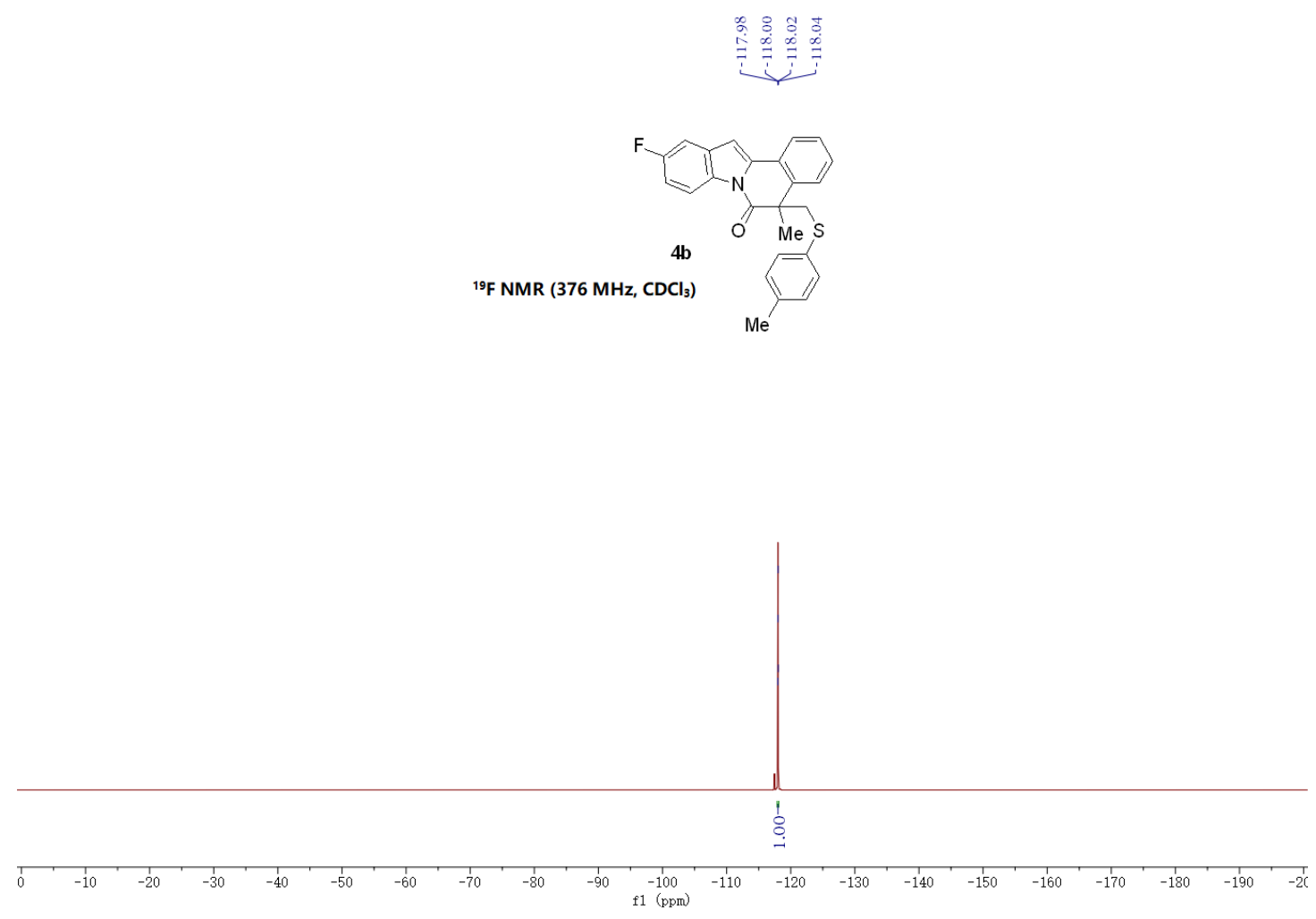

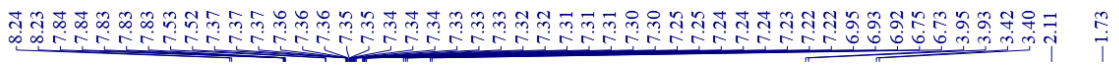

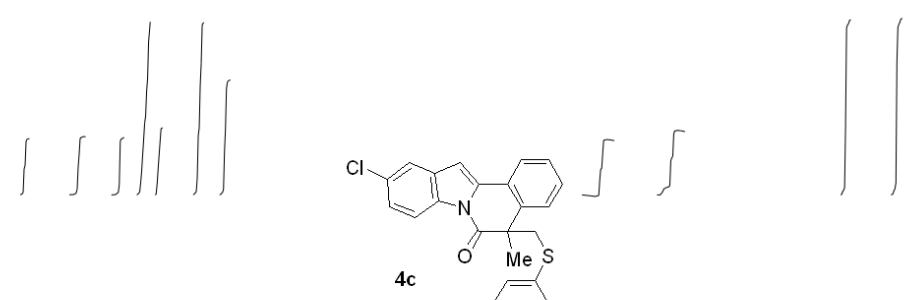

('H NMR) $\left(600 \mathrm{MHz}, \mathrm{CDCl}_{3}\right)$

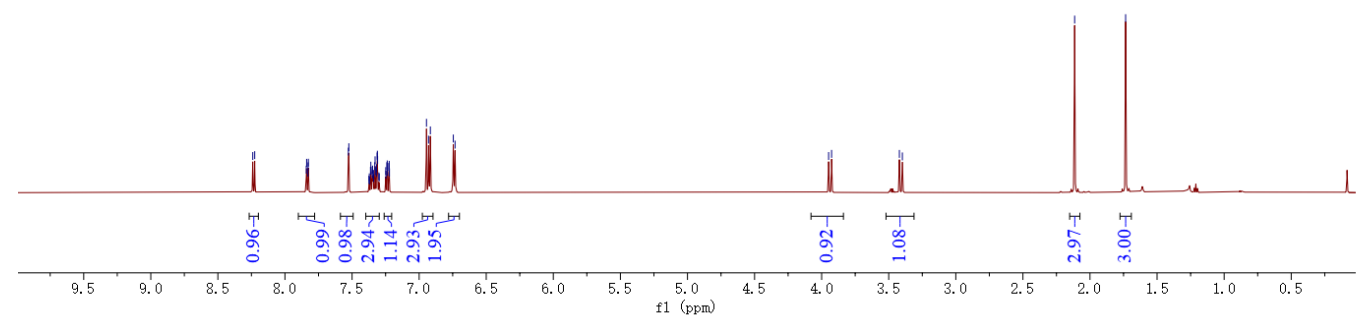



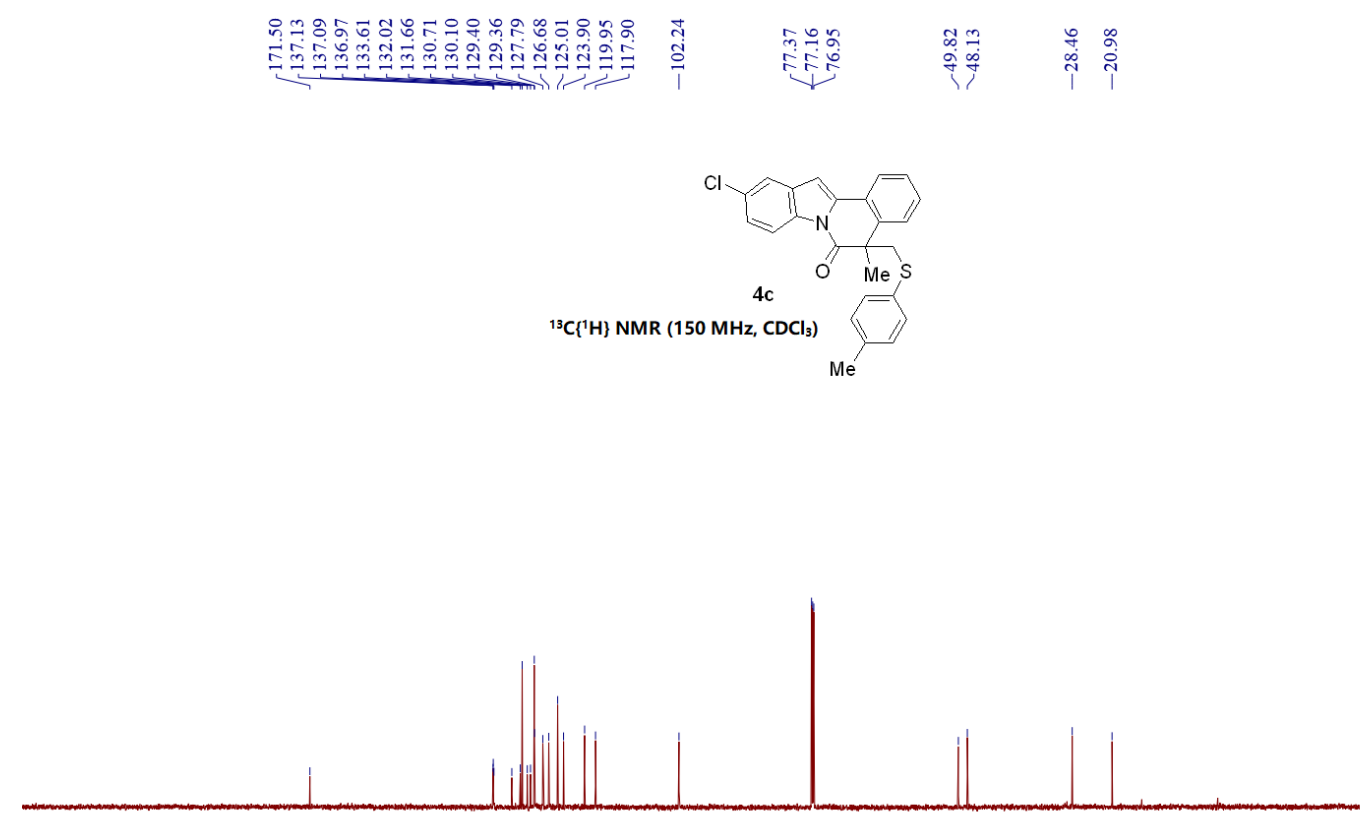

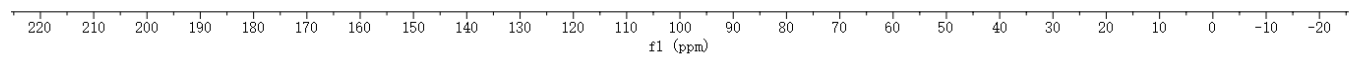

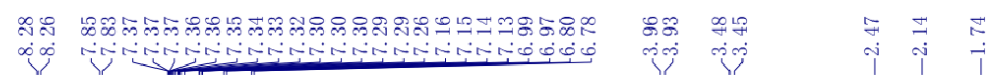
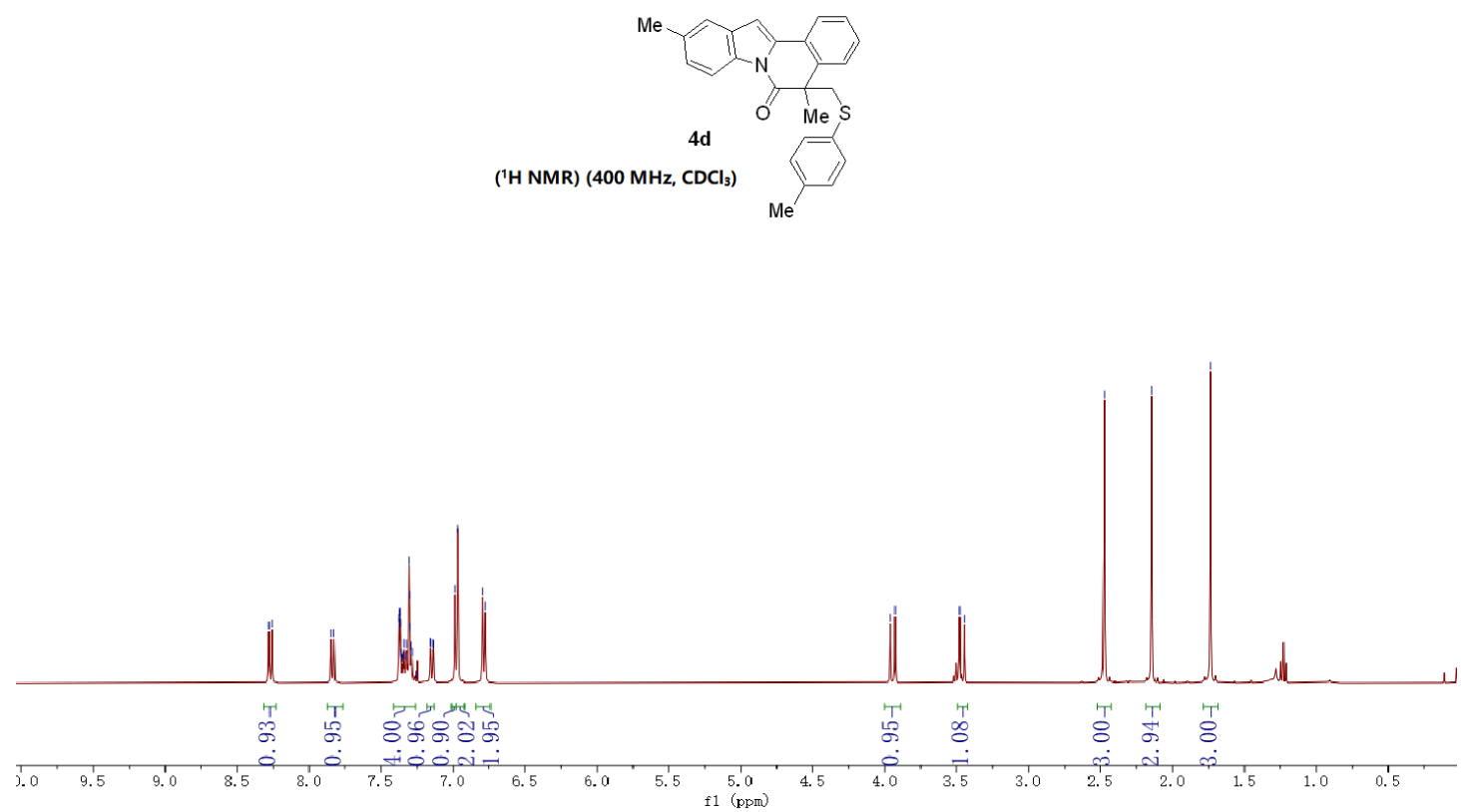


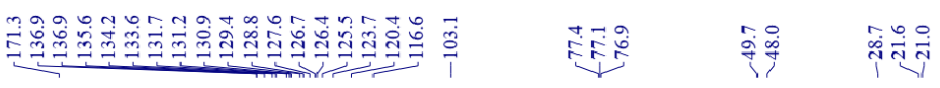

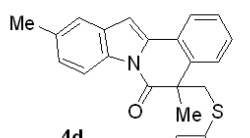

${ }^{13} \mathrm{C}\left\{{ }^{1} \mathrm{H}\right\}$ NMR $\left(100 \mathrm{MHz}, \mathrm{CDCl}_{3}\right)$

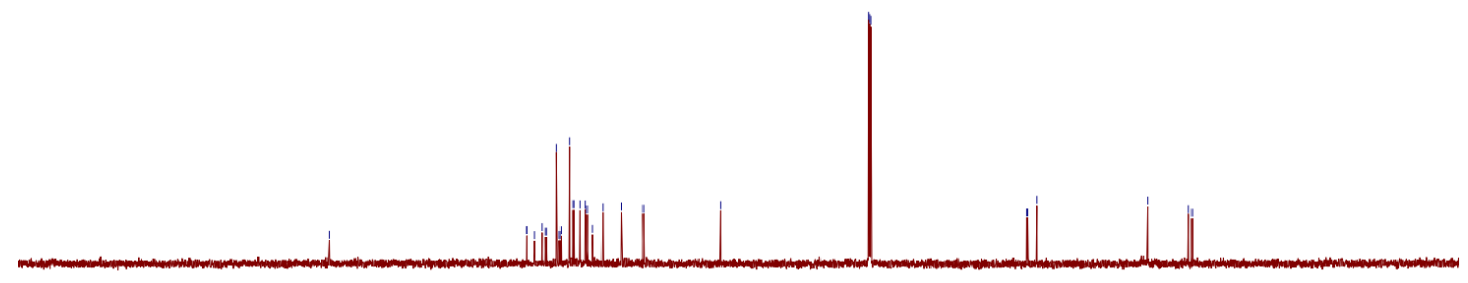

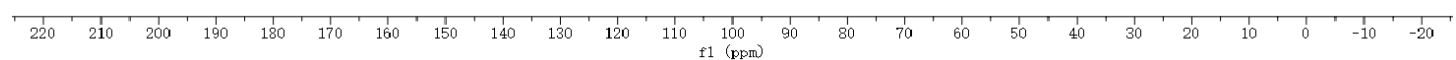

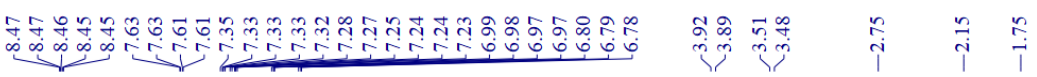
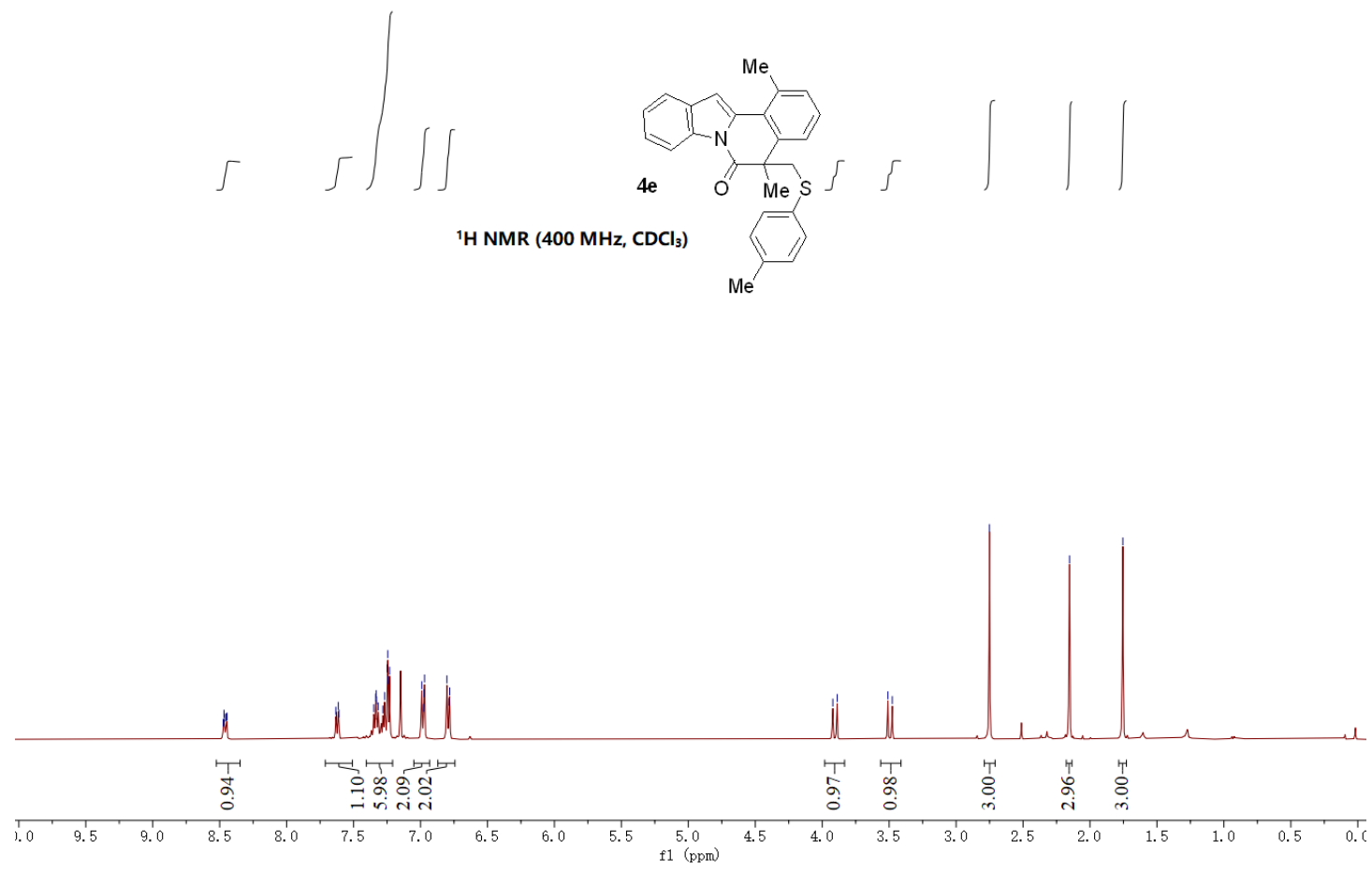


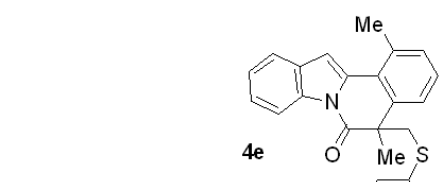

${ }^{13} \mathrm{C}\left\{{ }^{1} \mathrm{H}\right\}$ NMR $\left(100 \mathrm{MHz}, \mathrm{CDCl}_{3}\right)$

$\mathrm{Me}^{\prime}$

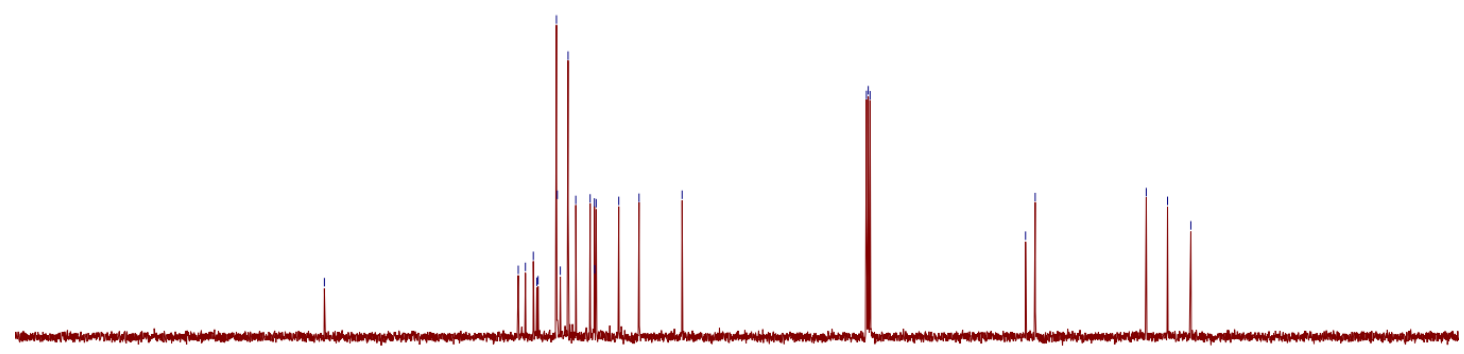

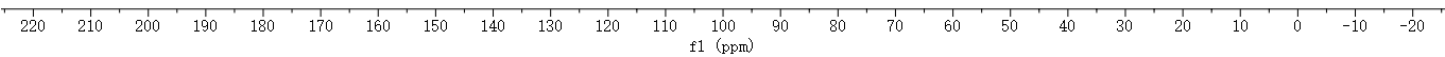

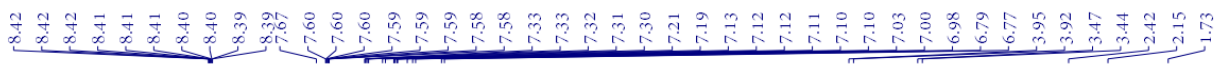

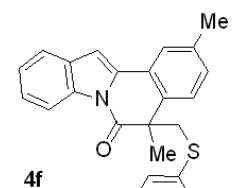

(1 $\mathrm{H}$ NMR) (400 MHz, $\left.\mathrm{CDCl}_{3}\right)$

$\mathrm{Me}$

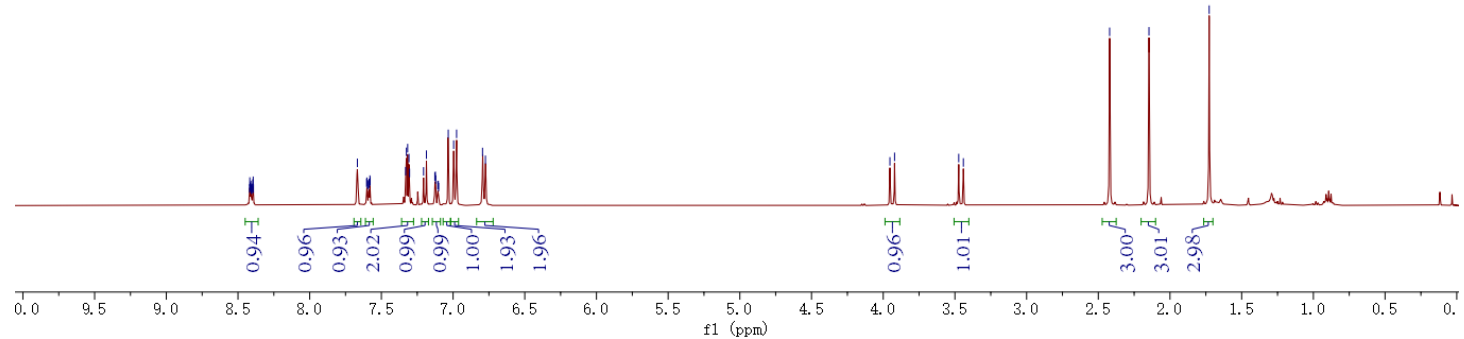



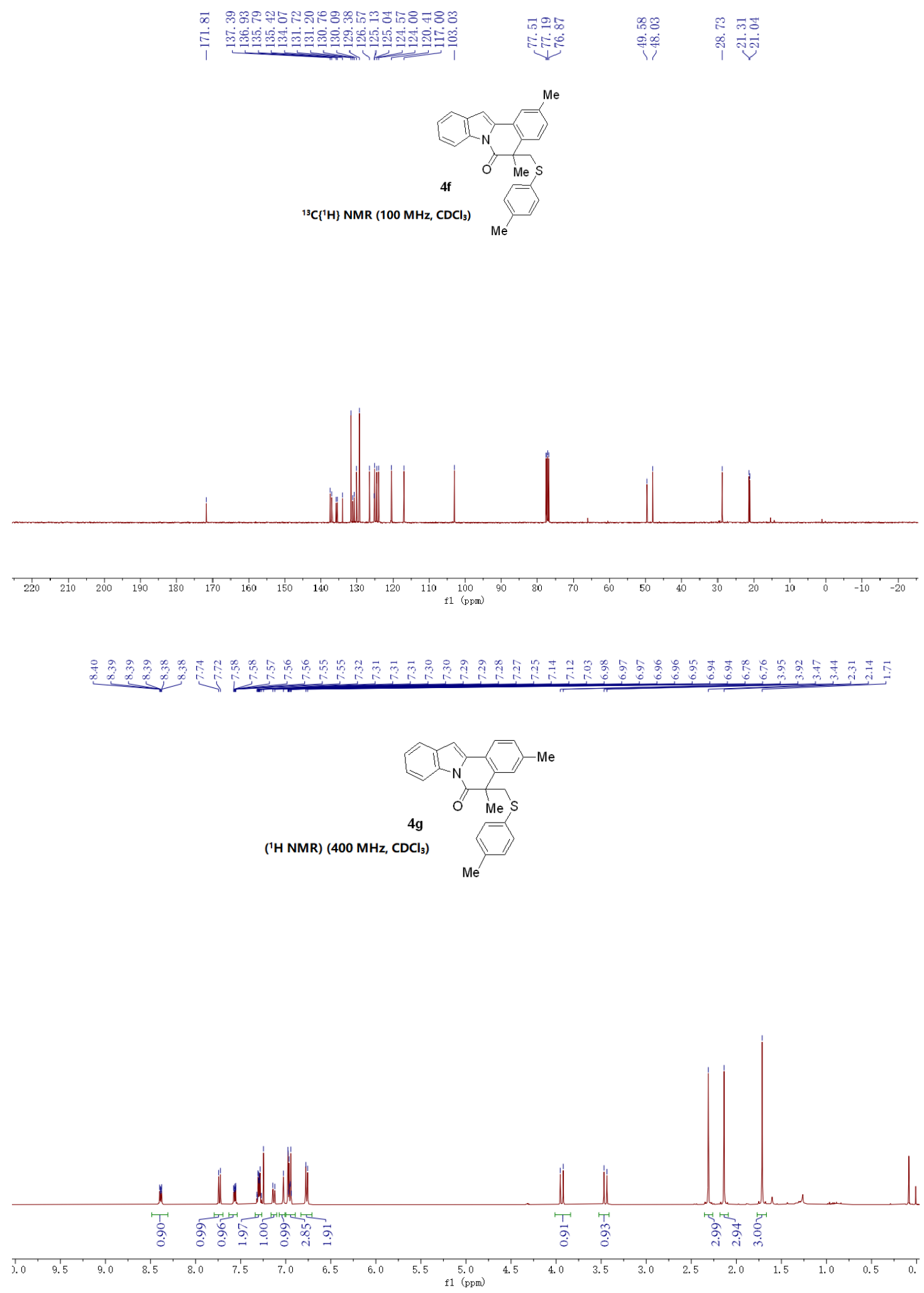

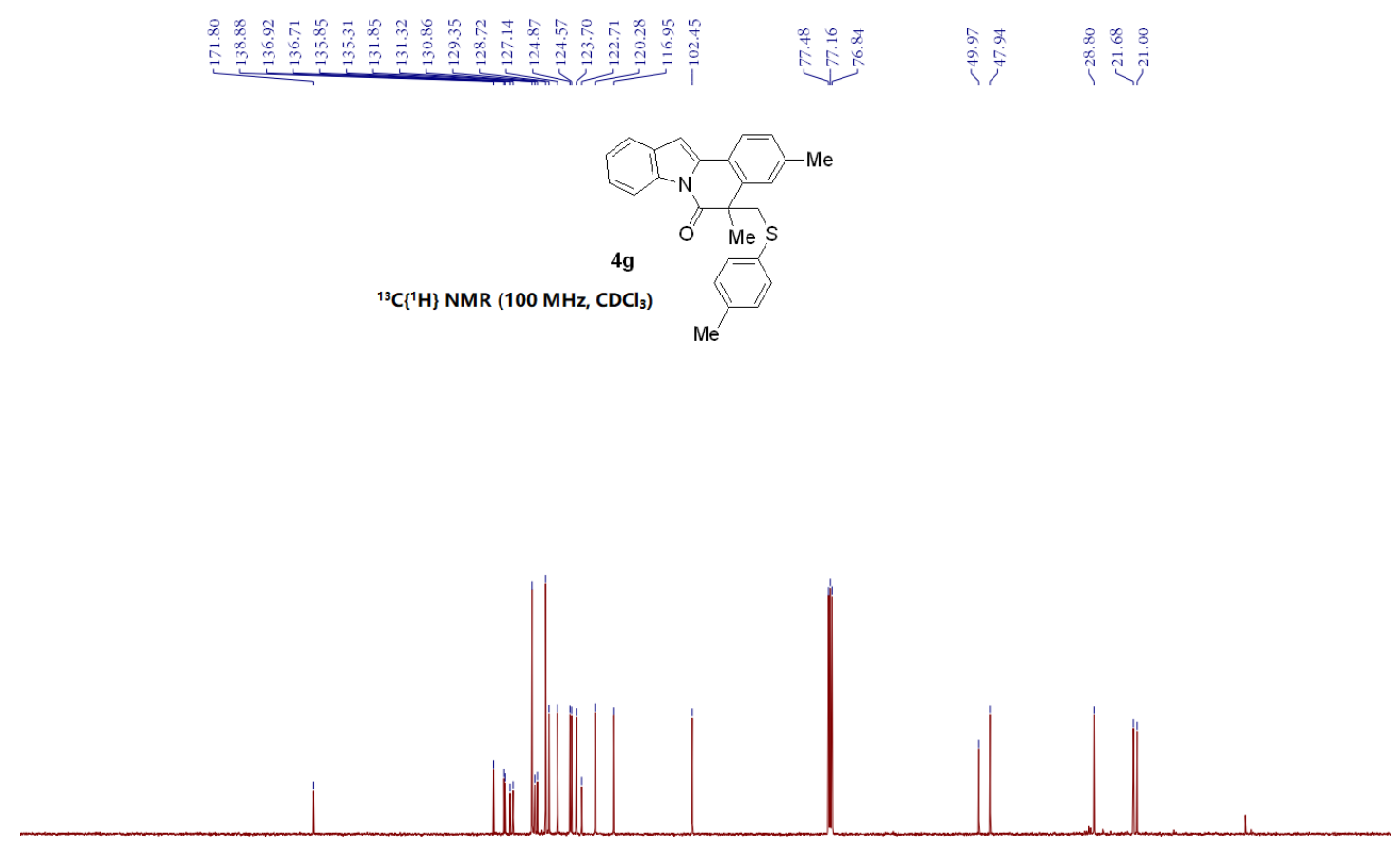

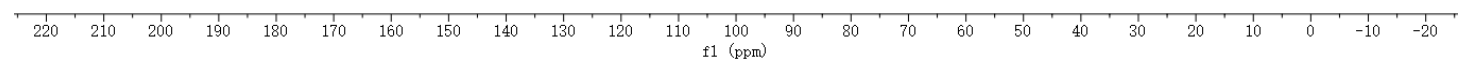

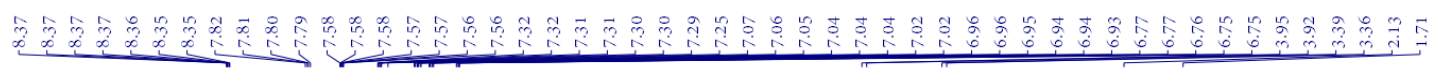
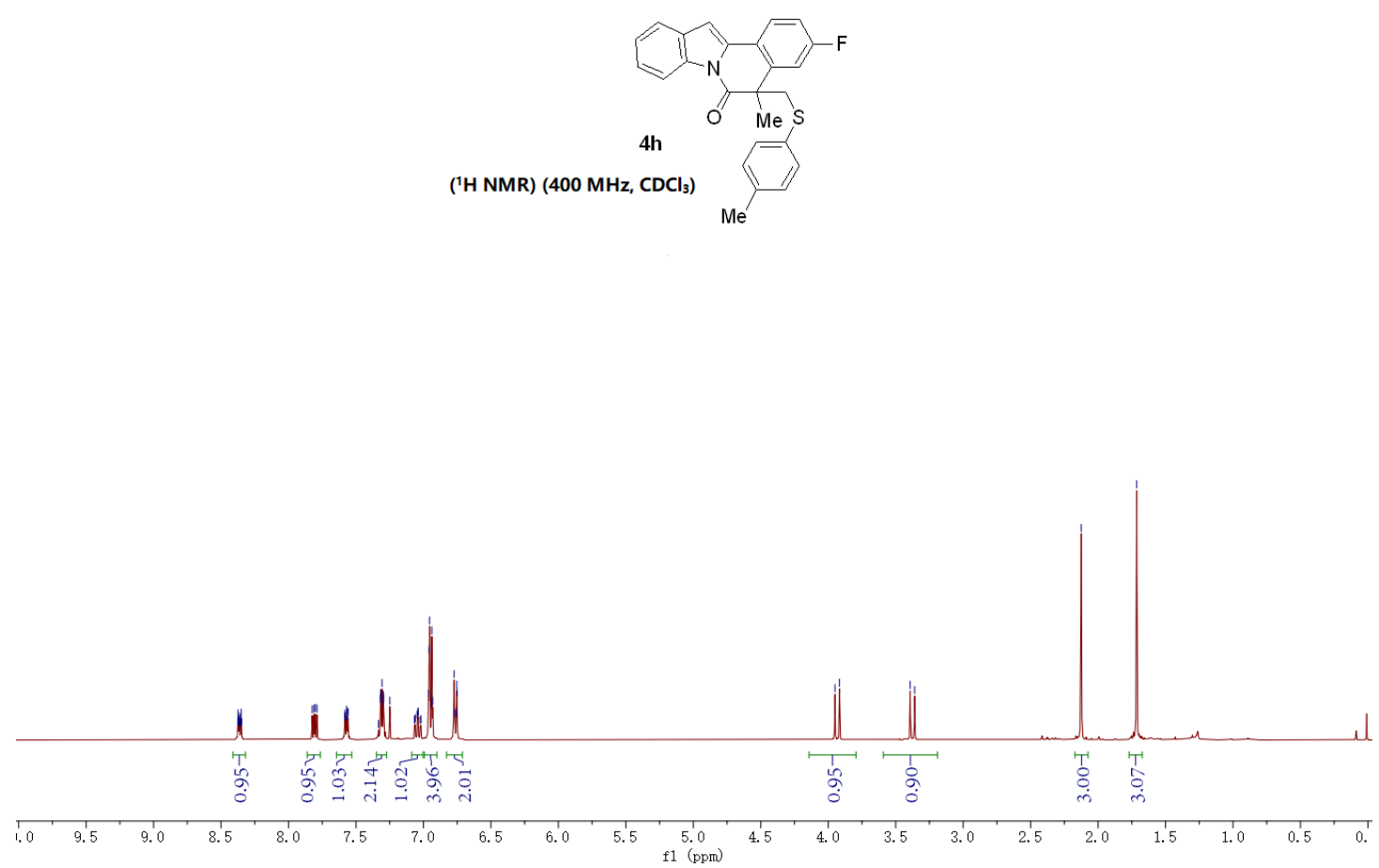


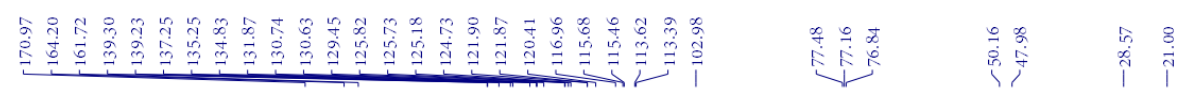

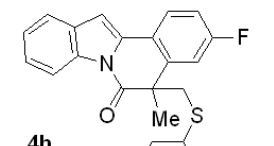

${ }^{13} \mathrm{C}\left\{{ }^{1} \mathrm{H}\right\}$ NMR $\left(100 \mathrm{MHz}, \mathrm{CDCl}_{3}\right)$

$\left.\mathrm{CDCl}_{3}\right)$

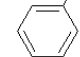

$\mathrm{Me}$

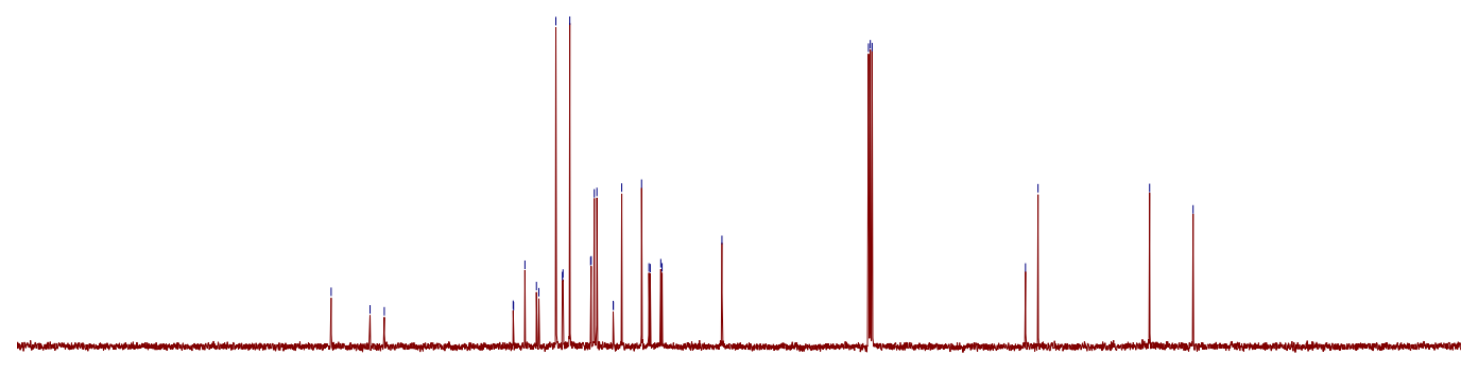

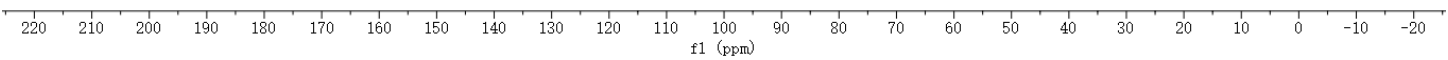

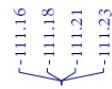

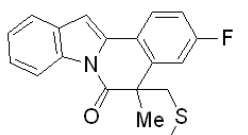

4h

${ }^{19} \mathrm{~F}$ NMR (376 $\mathrm{MHz}, \mathrm{CDCl}_{3}$ )

$\mathrm{Me}$

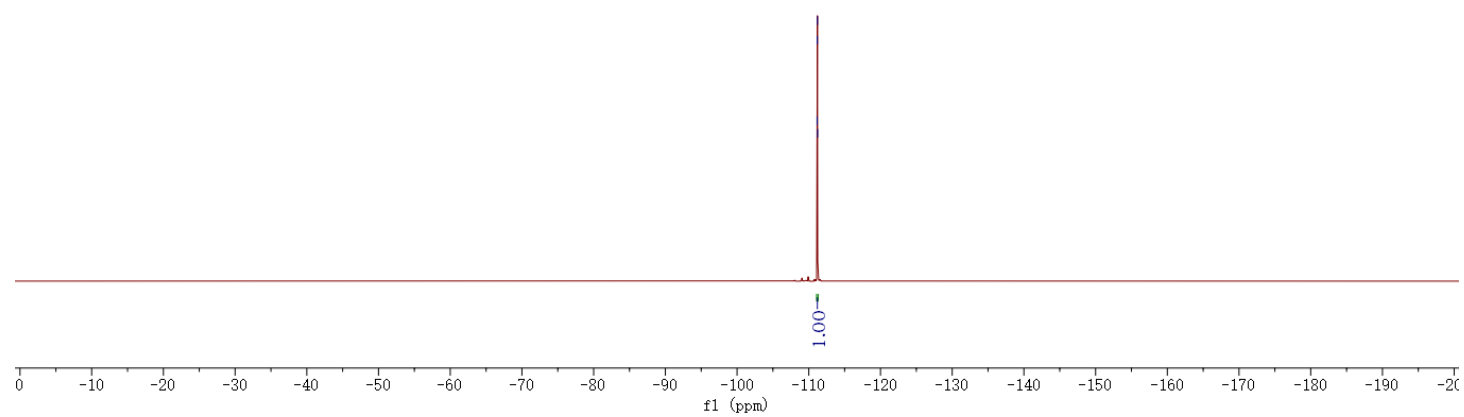




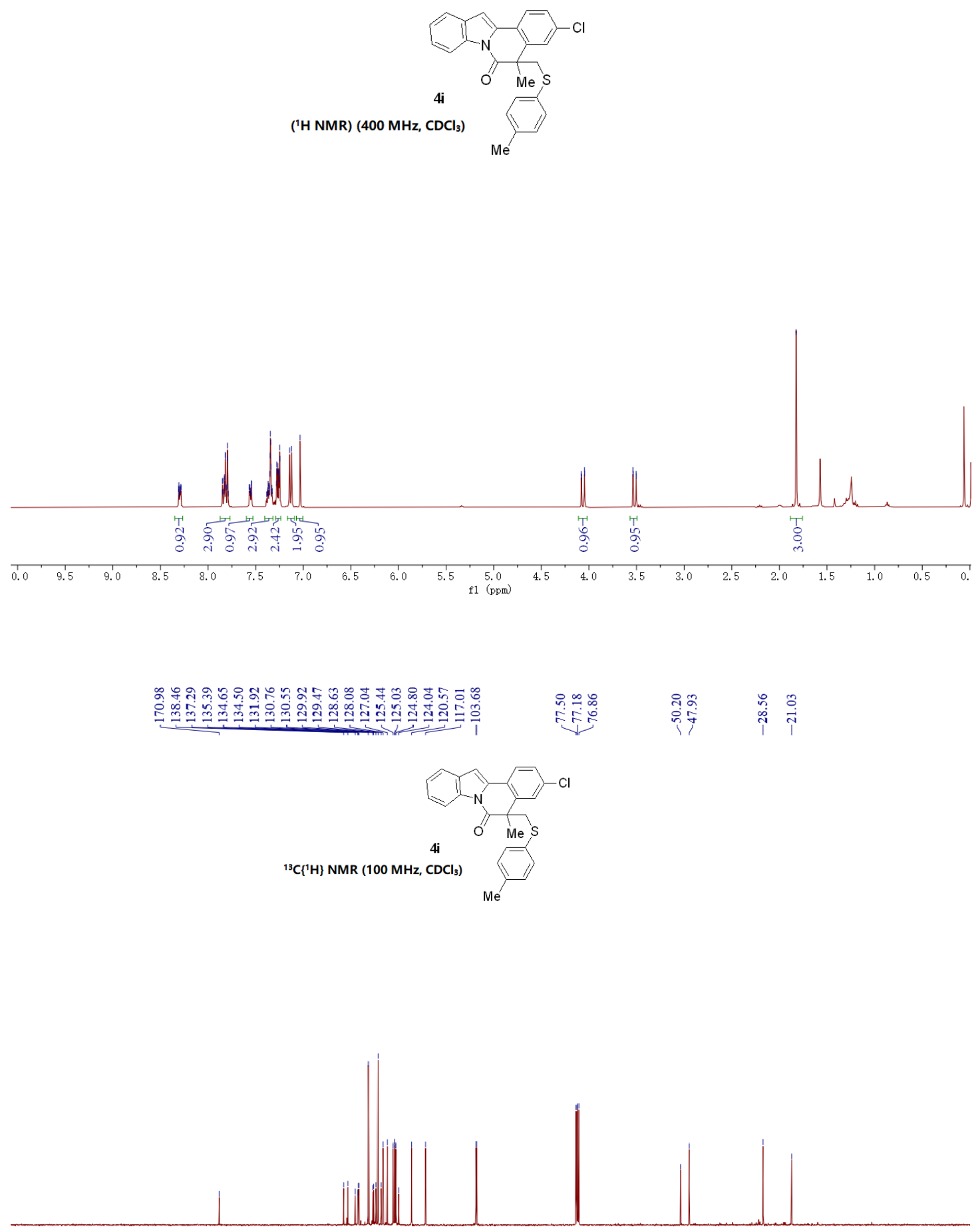

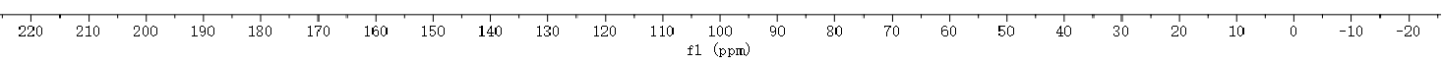



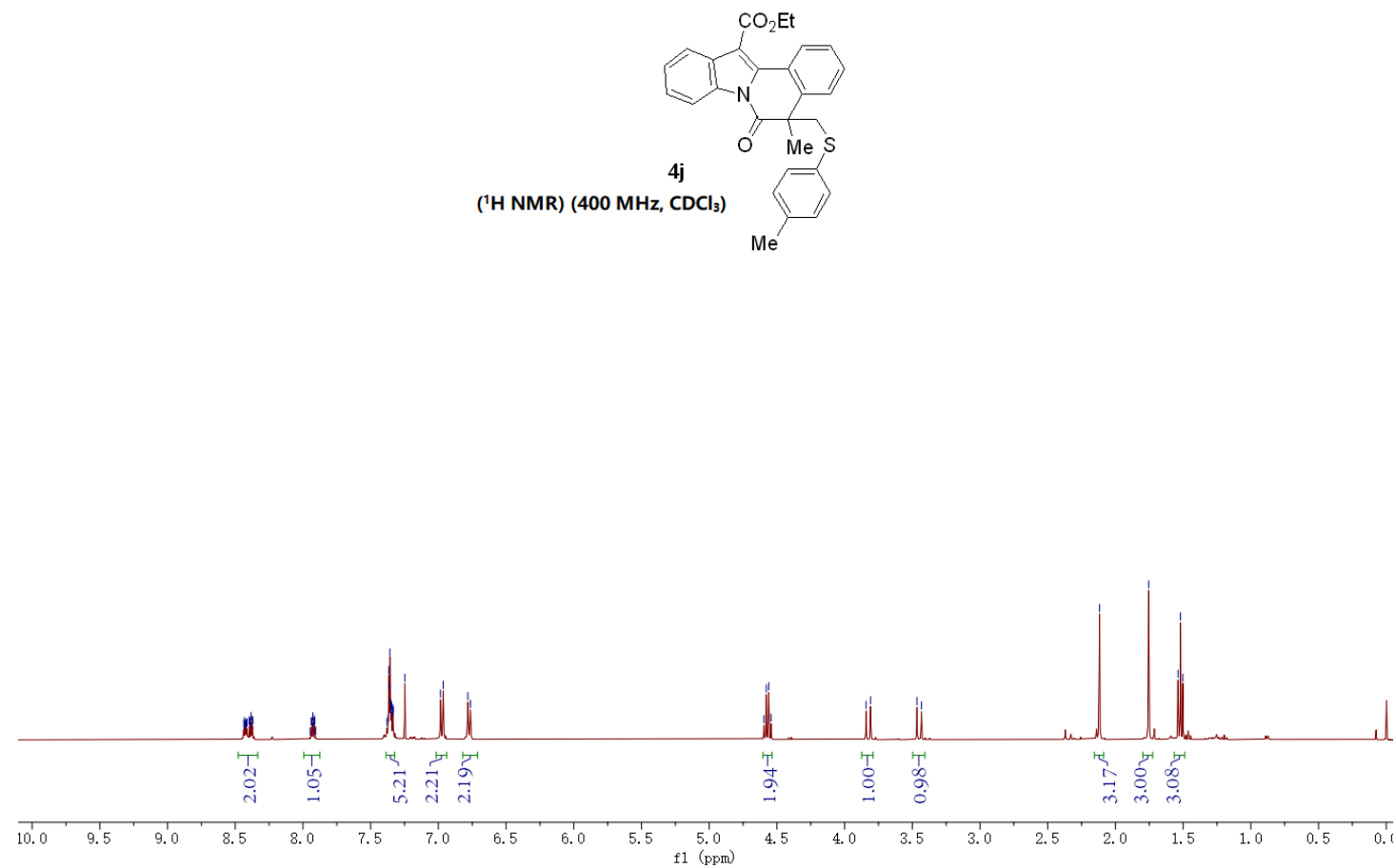

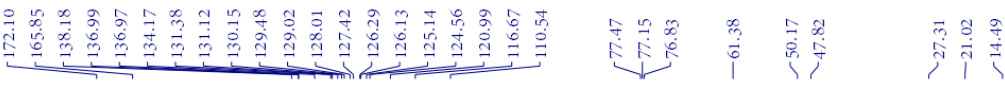

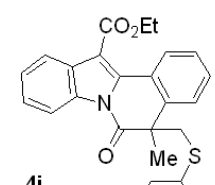

${ }^{13} \mathrm{C}\left\{{ }^{1} \mathrm{H}\right\}$ NMR $\left.\left(100 \mathrm{MHz}^{\mathrm{CDCl}}\right)_{3}\right)$

Me S

$$
\mathrm{Me}
$$

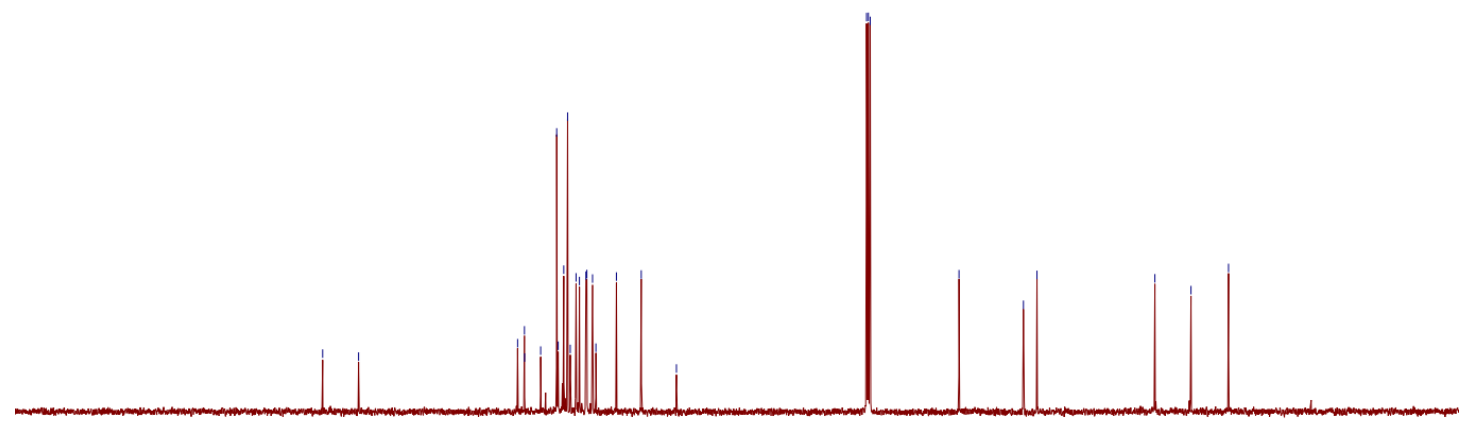

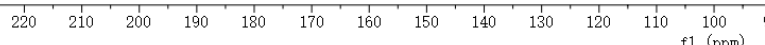




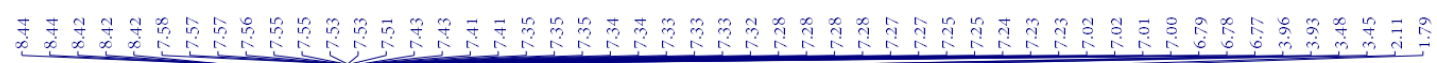
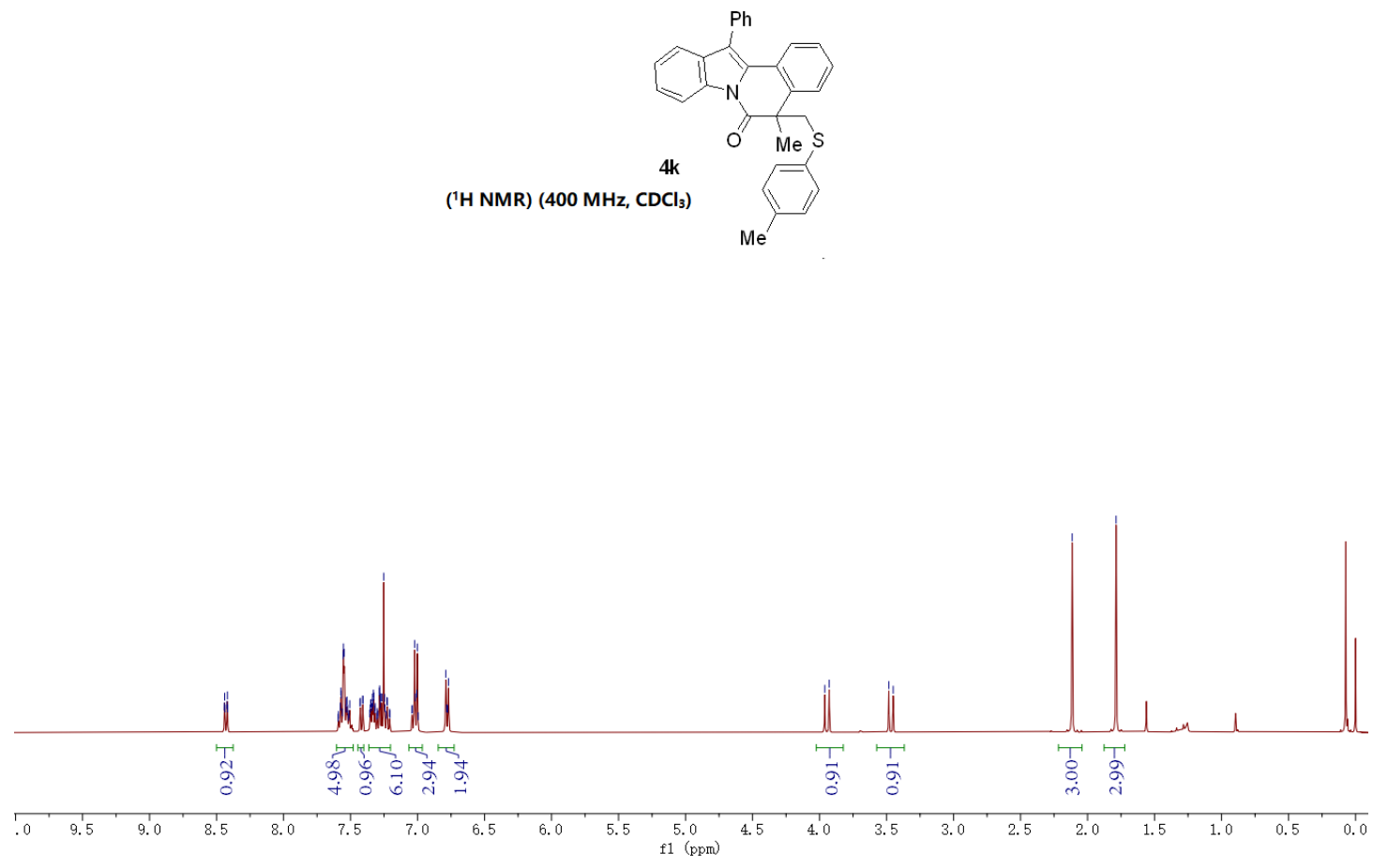

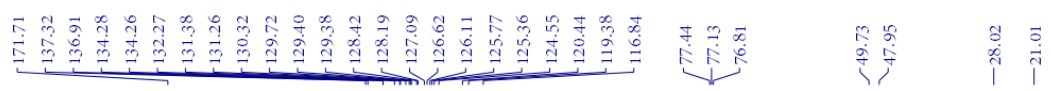

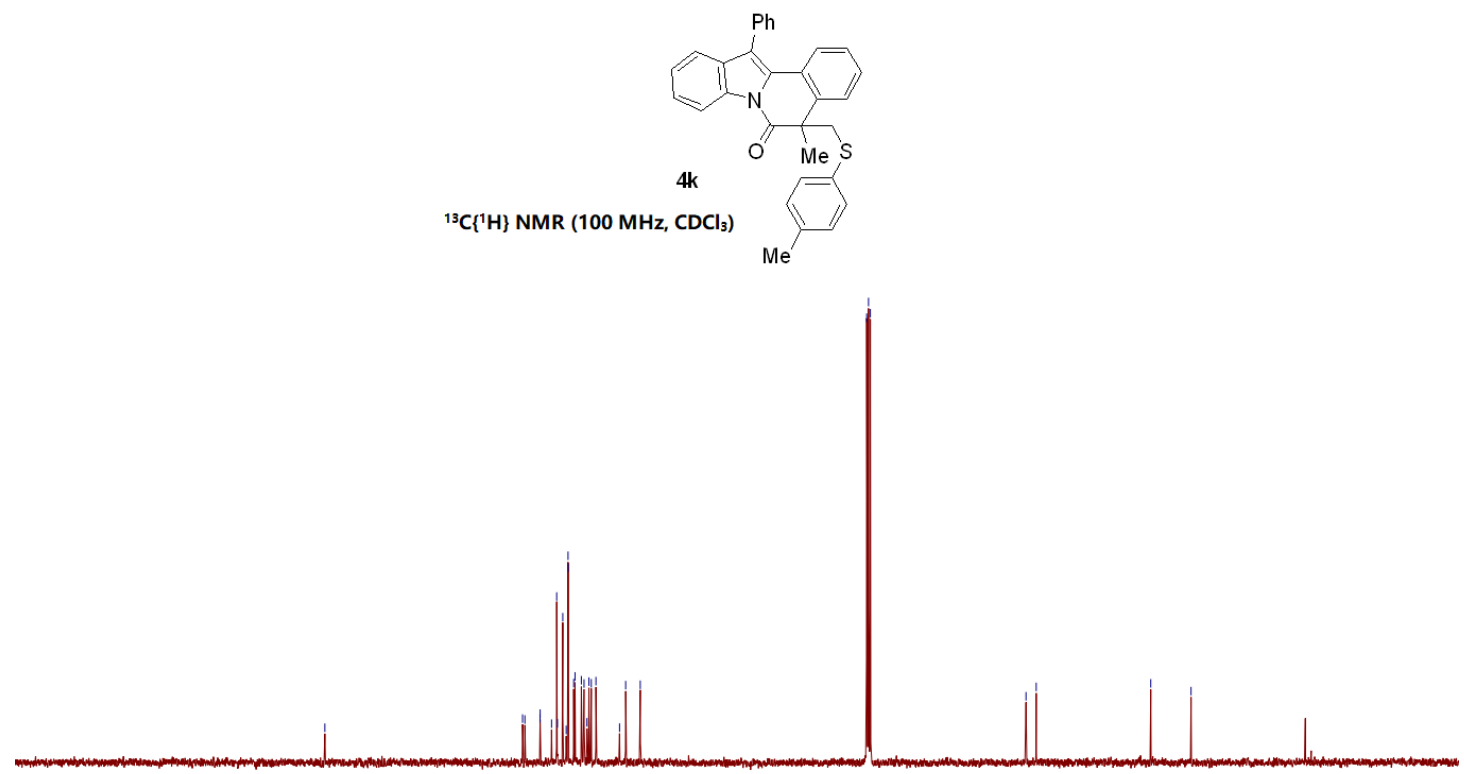

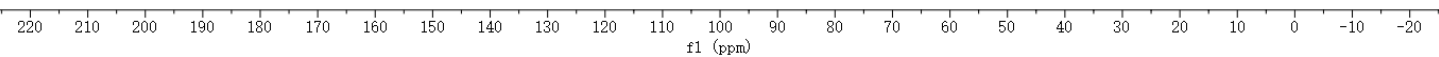



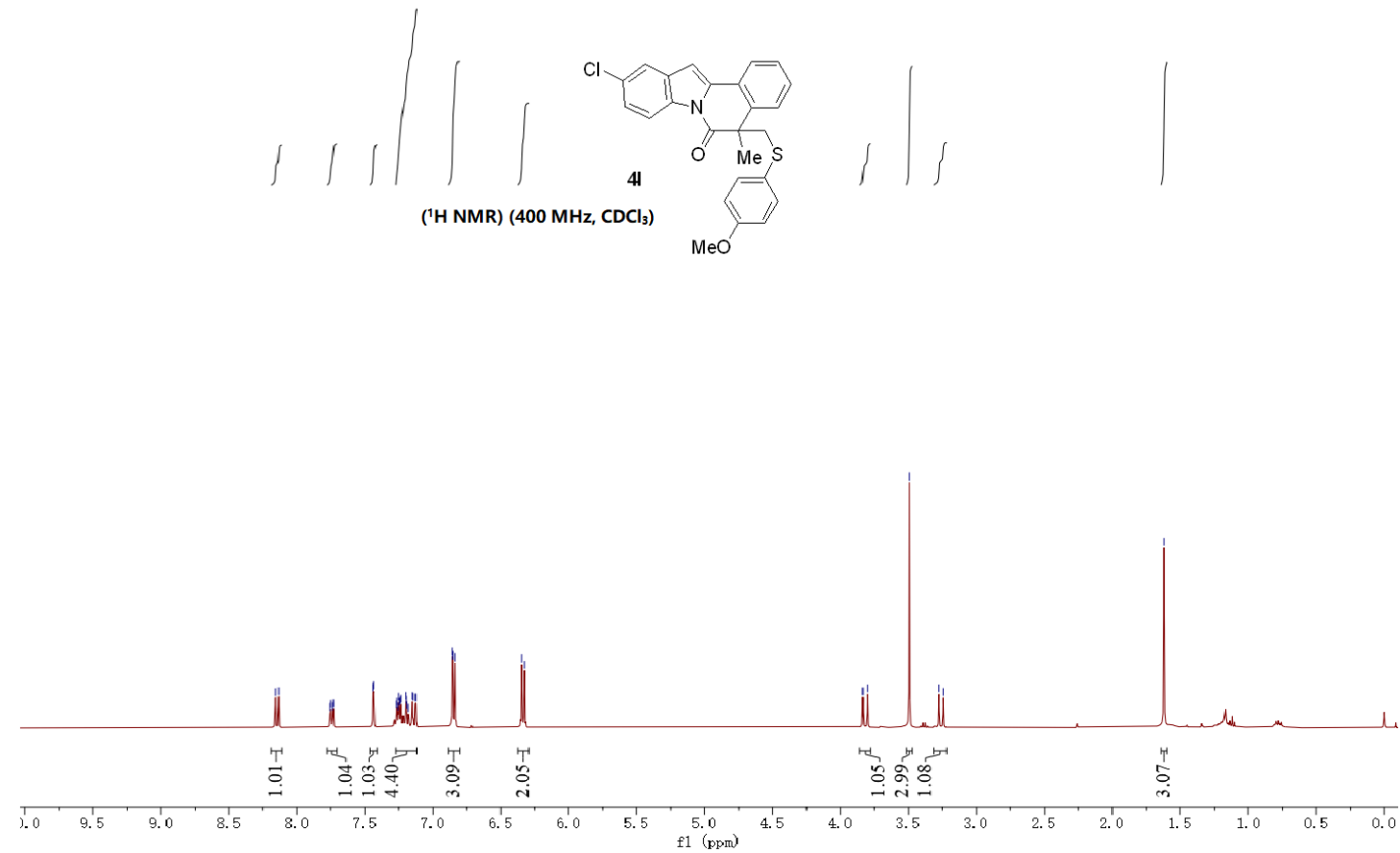

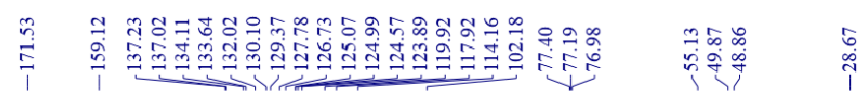

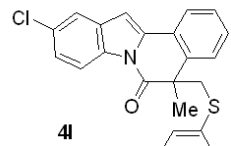

${ }^{13} \mathrm{C}\left\{{ }^{1} \mathrm{H}\right\}$ NMR $\left(150 \mathrm{MHz}, \mathrm{CDCl}_{\mathrm{s}}\right)$

MeO

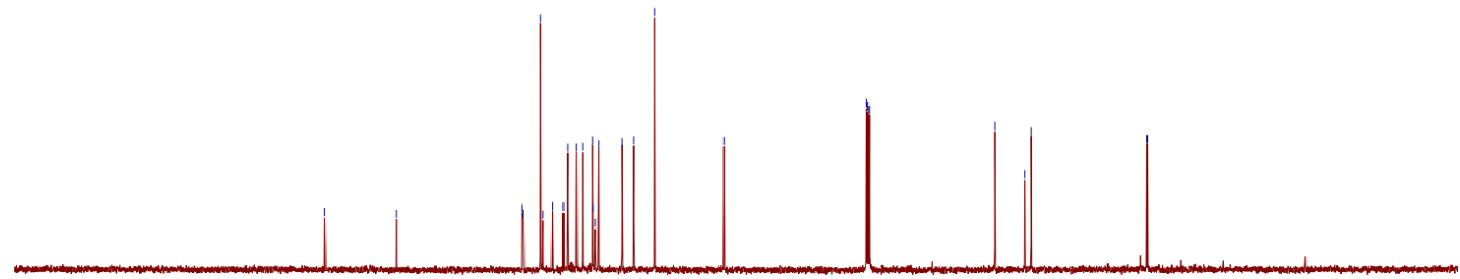

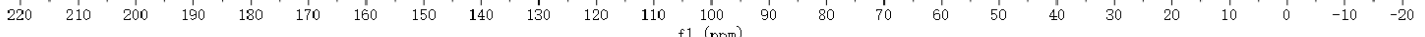




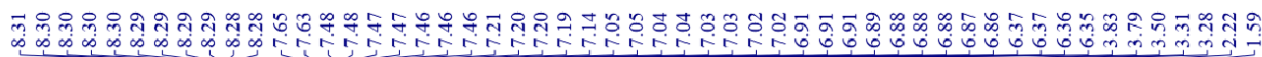

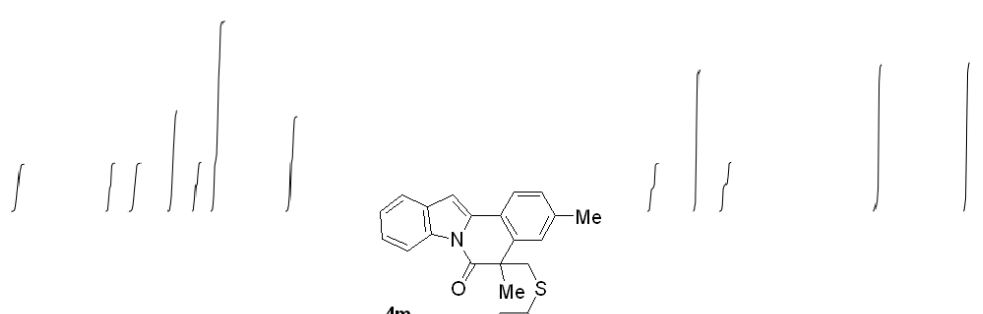

('H NMR) (400 MHz, $\left.\mathrm{CDCl}_{3}\right)$

Me

$\mathrm{MeO}$

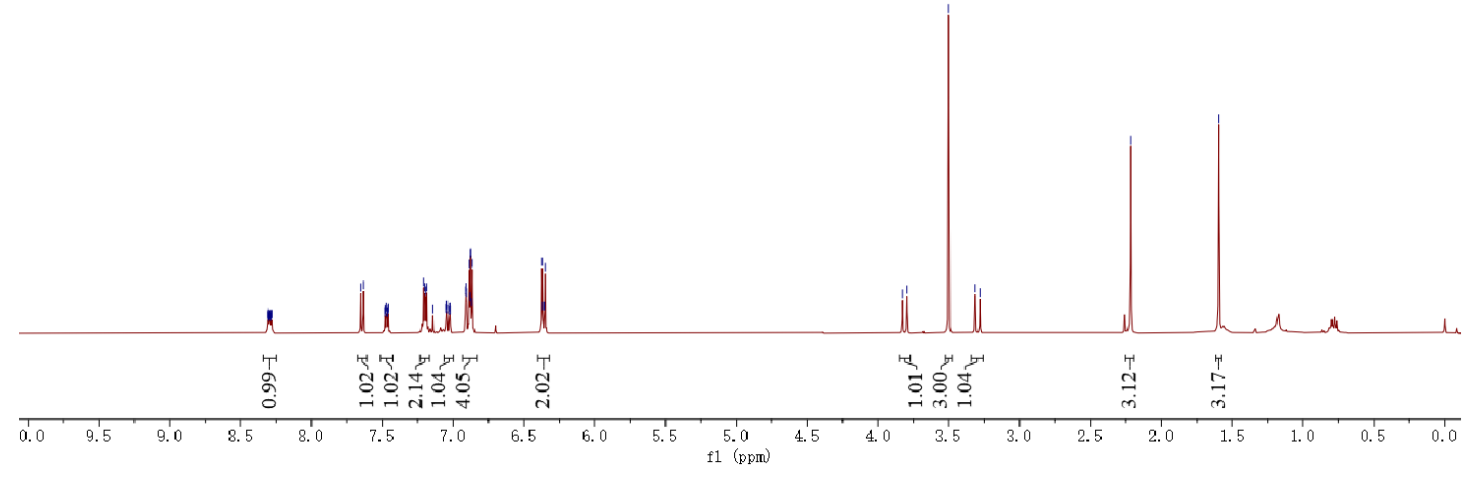

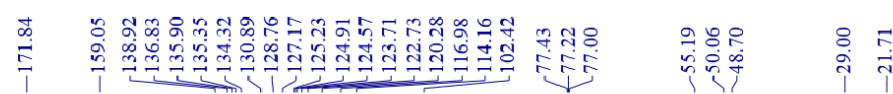

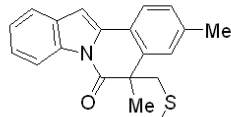

$4 m$

0 Mes

${ }^{13} \mathrm{C}\left\{{ }^{1} \mathrm{H}\right\}$ NMR $\left(151 \mathrm{MHz}, \mathrm{CDCl}_{3}\right)$

$\mathrm{MeO}$

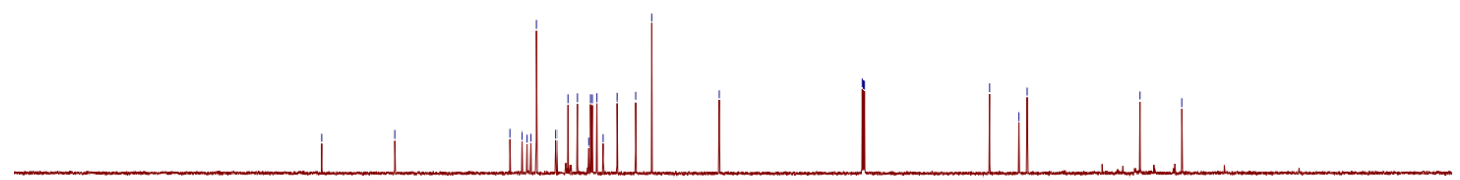

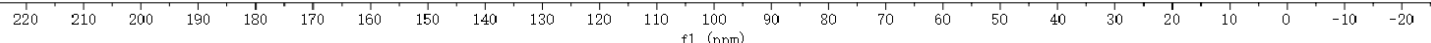




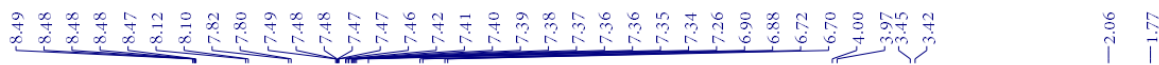

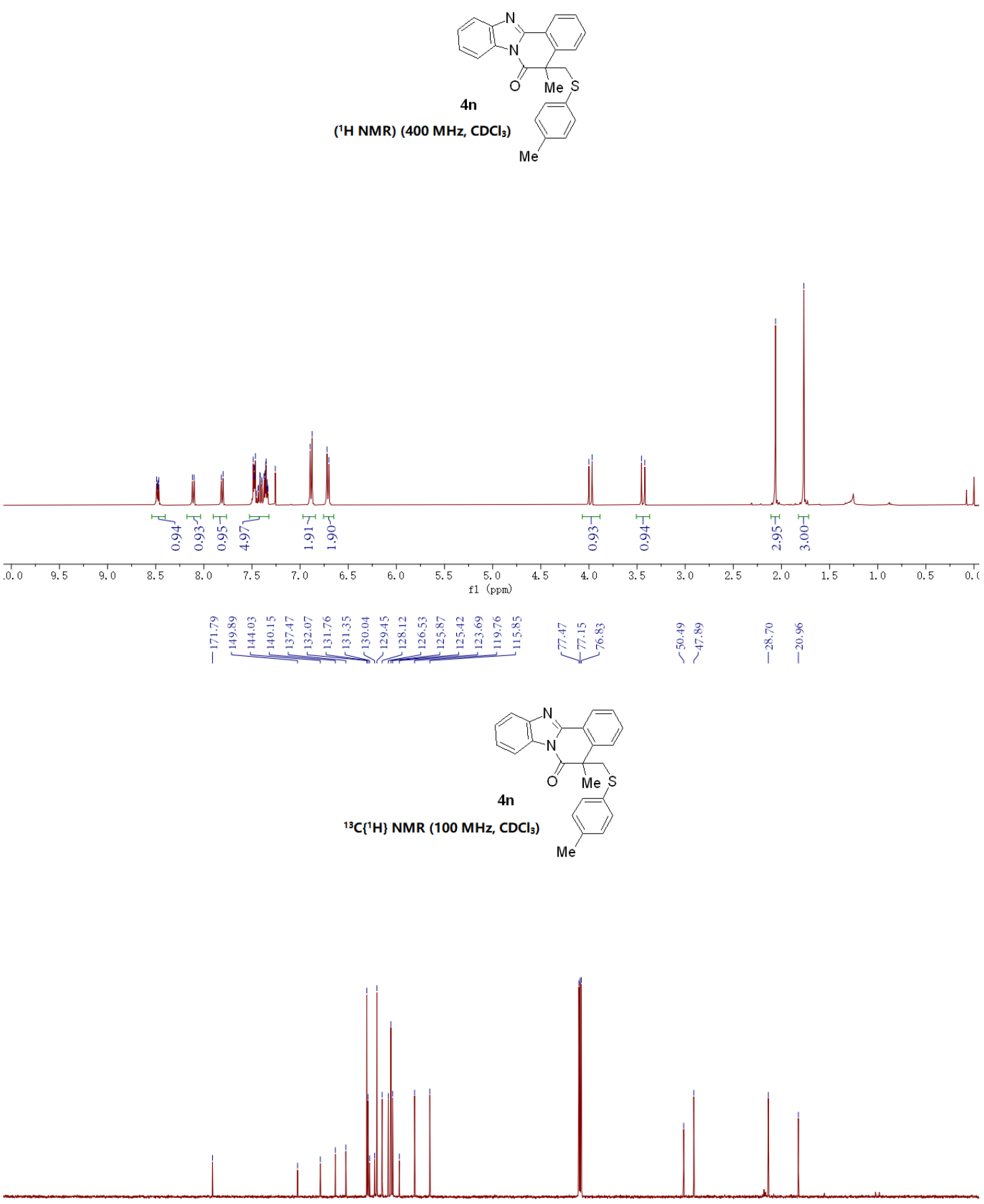

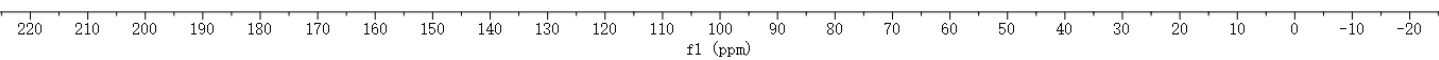



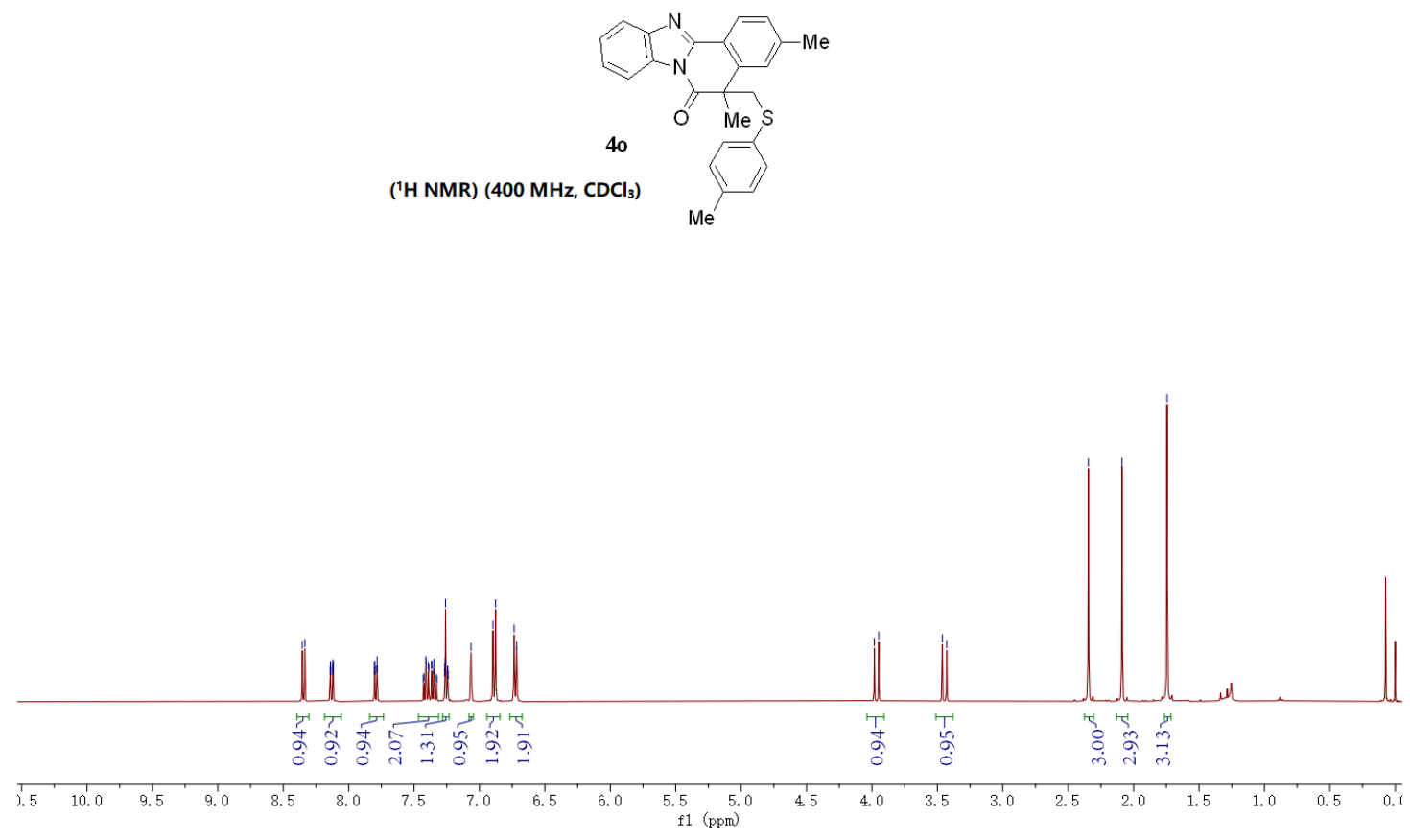

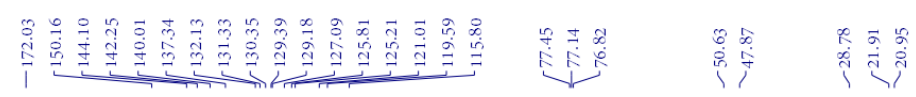

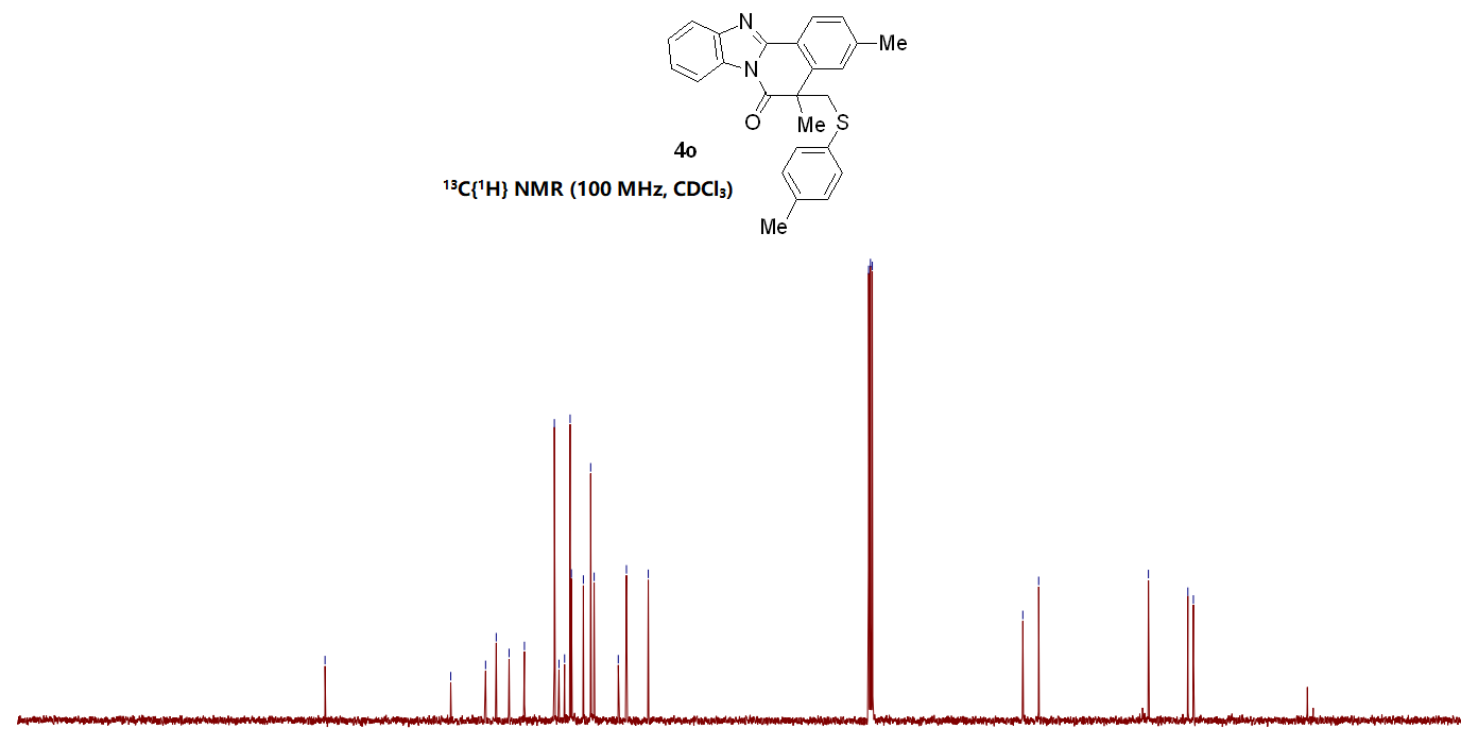

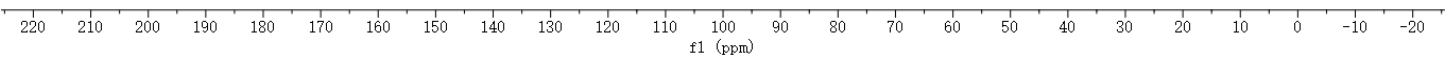



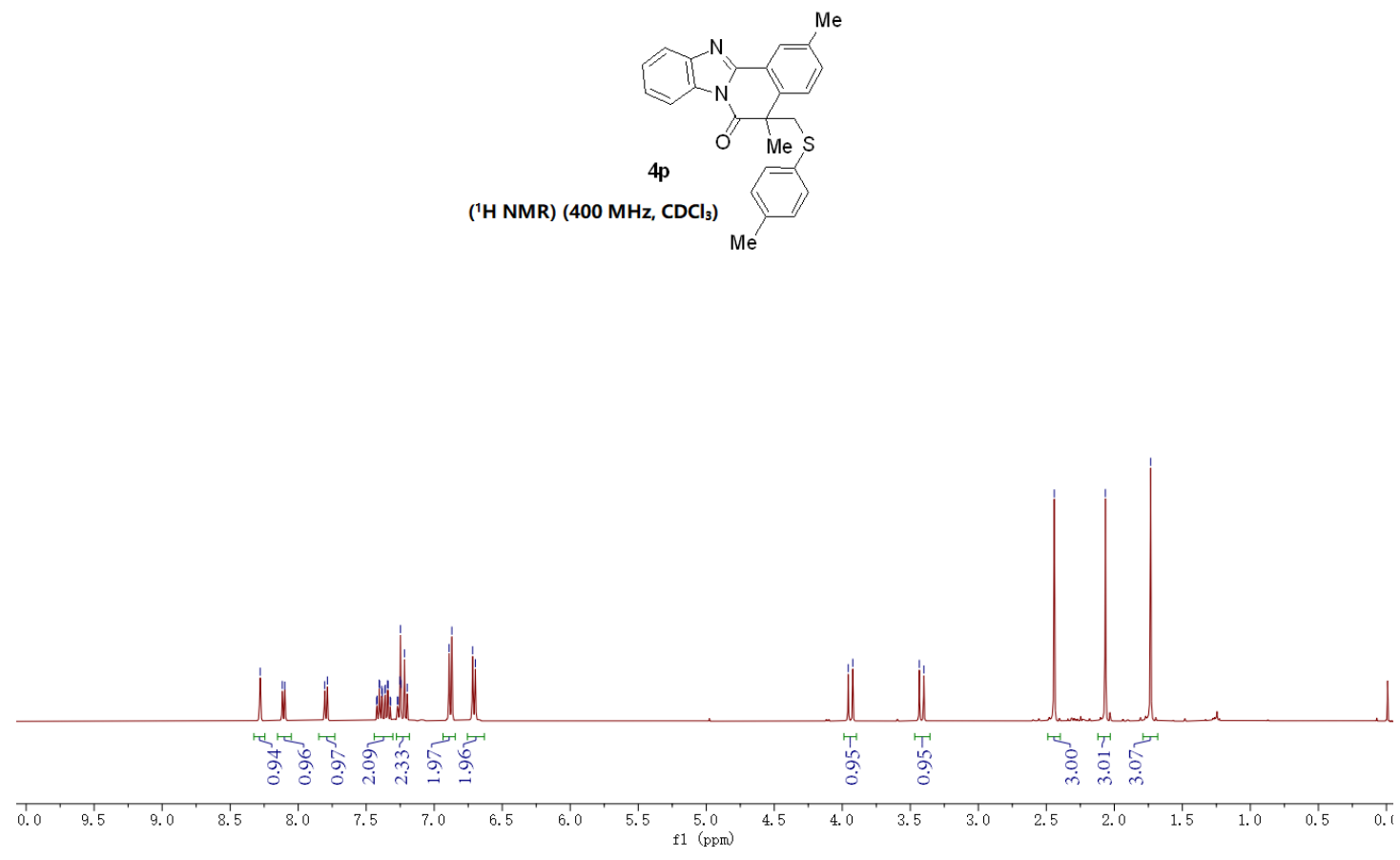

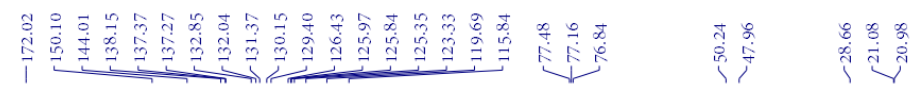
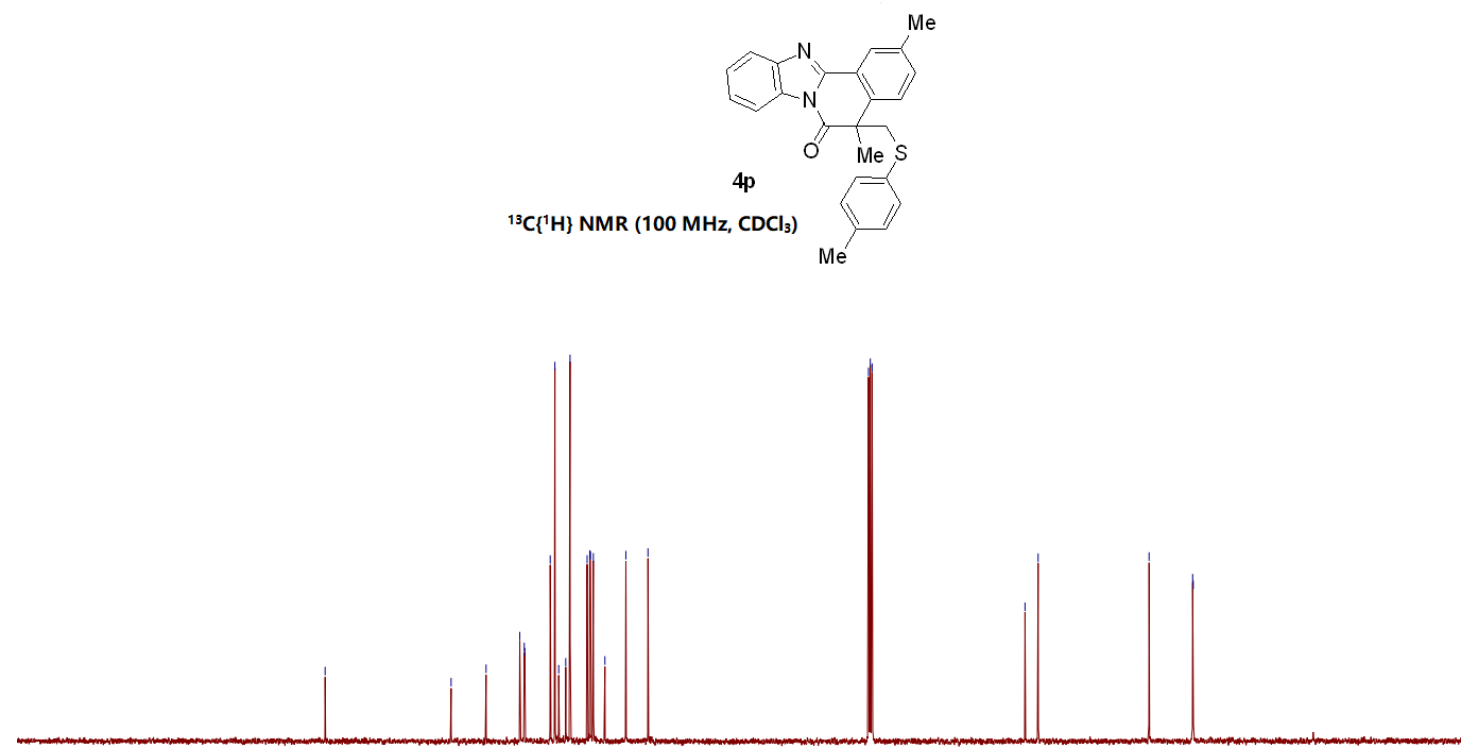

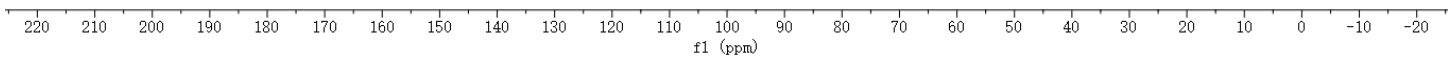




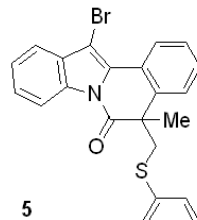

('H NMR) (400 MHz, $\left.\mathrm{CDCl}_{3}\right)$
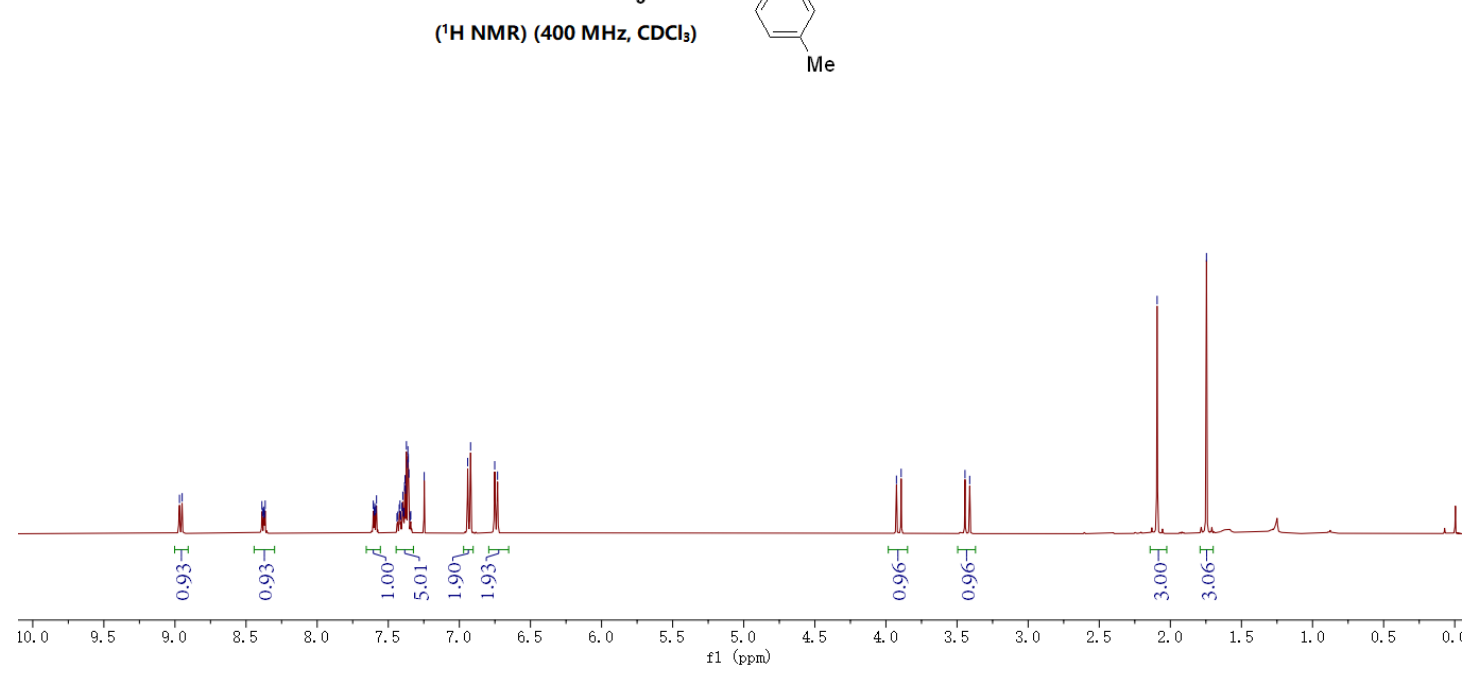

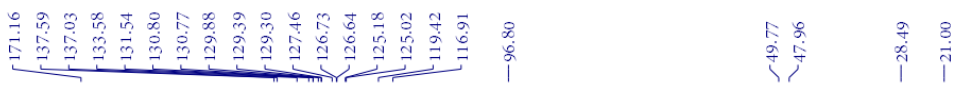
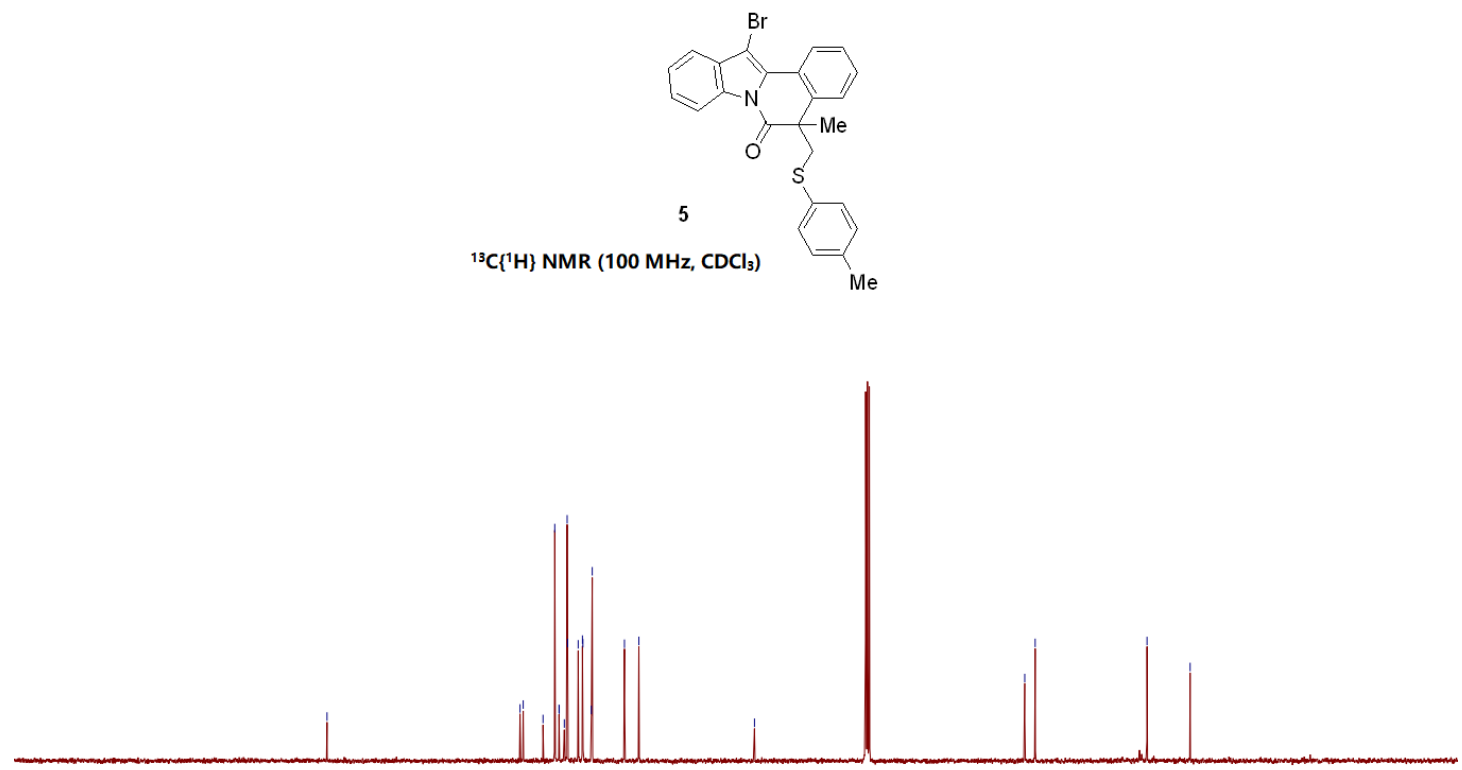

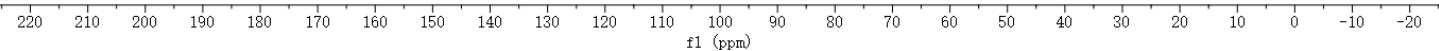




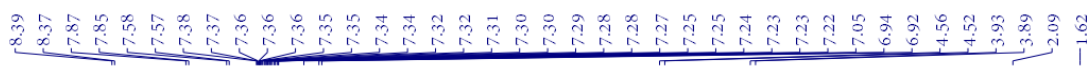

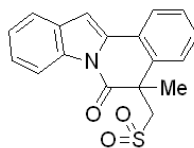

('H NMR) (400 MHz, $\left.\mathrm{CDCl}_{3}\right)$

6

$0=3$
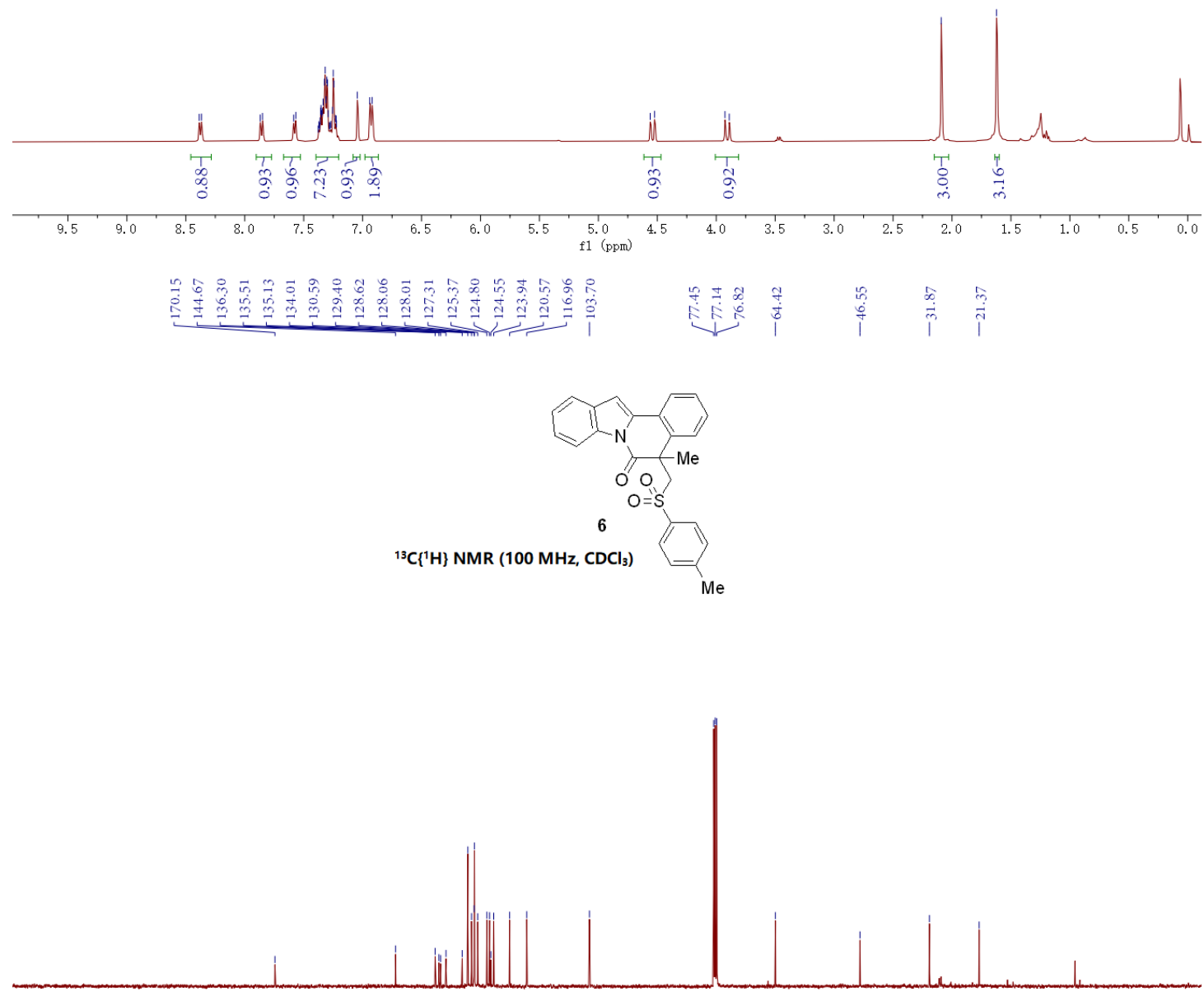

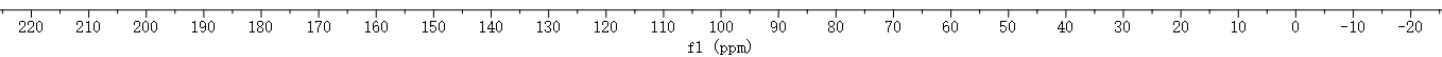




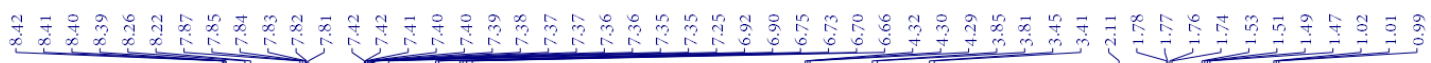
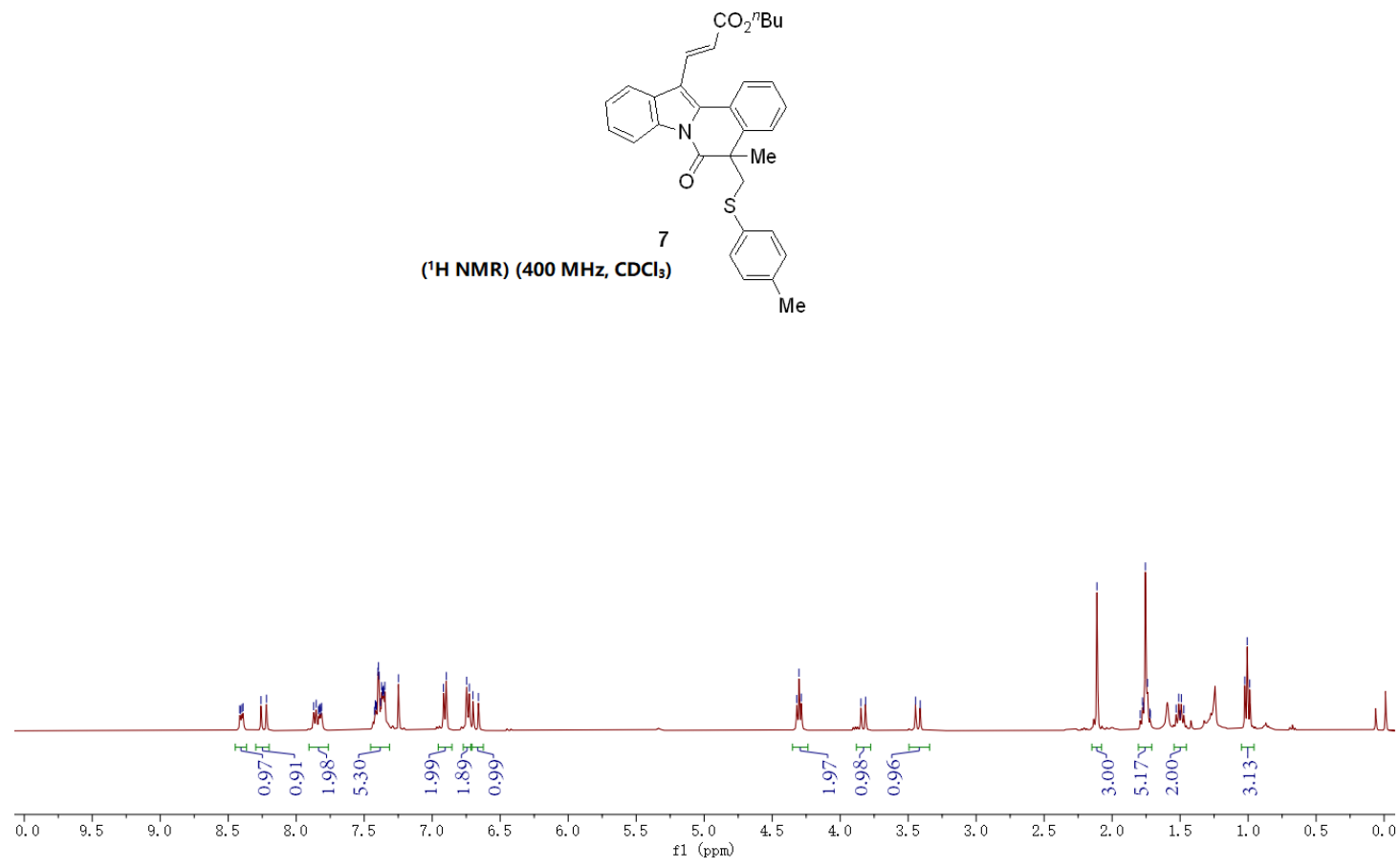

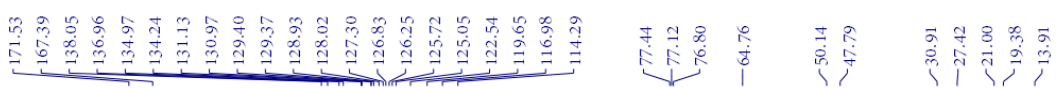

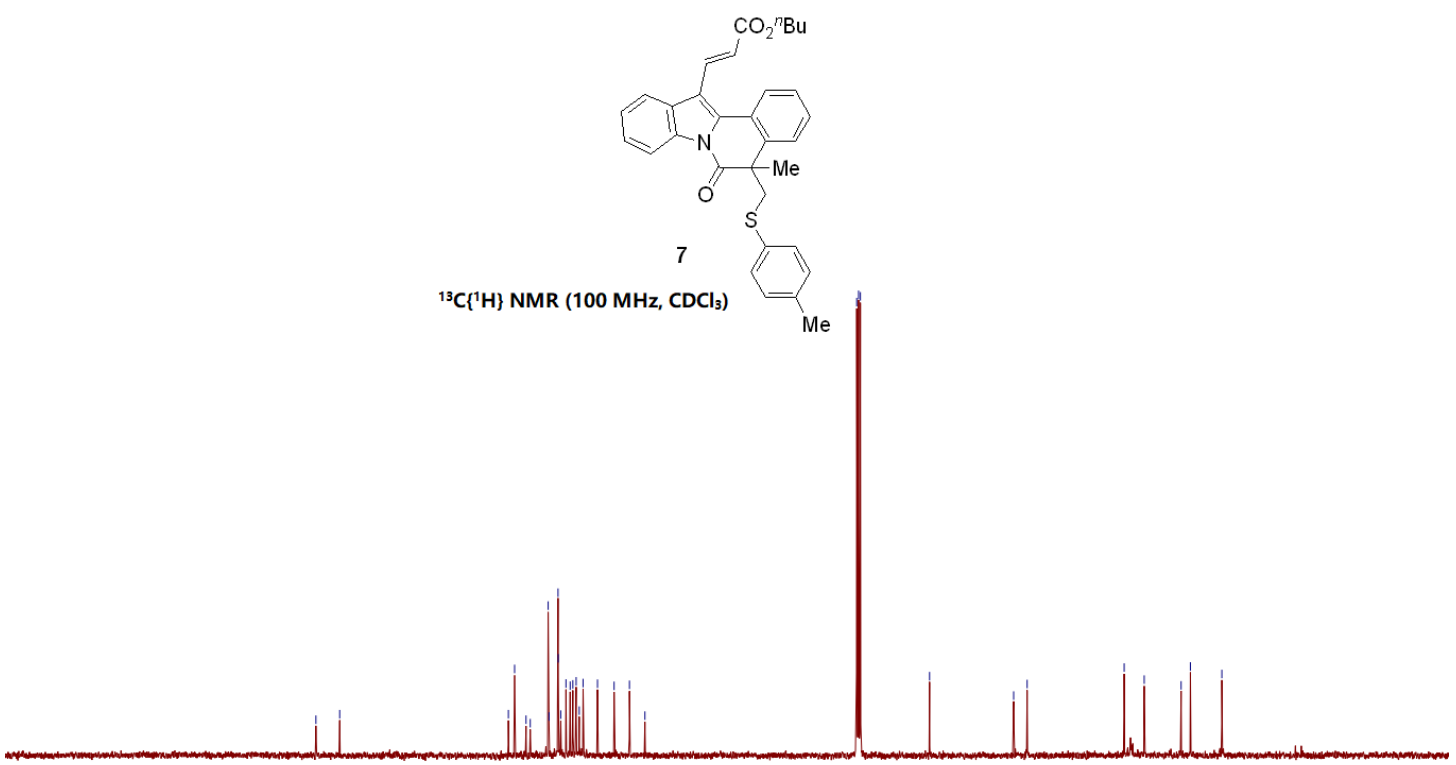

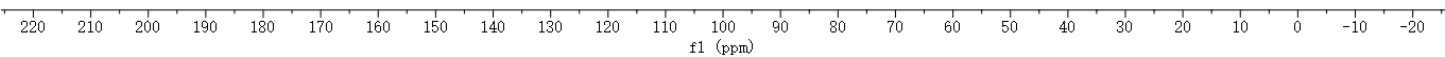

